\title{
Rethinking Law School Tenure Standards
}

\author{
Adam Chilton, Jonathan Masur, \& Kyle Rozema*
}

September 17, 2019

\begin{abstract}
Academic departments decide on tenure standards with limited evidence about their accuracy and efficacy. We study the implications of stricter tenure standards in law schools, an environment in which 95 percent of all tenure track hires receive tenure. To do so, we construct a novel dataset of the articles and citation counts of 1,720 law professors who were granted tenure at top-100 law schools between 1970 and 2007. We first show that pre-tenure research records are highly predictive of future academic impact. We then simulate the costs and benefits of applying stricter tenure standards using predictions of law professors' future academic impact at the time of their tenure decision. Of faculty members not tenured under stricter standards, only 5 percent have greater future academic impacts than their counterfactual replacements. Moreover, increasing tenure denials by 10 percentage points would increase the academic impact of a school's median professor by over 50 percent.
\end{abstract}

JEL: I23, J24, J44, M51, O31

${ }^{*}$ Chilton: University of Chicago Law School, e-mail: adamchilton@uchicago.edu. Masur: University of Chicago Law School, e-mail: jmasur@uchicago.edu. Rozema: Washington University Law School, e-mail: kylerozema@wustl.edu. 


\section{Introduction}

Tenure is a central feature of modern universities. Tenure enables the academic market to function by providing the necessary incentives to make a risky human capital investment in highly specialized work. ${ }^{1}$ It allows faculty to hire candidates who are stronger than themselves without fear that they will be pushed out of the department by newcomers. ${ }^{2}$ It protects scholars from political forces at odds with their research and the positions they take. $^{3}$ It provides economic security to scholars and motivates them to pursue risky but potentially groundbreaking research that is more prone to failure. ${ }^{4}$ It gives faculty a long term interest in the university, generating incentives to monitor university leadership. ${ }^{5}$ But tenure also commits a faculty spot to a scholar for decades,${ }^{6}$ which requires millions of dollars in compensation and eliminates an opportunity to hire another scholar. ${ }^{7}$ And, in protecting faculty from dismissal, it decreases incentives to produce research. ${ }^{8}$

Given these stakes, departments generally apply strict tenure standards that grant tenure to only the most talented and productive scholars. ${ }^{9}$ But this is typically not true in at least one university department: law. By our estimates, at least 95 percent of tenure-track faculty hired at an elite law school get tenure, and 92 percent of those getting tenure get tenure at the law school they started. ${ }^{10}$ This results in unproductive faculty occupying some

\footnotetext{
${ }^{1}$ See, e.g., McPherson and Winston (1983).

2 See, e.g., Carmichael (1988); Siow (1998); Dnes and Garoupa (2005).

${ }^{3}$ See, e.g., Mckenzie (1996).

${ }^{4}$ For conflicting evidence on whether economists reduce risk-taking in the years after tenure, see Brogaard et al. (2018) and Mixon (2018). Azoulay et al. (2011) finds that differences in how funding tolerates early failure and rewards long-term success, similar to the change in incentives from tenure, changes the rate and direction of scientific exploration in the life sciences.

${ }^{5}$ See, e.g., Brown (1997).

${ }^{6}$ Universities cannot impose mandatory retirement requirements which extends the life of academics (Ashenfelter and Card, 2002).

7 Just one of the costs of incorrect tenure decisions is that, if the spot was filled by a more productive faculty member, it could generate millions of dollars of research funding. For instance, the National Science Foundation alone gave researchers $\$ 5.8$ billion in research funding in 2014 (Foundation, 2014).

${ }^{8}$ Researchers have been found to be less productive as they age. This has been found to be true for economists (Oster and Hamermesh, 1998) as well as scientists like physicists, oceanographers, geophysicists, and geologists (Levin and Stephan, 1991).

${ }^{9}$ For example, Kaminski and Geisler (2012) find that over 35 percent of science and engineering faculty are not promoted to tenure within their home institutions. Given that high denial rates can push scholars away from the academy, departments with high denial rates can respond by paying higher salaries to tenuretrack professors (Ehrenberg et al., 1998).

10 These numbers are based on data we collected on entry level hires at top 14 law schools who started from 2000 to 2012 . We classify a law professor as having obtained tenure if she obtains tenure at the school where
} 
of the world's most valuable academic real estate while leaving more productive scholars under-placed and preventing new scholars from breaking into the legal academy. ${ }^{11}$ Moreover, lax standards likely decrease research productivity by reducing incentives to produce quality research and by decreasing knowledge diffusion that would have occurred from the interactions between better colleagues (Akcigit et al., 2018). In short, lax tenure standards can have high costs for law schools' academic impact.

However, increasing tenure standards will only increase law schools' academic impact if a scholar's research record at the time of tenure provides a strong signal about her future academic impact. If tenure judgments are based on unreliable information, those judgments will not lead to improvements in a school's overall quality. But randomness in both the publication process and the way articles are cited could mean that a scholar's pretenure research record only contains very noisy signals. Moreover, academic impact might be unstable over a scholar's career, which would make it difficult at the time of tenure to distinguish between professors who will have more or less influential academic careers.

These general problems are exacerbated by two features of the legal academy. First, tenure clocks in law schools are relatively short, which results in decisions being made based on less information than in departments with longer tenure clocks. Second, the fact that students make publication decisions for the journals in which law professors primarily publish may limit the informational value of the three traditional objective measures of research records: number of articles, placement of articles, and citations. In other fields, the peer review process is thought to both filter out articles that make a limited contribution and allow article placement to serve as a strong signal of research quality. In law, the fact that students decide where articles place, combined with the fact that there are more than 500

she was initially hired or at a similarly ranked law school (which we define as no more than 5 spots lower in the ranking). Other than our estimates, we are unaware of existing estimates of comparative tenure denial rates to fully support this claim, but in our experience it is a stylized fact that is widely believed and repeated by law professors. See, e.g., LeiterReports (2005) and PrawfsBlawg (2014). Note that Yoon (2016) studies entry-level law professors in all law schools who were hired between 1993 through 2002, and reports that a "small fraction of pretenured faculty -5 percent in our data - [do] not receive tenure and subsequently leave legal academia." This number is not the tenure rate but rather the rate at which entry-level legal academics exit the legal academy, so although the rate is similar to ours it is not directly comparable.

11 This might be particularly surprising given that only one in seven entry level candidates obtain a position each year (George and Yoon, 2014) and claims that problems in the entry level academic market in law schools lead to highly inefficient outcomes (Redding, 2003). 
student run law reviews, ${ }^{12}$ suggests that placement may signal limited information about the quality of the research. ${ }^{13}$ Moreover, even though citations are a revealed preference of other legal scholars, it is hard to imagine that article placement does not have an independent effect on citations, implying that even citations are likely influenced by students. These three traditional measures of scholar's research record may thus offer weak signals about pre-tenure law professors' future academic impact.

Of course, the legal academy is not the only industry that might use prior performance to make predictions about future performance. Across a range of labor markets, research has increasingly found that objective measures of employees' (and potential employees') past performance are highly predictive of future performance (e.g., Lewis, 2004). Although employers undoubtedly still exercise significant subjective discretion in personnel decisions (e.g., Rivera, 2012), this research has led firms in many industries to use data and rigorous statistical methods to inform their personnel decisions (e.g., Brynjolfsson et al., 2011). This "Moneyball" approach to human resource management has even begun to influence the hiring and promotion of academics (e.g., Bertsimas et al., 2015). ${ }^{14}$ But despite the increasing use of this data-driven approach, it has not made its way into the legal academy. ${ }^{15}$

In this article, we study the implications of stricter tenure standards in law schools.

To do so, we constructed a unique dataset from two sources. First, we parsed information from an annual list of law professors at each law school from the Association of American Law Schools to identify law professors who received tenure at a top 100 law school between 1970 and 2007. These data allow us to observe the law school and year in which law professors were granted tenure. Second, we scraped HeinOnline to obtain a list of these law professors' publications and information about each of the publications, including the journal and the

\footnotetext{
12 Although we have not seen any empirical evidence on how many articles submitted to law reviews are not placed in any given year, our anecdotal impression is that most law professors in tenure track positions are able to gain publication offers for most of their articles at law reviews.

${ }^{13}$ For articles debating the advantages and drawbacks of allowing students to accept academic articles, see Rodell (1936); Posner (1995); Harper (1997); Sunstein (2016).

14 It is important to note that there has been backlash against using a Moneyball approach in the academy generally (see, e.g., Gingras, 2016) and in the legal academy specifically (see, e.g., Caron and Gely, 2004; PrawfsBlawg, 2015; LawProfBlawg and TempDean, 2016). In part because of the use of a firm called Academic Analytics, some universities - e.g., University of Texas at Austin, Georegetown University, and Rutgers - have policies in place limiting or banning the use of metrics in personnel decisions (Basken, 2018).

15 The research that comes closest to studying this topic is Yoon (2016), who uses data on law professors' research records to study how tenure effects research behavior.
} 
year of publication. For each of these articles, we then scraped information about each citation to the article, including the year the citing article was published. These data allow us to observe professors' research records - number of articles, their placement, and citationsas they would have appeard to law schools in the year of the tenure decision, along with all subsequent articles and citations. Our final sample contains information on 1,720 professors, 29,694 articles they have published, and 1,070,092 citations that those articles have received.

Using these data, we first explore the extent to which law professors' research records at the time of tenure decisions predict those professors' future academic impact and their outside options after tenure. ${ }^{16}$ Despite the role that students play in publishing legal scholarship, we find that law professors' research records are highly predictive of their future academic impact. By our estimates, law professors with 1 percent more citations (publications) before tenure have an average of 0.2 (0.8) percent more citations to articles published after tenure. Perhaps more surprisingly, we also find evidence that there is information contained in article placements, even after controlling for citations and the number of publications. By our estimates, law professors with 1 percent more articles in top 20 law reviews before tenure have an average of 1.0 percent more citations to articles published after tenure. These latter results provocatively suggest that law schools would not be wrong to partly rely on the decisions of second-year law students in making tenure decisions. Next, using hand collected data on the most recent university affiliation of each law professor, we find that law professors' research records are highly predictive of their outside options after tenure, as measured by whether they lateraled to another law school after tenure.

After establishing that pre-tenure research records can be used to generate reliable predictions of future academic impact, we run simulations to assess the costs and benefits of stricter tenure standards. To do so, we first form out-of-sample predictions of future academic impact for every professor in the year they were considered for tenure. We then rank law professors by their predicted future impact within well-defined law school and tenure cohorts. $^{17}$ We then impose hypothetical tenure denial rates and replace faculty members

\footnotetext{
${ }^{16}$ In our primary analysis, we take a conservative approach to measuring post-tenure academic impact by assessing post-tenure citations to articles published post-tenure, which breaks all mechanical relationships between law professors' pre-tenure research record and post-tenure academic impact.

17 In our preferred specification, we form leave-out predictions for each law professor where we estimate a regression for each law professor leaving the law professor in question out of the model and then predicting
} 
who would be denied tenure under stricter tenure standards with other faculty under various counterfactual scenarios.

A main cost of stricter tenure standards stems from the inevitable mistakes that will be made in tenure decisions resulting from imperfect foresight about a law professor's future academic impact. We assess these potential costs by estimating the percent of tenure denials that are mistakes, measured by the percentage of law professors denied tenure who go on to have more academic impact than their hypothetical replacements. We find evidence that the rate of mistakes would be modest. If law schools replace those denied tenure with either the best law professors at law schools ranked 20 spots down in the law school ranking or with a random draw of the type of law professors the law school tenures, the rate of tenure denial mistakes is always below 10 percent and is usually around 5 percent.

A main benefit of stricter tenure standards stems from the increased academic impact of a law school's faculty. We assess these benefits by estimating the change to each law school faculty's academic impact if the school increased tenure denial rates and replaced those professors denied tenure with other law professors whom the school could plausibly have hired. These simulations allow us to produce counterfactual estimates of law schools' academic impact compared to what they would have been if the schools had imposed stricter tenure standards. Our estimates suggest that law schools could have drastically enhanced the academic impact of their median faculty member by increasing tenure standards even modestly. For example, our counterfactuals suggest that increasing the tenure denial rate by 10 percentage points and filling those spots with the best of either a lateral candidate or a random draw from the entry level market would have increased the citations to the law school's median faculty member by 56 percent. These numbers increase to 94 and 125 percent if law schools increased tenure denial rates by 20 and 30 percentage points.

We then test whether the estimated benefits of stricter tenure standards in our simulations are driven primarily by differential denial rates across law schools, teaching fields, or professor demographics. If applying a uniform tenure standard would result in unacceptable losses to a faculty's diversity across a range of dimensions, then the counterfactuals would be unrealistic and the benefits we estimate cannot plausibly be achieved. For instance, our

their citations to articles published after tenure. 
simulations would not be realistic if they resulted from denying tenure to all tax law professors and replacing them with constitutional law professors. We find that our results are not driven overwhelmingly by denying professors from the same schools, fields, or demographic backgrounds. That said, we do find some differences in denial rates that suggest uniform tenure policies may not be optimal.

It is important to emphasize that we employ static microsimulations, and not a dynamic structural model, to estimate the effects of changing tenure standards on law schools' academic impact. The distinction between static and dynamic microsimulations is that static models assume that the policy changes being studied do not produce behavioral responses. Given their considerable utility, static microsimulations are a widely used method to estimate the effect of policy changes on outcomes of interest. ${ }^{18}$ For instance, academics have used static microsimulations to assess the stabilizing effect of the federal income tax system over the business cycle (e.g., Auerbach and Feenberg, 2000; Saez, 2004; Kingi and Rozema, 2017) and the distributional effects of tax expenditures (e.g., Cole et al., 2011; Hemel and Rozema, 2017). ${ }^{19}$ Additionally, government agencies around the world use static models to estimate the effects of tax and transfer policies. ${ }^{20}$ In the United States, for instance, static microsimulations are used by the Joint Committee on Taxation to estimate tax expenditures (Joint Committee on Taxation, 2018). Although major changes in government tax and transfers policies are likely to produce behavioral responses, static microsimulations have remained a standard method to assess their impacts because they offer the practical advantage of producing transparent estimates without relying on difficult to verify assumptions about how individuals will respond to policy changes. Similarly, although we recognize that

\footnotetext{
${ }^{18}$ For a review and comparison with dynamic models in the labor context, see Aaberge and Colombino (2018).

19 Although the static assumptions in tax expenditure estimation are relaxed in some academic work (Gale et al., 2007), the starting point for analyses is always static and relaxing assumptions comes with problems (e.g., with the mortgage interest deduction, one must assume portfolio re-balancing once the tax break is no longer available, but the problem is that most households could re-balance their portfolio even with the mortgage interest deduction to reduce their tax bill).

${ }^{20}$ As described in Stevenson et al. (2017): "A number of institutions around the world currently use static microsimulation models to analyse the distributional effect of changes to tax-transfer policies. For example in the United Kingdom, Her Majesty's Treasury uses the Intra-Governmental Tax and Benefit Model . . . and the Department of Work and Pensions uses the Policy Simulation Model, . . . The New Zealand Treasury uses TaxWell, . . . Canada . . . [uses the] Social Policy Simulation Database/Model, . . . and EUROMOD . . . is used by policy makers and researchers across Europe."
} 
changes to tenure standards will almost certainly produce behavioral responses, we believe that static microsimulations are a reasonable method to use to begin to assess law school tenure standards.

We contribute to a body of work in economics on the prevalence and implications of academic tenure. Although there has been much discussion on the incidence of tenure within a university (e.g., McPherson and Schapiro, 1999), as well as some empirical work on whether tenure decisions are made properly (e.g., Bertsimas et al., 2015) and on the determinants of tenure decisions (Liner and Sewell, 2009; Heckman and Moktan, 2018), we are unaware of any work studying the benefits and costs of different tenure standards. We build on the literature on tenure by studying the implications of stricter tenure standards in law schools, which is one of the departments in the university that is thought to have the weakest tenure standards. In doing so, we also begin a discussion on several important conceptual points regarding the purpose of tenure standards and what faculties should try to maximize when making promotion decisions.

Our research relates to a recent discussion in economics about which factors departments should rely upon as screening mechanisms in tenure decisions. Heckman and Moktan (2018) document that the current practice in economics departments is to rely heavily on placements in the top 5 economics journals rather than citations in tenure decisions. ${ }^{21}$ They argue that their findings "should spark a serious conversation in the profession about how to develop implementable alternatives to judge quality research," such as the practice of relying on individual reading of papers (for a discussion, see Akerlof, 2018). This is particularly relevant to tenure in law schools, given that publication decisions are made by law students, so many law schools rely heavily on departmental peer review of a candidates work.

At the outset, it is worth emphasizing a few qualifications that we discuss in some detail below. First, we recognize that research productivity and quality are not the only criteria for making tenure decisions, and we readily acknowledge that law schools are trying to retain faculty who will do more than just be widely cited in the future. Accomplishing a law school's educational mission requires also identifying professors who are excellent teachers

\footnotetext{
21 See also Anauati et al. (2018), providing evidence that journal placement influences an article's total and life cycle of citations.
} 
and who perform valuable service to their institutions, the academy, and the legal profession. Our research should not be read to suggest anything else. Second, there are limitations to our approach. Our sample is professors from top 100 law schools that we were able to match to their HeinOnline pages, which means that we do not have all law professors and, because not all papers and citations are available on HeinOnline, we do not have their complete research records. Moreover, our simulation methods rest on a number of assumptions, and several of them we are unable to verify. For instance, we assume that research productivity would have been stable even if tenure standards had increased, but it is possible that stricter standards would alter behavior in a range of ways that we cannot predict. In addition, applying a uniform tenure standard based on these research measures, whether lax or strict, may result in unacceptable losses to a faculty's diversity. Our goal is not to suggest a formula that should be rigidly applied when making tenure decisions. Instead, our goal is to illustrate the possible costs and benefits of raising tenure standards. Finally, the main contribution of this work is to start, rather than end, the discussion of how law schools could use objective assessments of legal scholars in human resource decisions. We thus caution against jumping to conclusions about whether tenure standards should be increased, and we hope future work builds on ours to better understand how the legal academy's personnel decisions can be improved.

We proceed as follows. Part 2 provides background on the process used to make tenure decisions and explains the unique features of legal publishing that may compromise the informational value of data on publishing productivity and quality. Part 3 introduces the original dataset we constructed for this project. Part 4 investigates the extent to which information available at the time of tenure decisions is predictive of citations of post-tenure articles. Part 5 builds on this analysis by conducting counterfactual simulations to show how changes to tenure standards can change the academic impact of law schools. Part 6 assesses the differential impact of applying uniform tenure standards across law schools, fields, and faculty diversity. Part 7 discusses the limitations of our results, as well as the implications of raising tenure standards at law schools. Part 8 concludes. 


\section{Background}

We begin by providing background on how tenure decisions are made, discussing how using objective data to measure past performance may improve predictions about future behavior, and explaining why student-edited law reviews may reduce the value of the signal provided by law professors' publication records.

\subsection{Tenure Decisions}

In building an academic faculty, academic departments must make personnel decisions about whom to hire, grant tenure, laterally recruit, promote to full professor, and award an endowed chair. Although the processes and criteria used in making all of these personnel decisions are likely to be similar, our focus is on the decision of whether to grant tenure. The exact processes used to make tenure decisions vary by department and institution, but we imagine most follow the same general pattern. Usually, the dean of the academic unit or the chair of the department appoints a tenure committee; the committee gathers information and makes recommendations to the faculty; the faculty holds meetings and votes on whether to grant tenure; the dean reviews the vote and, if she agrees, forwards it to a university-wide tenure committee; the university-wide committee reviews the case and votes again; and then the university provost makes a final decision.

Throughout this process, candidates are typically evaluated based on three criteria: research, teaching, and service. Although the relative weights placed on each of these criteria likely vary across schools and departments and over time, we believe that the primary criteria in most departments at most research universities is the quality of the candidate's research. To evaluate the quality of a candidate's research, most departments rely on a combination of subjective evaluations and objective data. The subjective evaluations are assessments of the quality of a candidate's research that are solicited from relevant internal and external experts (as well as independent evaluations made by the committees, faculty, deans, and provost). The objective data are the number of academic articles the candidate has published, the prestige of the journals where the articles were published, and the number of citations the articles have received. 
The subjective evaluations and objective data are then used to assess whether a candidate has produced sufficient quality and quantity of research to have met the bar for tenure. This often, though not always, involves a prediction about the candidate's future scholarly impact. In some cases, some candidates may be awarded tenure on the basis of past work despite misgivings that they will not be productive or influential in the future. In other cases, candidates may be awarded tenure despite a thin file because of optimism about their future academic achievements. In either case, departments will base their tenure decisions in large part on whether they believe the candidates will be productive scholars in the future, and they will use a candidate's past scholarly productivity and impact as the most probative evidence on this point.

Making tenure decisions thus typically involves predicting a candidate's future academic impact. Although there are many ways to measure academic impact, the standard way to measure it is by citations. Citations are an imperfect measure of scholarly impact, but they are still widely used across disciplines to gauge influence, and research in multiple fields has both validated their use and documented the problems with them (e.g., Mingers and Xu, 2010; McCabe and Snyder, 2015; Tahamtan et al., 2016). ${ }^{22}$ Consequently, although citations are not a perfect measure, they are a reasonable proxy for academic impact.

\subsection{Using Data to Improve Personnel Decisions}

Even when an academic department agrees on both the criteria to use when making personnel decisions and the goals they are trying to maximize, these decisions may still be difficult to make. To start, some of the information used in making the decisions - including both the subjective evaluations and objective data - may be plagued by biases. For instance, teaching is one of the standard criteria used in making tenure decisions, but a large literature has documented bias in teaching evaluations (e.g., Boring, 2017). Additionally, whether a scholar has published research in leading journals is another consideration in tenure decisions, but research has suggested that publishing decisions in leading journals may be based in part on factors unrelated to the quality of the research, such as the professional networks

\footnotetext{
${ }^{22}$ For use of citations in law, see, e.g., Sisk et al. (2015) and Harvard Law Today (2018). Using citations to rank economics departments dates back at least to Gerrity and McKenzie (1978). For a review of the use of citations in economics, see Hamermesh (2018).
} 
or political leanings of the journals' editors (Abrevaya and Hamermesh, 2012; Hengel, 2016; Tomkins et al., 2017; Colussi, 2017; Chilton et al., 2018). Moreover, even if decisionmakers had unbiased information, they still might not know how to use the information to make reliable predictions about the candidates impact going forward. For example, a department might wish to tenure scholars who will generate a large number of lifetime citations, but the department could still be unsure how to predict future citations on the basis of the scholar's citations to date or the number of papers the scholar has published.

In other labor markets, firms have tried to improve the quality of their personnel decisions by employing data. The most famous example of this phenomenon - and the origination of the term Moneyball-is professional sports (Lewis, 2004). Across a range of industries, evidence suggests that firms are able to make better personnel decisions with a data-driven approach than they would have if they had relied solely on more traditional methods (e.g., Davenport and Harris, 2007; Brynjolfsson et al., 2011; Rivera, 2012; Hoffman et al., 2018). For example, Hoffman et al. (2018) find that "[w]hen faced with similar applicant pools . . . managers who appear to hire against test recommendations end up with worse average hires," suggesting "that managers often overrule test recommendations because they are biased or mistaken, not only because they have superior private information." This is consistent with literature in behavioral economics and psychology suggesting that data-driven approaches can mitigate biases in human judgement (Kuncel et al., 2013; Kahneman, 2011; Kleinberg et al., 2018). ${ }^{23}$

The "Moneyball" approach to making personnel decisions through the use of data analysis has even been adopted in some corners of the academy (e.g., Dorsey et al., 2006; Dustin et al., 2014; Bertsimas et al., 2015; Hamermesh, 2018). Of course, objective measures of scholarly productivity should not be the only input into tenure decisions, both because a candidate's scholarship is only one part of the tenure decision and because objective measures of scholarly impact are not the only - and not necessarily the best - means of measuring the quality of a candidate's scholarship (e.g., Basken, 2018). Nonetheless, at minimum, objective measures of scholarly impact represent potentially valuable information that should not be

\footnotetext{
${ }^{23}$ This is part of a wider influence of screening technologies and "workforce analytics" (Baker and Hubbard, 2004; Autor and Scarborough, 2008; Bersin, 2013).
} 
discarded. There is reason to believe that objective data, used in combination with more traditional criteria, could improve academic personnel decision-making. To our knowledge, however, there have been no efforts to assess whether data could be used to improve personnel decisions in the legal academy (but see Yoon, 2016).

\subsection{Student Editing and the Value of Legal Publishing Data}

There are three primary objective measures of a scholar's research record that could be used to make predictions about future academic influence: number of articles published, the journals those articles are placed in, and the citations to those articles. The number of articles an academic writes pre-tenure is a measure of their productivity; the journals an academic publishes in might serve as measure of the quality of their research; and citations are the revealed preferences of peers, and therefore serve as a proxy for the quality and influence of the research.

However, the extent to which these three measures predict future scholarly impact is an empirical question. It is possible that some of the measures are less predictive of future impact than others or that some measures are not predictive at all. In addition, there are problems with relying on publication data that are unique to law schools. Unlikely other academic fields, the legal academy largely defers to law students, rather than academics, to make publication decisions. The fact that students run law reviews may weaken the signal from all three measures of a scholar's research record.

Publications. The law review process makes it easier to publish articles. Peer review acts to filter out articles that make limited original contributions or that have flaws in their analyses. Although peer review is not perfect, we would like to think it creates barriers to publishing at will (at least in respectable journals). In contrast, although we have not seen any empirical evidence on how many articles submitted to law reviews are not placed in any given year, our anecdotal impression is that most law professors in tenure-track positions are able to gain publication offers for most of their articles at law reviews, in part because there are hundreds of student-edited law reviews. The number of articles a law professor has published pre-tenure thus may signal limited information about the quality of the research because students do not filter out low quality research to the same extent as the editors and 
reviewers of peer-reviewed journals.

Article Placement. Whether a given article places in a leading law review depends on the judgment of law students. Although some law reviews solicit faculty input, the students both decide which articles to solicit feedback on and retain the final judgment on which articles to publish. The students making the publication decisions typically have at most two and a half years of legal training. Moreover, the large majority of them do not have any relevant experience evaluating academic scholarship and may also lack the subject-matter expertise necessary to conduct an adequate review of the articles under consideration. As a result, the selection of articles into law reviews may be due in part to randomness, irrelevant criteria, or errors.

Citations. Finally, it is hard to imagine that article placement does not have an independent effect on citations, implying that even citations are likely influenced by students. $^{24}$ This may be for several reasons. For one, higher-ranked journals have higher circulation. An article is simply more likely to be seen and subsequently cited because it is in a higher-ranked journal. Additionally, law professors are likely to cite articles in higherranked journals regardless of article quality, in part to signal to student editors that their article under review is of similar significance. The number of citations a law professor has received pre-tenure thus is likely influenced by the decisions of student editors about whether to publish that scholar's work. ${ }^{25}$

\subsection{What Should Tenure Committees Maximize?}

Even if a tenure committee decides to base its decisions, at least in part, on expected future scholarly influence, as measured by citation counts, there is still a question of how to measure citation counts. Answering this question is complicated because future

\footnotetext{
${ }^{24}$ We are unaware of any empirical evidence documenting that the relationship between law review rankings and citations is causal, but it seems implausible to us that there is not some independent causal effect. The fact that so many law professors spend the law review submission season anxiously awaiting good news from law review editors suggests that law professors at least believe that it matters where their research is published.

${ }^{25}$ It is also worth noting that many of the citations in law review articles may have been added by the student editors rather than the authors themselves. This is another distinction between student-run law reviews and peer-reviewed journals. While we are accustomed to treating a citation as an indication that the cited article influenced a subsequent scholar, in the law review context it may indicate only that the cited article influenced a subsequent student.
} 
citations can be to both past and future research. An academic department might try to hire, tenure, and retain those scholars who will do the most important work in the future; those scholars who will have the greatest future impact from existing and future work; or simply those scholars who will have the greatest cumulative lifetime impact from existing and future work. In other words, when tenure committees make decisions, they might be attempting to predict one of three quantities: (1) future citations to future research; (2) future citations to all research (both past and future); or (3) lifetime citations.

We have not found a comprehensive discussion of this issue in existing literature, and there are arguments for the use of each of the measures. First, departments likely only want to grant tenure to someone whom they believe will produce impactful future work. It is hard to imagine a department not feeling reluctant to grant tenure to even the most influential scholar, if at the time of the tenure decision the scholar has pre-committed to not do any more research. To the extent a department is attempting to maximize future impact from future research, it should attempt to predict future citations to future work. At the same time, departments also likely care about whether a faculty member will have influence going forward regardless of whether that influence stems from past or future work. It is hard to imagine tenure committees placing little weight on past research that will be highly influential in the future. To the extent a department is attempting to maximize future impact, it should attempt to predict future citations to a scholar's entire body of research. Finally, a department might wish to hire, tenure, and retain those individuals who have had the greatest influence on their scholarly fields, regardless of whether that influence occurred before or after the moment of hiring or tenure. Universities like to be associated with influential scholars, even if those scholars have done their best work in the past. (We do not expect to see many unemployed Nobel laureates, even if they are no longer doing cutting-edge work.) To the extent a department is attempting to maximize the overall scholarly impact of its faculty, it should attempt to predict total lifetime citations.

Using any of these citation measures when making tenure decisions comes with advantages and disadvantages. Departments undoubtedly make context-specific decisions about how to value each of these measures in a given case. However, the decision to use one or another measure may influence the relative weight that the department should place on 
various elements of a scholar's pre-tenure portfolio. We are generally agnostic about which of these three measures should be used as the outcome variable of interest to tenure committees. However, there is a strong argument for using future citations to future research, at least in the context of tenure. Tenure is not meant as a reward merely for past work, but as a way to select scholars who will have the greatest impact going forward. Tenure clocks in law are relatively short, and our anecdotal impression is that tenure decisions in law schools are more focused on retaining and attracting scholars who will produce important work in the future, rather than on rewarding candidates for articles they produced in the years before tenure.

\section{$3 \quad$ Data and Descriptive Statistics}

Testing whether pre-tenure measures of research productivity and quality can be used to improve tenure decisions requires data on the identities of law professors and their pre- and post-tenure research record. Obtaining this information required us to construct two novel datasets. First, we compiled panel data for all professors that taught at top 100 law schools between 1970 and 2007 from the Association of American Law Schools. Second, we collected data from HeinOnline on the publication history and annual citations for articles that professors published.

\subsection{Association of American Law Schools Data}

We collected the law school and year in which law professors were first granted tenure from information available from the Association of American Law Schools ("AALS"). The AALS annually publishes a list of law professors at each law school called the "List of Law Teachers by School at Member Schools." As an example of the list, Figure 1 provides the first page of the 2007 AALS list. It shows that the name and information about law schools is followed by a complete list of all law professors at the school in the year and their title (e.g., assistant professor, associate professor, or professor).

We obtained files for the list of law teachers files from 1970 to 2007 in text format. We parsed the files to generate a panel of law professors at each top 100 law school between 
1970 and 2007. ${ }^{26}$ We restricted the sample to tenure or tenure-track professors by dropping lecturers and adjuncts, and we excluded professors who in 1970 already have tenure. Because our research design uses law professors' pre-tenure research record to predict posttenure academic impact, we also restricted our sample to professors who received the title of professor at some point in their career. For the remaining sample, we coded a law professor as receiving tenure in the year in which they are first listed with the title of "professor." 27

To illustrate the data, Table 1 shows part of the panel for Harvard Law Professor Cass Sunstein. As the table shows, Sunstein began his career in 1981 at the University of Chicago as an assistant professor. In 1985, Sunstein became a full professor. In our data, we thus code Sunstein as having receiving tenure in 1985.

The sample contains 3,931 law professors who received tenure at a top 100 law school between 1970 and 2007, not all of whom we were able to locate in HeinOnline (as discussed below). The number of tenures granted at the top 100 law schools is fairly constant over time. There were 1,056 tenures granted in the 1970s, 1,117 in the 1980s, 1,082 in the 1990s, and 676 from 2000 to 2007.

\subsection{HeinOnline Data}

We built a dataset containing the set of articles, article placements, and citations for law professors that would be observable by law schools in each year of the professor's career by scraping HeinOnline. HeinOnline is a searchable internet database containing information on law review publications. HeinOnline has unique webpages for authors that

\footnotetext{
${ }^{26}$ We did not use law professors that were granted tenure after 2007 because we wanted at least 10 years of post-tenure data on articles, placement, and citations.

27 One concern is that obtaining tenure may not always be accompanied by a position titled just "professor." For instance, an individual could obtain tenure with the title "associate professor." If someone obtained tenure as an associate professor, using the promotion to professor as the year of the tenure decision would usually lead us to observe a thicker research record as of the year coded as professor. To address this concern, we had research assistants obtain professor CVs and webpages. We found that a small percent of CVs and /or websites list someone as having tenure as an associate, in which case we coded the year of the tenure as the applicable year on the CV or webpage. Of course, someone could have obtained tenure as an associate, but not listed it on their CV or webpage. We addressed the remaining concern in two ways. First, we repeated the counterfactual simulations described below but treated the years before and after the actual year of tenure as the tenure year. We find consistent results, which provides some evidence that miscoding tenure year because tenure is awarded to associate professors does not meaningfully influence the results. Second, given our understanding that the practice of awarding tenure to associate professors has become less common, in Section A1 we repeat the counterfactual simulations using only tenure cases after 1996 and find consistent results.
} 
list all of the author's publications available in HeinOnline's database. Each publication then has a separate webpage that lists every citation it has received.

As an example, Panel A of Figure 2 provides the author webpage for Cass Sunstein. It shows the first three articles that load when visiting the webpage. As the figure shows, there is a box below each publication that contains a link to another HeinOnline webpage containing a list of each of the articles citing the article. For example, the link to the citations of the article A Behavioral Approach to Law and Economics is the blue text "Cited by 1192 Articles." Panel B of Figure 2 shows part of the article webpage that loads when clicking that link. It shows the first three citations for the article A Behavioral Approach to Law and Economics. Notably, for each of the citations, there is information about the year in which the citing article was published.

We first scraped each law professor's webpage we could identify to obtain a list of all of their publications. For each article, this included information on the journal publishing the article and the year of publication. Next, we scraped each article's citations webpage and obtained a list of all the citing articles and information about each of the citing articles, including the year of publication. Using this information, we created a dataset where the unit of observation is the article-citation level. The reason this is critical is that we care about not only the total number of citations that a professor received for a given article, but also the number of citations that the article received in each year. We use the date the citing article was published to construct the set of citations for each professor that would be observable to law schools in each year of a professor's career.

In total, we were able to locate HeinOnline author pages for 1,720 out of 3,931 law professors in the AALS data. ${ }^{28}$ For these professors, we were able to obtain information on 29,694 articles they have published. Of these articles, 5,848 of them were published in

\footnotetext{
${ }^{28}$ Any measurement error raises a serious concern for this research. This is because increasing the tenure denial rate necessarily focuses on the bottom tail of the distribution, and any mismatched law professors would affect the bottom tail of the distribution. For example, mis-matching information from a person's profile on the HeinOnline to a law professor at a top university would likely lead to a mis-characterization of the professor in the bottom tail. We thus took extensive efforts to verify our data. In particular, we had research assistants manually search for the law professors in the sample to confirm our data. If a professor's $\mathrm{CV}$ or website could not be located, that professor was dropped from the sample. We repeated this process twice and only retained law professors in which both sets of searches identified the same professor's articles, tenure school, and tenure year.
} 
top 20 law reviews. ${ }^{29}$ We also retrieved information on 1,070,092 citations received by the professors in our sample. To put the size of our sample in context, one can compare it to other papers that have studied the research of academics: Bertsimas et al. (2015) studied 54 scholars in operations research departments at top 10 programs, Chilton and Posner (2015) studied legal academics' ideological bias with a sample 156 law professors, and Yoon (2016) studied the impact of tenure on research output using a sample of 1,000 law professors.

\subsection{Descriptive Statistics}

Figure 3 reports the mean number of author articles, articles in top 20 law reviews, and citations for each tenure cohort over time, separately for before and after law professors receive tenure. The pre-tenure panels show a clear upward trend in pre-tenure articles, articles in top 20 law reviews, and citations over time. In the 1970s and 1980s, the average law professor granted tenure at a top 100 law school had published roughly 3 articles and had been cited by roughly 20 articles at the time of tenure. These numbers increased to roughly 5 articles and 40 citations for those professors granted tenure in the late 1980s and 1990s, and 6 articles and 60 citations for those professors granted tenure in the 2000s. Overall, the mean (median) author has 37 (18) citations before tenure and 662 (266) citations over their lifetime. ${ }^{30}$

It is worth emphasizing that these averages are for those professors granted tenure, and changes in the observed averages could be driven by factors unrelated to tenure standards, including any changes in the distribution of law schools granting tenure over time. We do not observe professors who were denied tenure or were pushed out of the legal academy before going up for tenure. As such, the figure does not provide direct evidence that tenure

29 Our decision to use number of articles in top-20 law reviews as our measure of quality placements requires some explanation. In some academic fields, there are well-defined lists of journals considered to be top journals (in economics, for example, see Hamermesh, 2018). In law, the division is less clear, both because there is not a well-accepted list of top journals and because the articles are not peer reviewed, but rather reviewed and accepted by law students. We acknowledge that any discrete definition of top law reviews is less than ideal. For the main analysis, we define top law reviews according to the list of 20 law reviews according to the 2017 Washington and Lee Law Review Ranking.

30 Section A2 in the Appendix reports the author-level distributions of citations, articles, and articles published in top 20 law reviews before tenure and after tenure. Because of changes in norms over time, the distributions first detrend each of the measures. To compare pre- and post-tenure distributions, we then divide by the standard deviations and report the normalized distributions. 
standards have increased over time, but merely shows that those granted tenure have been publishing more articles and getting cited more before tenure. The after-tenure panels show a downward trend in post-tenure articles, articles in top 20 law reviews, and citations over time. This downward trend may result from the fact that we are more likely to observe the full set of lifetime articles for professors granted tenure earlier in the sample than for professors granted tenure late in the sample.

Figure 3 hides any variation in pre-tenure research records between professors and between law schools. However, we are particularly interested in differences in citations of law professors at different law schools because increases in tenure standards create vacant positions that would need to be filled by other legal academics, including laterals. One might expect there to be imperfect sorting across law school ranks, which would imply that law schools would be able to improve the academic impact of their faculty by increasing tenure standards and filling vacant spots from the lateral market. We assess the extent to which influential law professors are distributed across law schools in Figure 4, which reports the distributions of the within-tenure cohort percentile of law professor citations at three groups of law schools. The figure provides strong evidence that there is a good deal of sorting between law schools. However, it also shows that there are meaningful numbers of law professors at all law schools who occupy both ends of the distribution. At one extreme, 3 (8) percent of law professors at top 20 schools are in the bottom 10 (20) percent of the distribution. At the other extreme, 4 (10) percent of law professors at law schools ranked 51 to 100 are in the top 10 (20) percent of the distribution.

\section{The Predictive Power of Law Professors' Research Records}

In this section, we estimate the extent to which law professors' pre-tenure research records predict future academic impact. We use three measures of a law professors' pretenure research record - the number of articles, the number of top 20 law review articles, and citations - and we use citations to post-tenure articles as our measure of academic impact. As discussed above, using citations to articles published post-tenure is a conservative approach to measuring post-tenure academic impact because it breaks any mechanical relationship 
between law professors' pre-tenure research records and post-tenure academic impact. ${ }^{31}$

Tenure committees have all three of these pre-tenure measures available to them, and the relevant question is how they should weigh them. To answer this question, we estimate the empirical specification in Equation 1.

$$
\ln \left(\text { impact }_{i}\right)=\alpha+\beta \ln \left(\text { citations }_{i}\right)+\delta \ln \left(\operatorname{articles}_{i}\right)+\gamma \ln \left(\text { placements }_{i}\right)+\phi_{t}+\epsilon_{i}
$$

where impact $_{i}$ is an author $i$ 's citations to post-tenure articles, citations $i$ is an author $i$ 's citations before their tenure, $\operatorname{articles}_{i}$ is the number of articles published before tenure, placements $_{i}$ is the number of top 20 law review articles published before tenure, ${ }^{32}$ and $\phi_{t}$ are tenure cohort fixed effects. ${ }^{33}$ It is worth emphasizing that citations ${ }_{i}$ is the number of citations as of the year of the tenure decision, and not the number of citations that law professor $i$ will later receive from all articles published before tenure. We are able to construct this former measure because we observe the year each citation to an article occurs - that is, the year each article citing to a given article was published.

Table 2 reports the results. ${ }^{34}$ Columns 1, 2, and 3 report the coefficients for articles, articles in top 20 law reviews, and citations estimated separately. Column 4 reports the specification estimated jointly. Column 4 suggests that each of the measures have independent predictive power. Law professors with 1 percent more articles, articles in top 20 law reviews, and citations before tenure have an average of $0.18,0.81$, and 1.02 percent more citations to post-tenure articles. Comparing the R-squared in Columns 1 and 3, pretenure citations explain less of the variation in citations than the number of articles in top 20 law reviews, and both explain more variation than the number of articles published. The R-squared in Column 4 is meaningfully higher than that in the other columns.

\footnotetext{
31 Section A3 in the Appendix shows that the conclusions that can be drawn from the results remain unchanged when using alternative measures.

${ }^{32}$ Section A4 in the Appendix explores different definitions of top law reviews and finds consistent results.

33 To account for zeros, we add 1 to each of the measures before taking the natural log. The natural $\log$ specification provides percentage interpretation and allows us to compare the coefficients on citations, articles, and articles in top 20 law reviews. This is also motivated in part because Figure A2 in the Appendix shows that pre-tenure citations, articles, and articles in top 20 law reviews are skewed to the right. Section A5 in the Appendix explores different functional forms and finds consistent results.

${ }^{34}$ Section A6 in the Appendix reports results using all post-tenure articles and article in top law reviews as the outcome variables.
} 
We assess the shape of the relationships with the binscatters in Figure 5. The $y$-axis is the mean of the natural log of citations to post tenure articles for each of the deciles of the $\mathrm{x}$-axis, and the $\mathrm{x}$-axis is the mean of the natural $\log$ of the given decile. ${ }^{35}$ Figure 5 provides evidence that the estimates in Table 2 are not being driven by extreme outliers. Moreover, the relationship between citations to post-tenure articles and pre-tenure articles, articles in top 20 law reviews, and citations are roughly linear (in log-log space). The assumed natural log functional form appears to adequately capture the shape of the relationships. ${ }^{36}$

Next, we assess the relative positions of law professors in the distribution of predicted impact based on pre-tenure research records and their relative position in actual academic impact. The fact that almost one fourth of the variation in citations to posttenure articles can be explained by law professors' pre-tenure research record provides some evidence that these objective measures might be able to identify, at the time of tenure, those professors who will have low future academic impact. ${ }^{37}$ However, it is possible that these results are largely due to accurate predictions of the top of the distribution, in which case a data-driven approach to tenure decisions would be unreliable for distinguishing between the professors at the bottom of the distribution (who are the relevant professors if tenure standards are at issue). To shed further light on this question, Table 3 reports the percentage of law professors from the predicted citation quartiles and the actual citation quartiles. Figure 6 reports the same results visually in a Sankey Diagram. Overall, the results suggest that a law professor's pre-tenure research record is highly predictive of actual citations to post-tenure articles. For example, the first row of the first column shows that 59 percent of

\footnotetext{
${ }^{35}$ To match the specification in Table 2 , each panel first residualizes the variables using tenure-cohort fixed effects.

${ }^{36}$ Section A7 in the Appendix reports analog results for the specifications comparable to Column 4, but where we create decile bins for each of the law professors pre-tenure research records by tenure cohort and estimate the specification in Equation 1 by replacing the continuous variables with indicators for the bins. The point estimates indicate the difference between the professors in the deciles relative to professors in the bottom 10 percent of each of the distributions. Note that over 30 percent of law professors do not publish an article in a top 20 law review before tenure, so they are grouped together in the bottom bin and serve as the control group. The basic patterns in Figure 5 are also seen in the estimates on the decile bins in Figure A6, which allow us to assess statistical differences between the pre-tenure deciles. The relationships are again roughly linear across the deciles.

${ }^{37}$ It is worth noting that this semi-parametric specification in Figure 5 explains more of the variation in citations than in Table 2. Compared to an R-squared of 0.258 in Column 4 of Table 2, the R-squared in this specification is 0.272 .
} 
professors in the bottom quartile of predicted citations were also in the bottom quartile of actual citations, and only 18 percent of law professors in the bottom quartile of predicted citations have actual citations above the median of their tenure cohort. These results provide further evidence that pre-tenure research records can be used to inform tenure decisions.

Finally, we assess whether the relative positions of law professors in the distribution of predicted impact based on pre-tenure research records are predictive of outside options after tenure. If law professors with low predicted impact have limited outside options after tenure, the stakes of the tenure decision are higher than they would be if those with low predicted impact have options after tenure. This is because granting tenure to someone with low predicted impact will be a long-term commitment, given that the professor is unlikely to be hired away by another law school. The ideal measure of outside option would be to observe whether other law schools made someone an offer. Then, we could identify outside options even if the person remained at the law school. Of course, this information is not publicly available. ${ }^{38}$ As a proxy for outside options, we use an equilibrium outcome of whether a law professor lateraled to another law school after tenure. In particular, we had research assistants search the internet for law professors' webpages and/or CVs, and collect information on the most recent university affiliation of each law professor. For active professors, we use their current affiliation. For professors who have retired or are emeritus, we use the latest university affiliation we could find. Although we acknowledge that this proxy is less than ideal, we believe that it nonetheless contains some information about an individual's outside options after tenure.

Using these data, we define law professor cohorts by tenure year and the ranking of the law school where they were granted tenure (as further discussed below, we group professors into 5 year tenure bins, and for law school companion schools we group law schools into 10 ranking bins). Then, within each law professor cohort, we calculate the decile of the predicted impact, and estimate the percentage of law professors within each decile who left the law school. Figure 7 presents the results. We find that law professors' research records

\footnotetext{
${ }^{38}$ Another possible proxy for an outside option would be whether the law professor was a visiting professor at another law school, but many outside offers come without a visiting position and many visits do not come with an offer. Moreover, many visits are simply to fill teaching needs at a law school, where visitors are told that they are not under consideration.
} 
are predictive of their outside options after tenure. For the law professors in the bottom three deciles in predicted future impact, one in four have since left the law school that granted them tenure, compared to one in three for those in the top 50 percent of predicted impact and one in two for those in the top 10 percent of predicted impact. ${ }^{39}$

\section{$5 \quad$ Rethinking Law School Tenure Standards}

Now that we have demonstrated that measures of law professors' pre-tenure research records can predict citations to post-tenure articles, we turn to studying the costs and benefits of increasing tenure standards. In this section, we begin by outlining the assumptions of the counterfactual analysis. We then use the counterfactual analysis to quantify the potential benefits of stricter tenure standards. We estimate the percentage increase in a law school's median faculty citations that law school could have obtained by replacing professors who would have been denied tenure under hypothetical stricter tenure standards with plausible alternative candidates. Finally, we quantify the potential costs of stricter tenure standards by estimating the percentage of law professors who would have been denied tenure under stricter tenure standards but who go on to have greater future academic impact than their hypothetical replacements.

\subsection{Counterfactual Microsimulation}

The general framework proceeds in four steps. First, we estimate Equation 1 and use the estimated coefficients to form predicted citations for each law professor. To avoid over-fitting the model, we form leave-out predictions for each law professor where we estimate a regression for each law professor while leaving the law professor in question out of the regression and then predicting her citations. This allows us to form out-of-sample

\footnotetext{
${ }^{39}$ One concern with the results reported in Figure 7 is that there may be significant differences in the mobility of the lower of the distribution for tenure cohorts at top law schools. On the one hand, professors at the bottom of the distribution at top law schools might be cited more than professors at lower ranked schools and would therefore might be expect to have outside options. On the other hand, Figure 4 shows that there is a large density of professors in the bottom 30 percent of the citations distribution even at the top 20 law schools. We assess differences in mobility by law school rank in Section A8 in the Appendix. We find evidence that professors at the bottom of the predicted impact distribution are less mobile at lower ranked law schools.
} 
predictions of future scholarly impact for every professor. This prediction can be viewed as a single statistic that tenure committees would use in making tenure decisions. ${ }^{40}$

Second, we define law professor cohorts to which we will apply hypothetical tenure standards. In particular, we group cohorts of professors along two dimensions: the year in which the professor received tenure and the ranking of the law school where she was granted tenure. For the tenure year, we group professors into 5-year bins. For law school companion schools, we group law schools in 10-ranking bins. This creates 80 cohorts of law professors. Cohort sizes are as small as 4 to as large as 44 . The mean cohort has 21 professors, where 25 (50) percent of cohorts have less than 15 (21) professors. We then calculate the percentile of each law professor's predicted citations within their cohort. This percentile will be used to deny tenure to law professors in the counterfactuals. ${ }^{41}$

Third, we impose a rule to deny tenure to some percentage of law professors across the cohorts. We then conduct several counterfactuals in which we replace the law professors who have hypothetically been denied tenure with plausible alternative candidates, chosen according to a specified procedure. We run five separate counterfactuals.

- Median. This counterfactual replaces the law professors denied tenure with the median law professor in the same cohort. This counterfactual would make sense if we think that law schools re-sample from the entry-level distribution. This counterfactual would only make sense if the observed entry-level cohort is representative of the expanded entry-level market, which might be the case given claims about problems in the entry-level academic market in law schools (Redding, 2003). The counterfactual assumes that the law school grants tenure to that median professor. This counterfactual is a relatively extreme lower-bound estimate because under normal circumstances the law school is denying tenure and so would not hire the median of the entire professor distribution. Instead, a typical would law school would hire only from distribution of professors who would be granted tenure under the new tenure regime.

- Median of Remainder. This replaces the law professors denied tenure with the

\footnotetext{
40 Section A9 in the Appendix reports results using each of the three measures separately.

41 We experimented with different definitions of cohorts and the results are not highly sensitive to the particular definition used.
} 
median of professors within a cohort that meets the tenure standard. For example, if law schools denied tenure to 30 percent of law professors, the counterfactual uses the median of the remaining 70 percent of law professors.

- Random Draw. This replaces the law professors denied tenure with a random draw from the cohort of law professors who meet the tenure standard. This counterfactual is similar to the Median of Remainder counterfactual, but with one potentially important difference: the median of remainder counterfactual prevents the possibility of the law schools denying tenure and then hiring someone from the right tail of the distribution. Randomly drawing from the same distribution from which the median is calculated allows for the possibility that a law school will hire a high-performing outlier. It is worth emphasizing that simulating the random draws again and again and then taking the average of the random draws converges on the mean of the law professor distribution that the random draw pulls from. As such, the random draw counterfactual is mechanically the same as taking the mean of the remainder counterfactual.

- Lateral. This replaces the law professors denied tenure with professors from lowerranked law schools. The first three counterfactuals pull from the cohort of law professors at similarly ranked schools. These are intended to resemble a replacement from the entry-level market. In this counterfactual, we instead make a replacement not with someone that looks like a plausible entry-level replacement, but with a lateral hire who has already proven herself. The counterfactual we consider makes an assumption about who law schools might be able to recruit in the lateral market. In particular, we assume that law schools can hire anyone from the law schools ranked 20 spots below. This enables them to pick the best professors from the lower-ranked schools to fill open spots. We randomly assign the top lower-ranked professors across the law schools that are filling open spots.

- Maximize. This simulation combines the entry-level and lateral counterfactuals, allowing for the intuition that the law school would hire a lateral only if the lateral is better than whomever the school could expect to hire in the entry-level market. To do so, we simply use the procedure above for the lateral counterfactual, but replace 
the laterals who are worse than the median remainder (of the cohort) with the median remainder.

Finally, after simulating these counterfactuals, for each law school we compare the counterfactual median professor's post-tenure citations (to post-tenure articles) to the law school's actual median professor's post-tenure citations (to post-tenure articles). The difference between the median counterfactual citations and median actual citations indicates how many more citations a law school's median professor could have received had the school increased its tenure denial rate by the specified amount. We use the percentage increase in median citations as the main statistic of interest because it is not influenced by outliers, but we note that the main conclusions from the article can drawn using other statistics as well.

We employ five different simulations based on a belief that there is no single best replacement procedure. For the lateral replacement procedure, the assumption that a law school could hire whomever it wished from a school 20 spots lower in the rankings is likely over- and under-stated. There are undoubtedly many faculty at lower-ranked schools who cannot be moved, as well as faculty at peer (or better) schools who could be hired away. The entry-level replacement procedures are speculative to some degree as well. The true gains from replacement from the entry-level market are likely somewhere between the lines for the Median of Remainder and the Random Draw replacement procedures. This is because there is likely selection already, and this is particularly true among the very best entry-level candidates. As such, the Random Draw replacement procedure is likely an overestimate of what could be achieved on the entry-level market. The Median of Remainder counterfactual is not quite the lower bound, because law schools could always just deny tenure to more entry-levels it hires. However, there are dynamic feedback effects that complicate the analysis. In order to hire an entry-level candidate who will have a predicted post-tenure citations of at least the median of the remainder, more and more of those hired candidates will in turn have to be denied tenure, driving up the tenure denial rate. This is why we include the median line, which is an extreme lower-bound.

Our simulations make several assumptions that are worth noting. First, our simulations assume that imposing stricter tenure standards and replacing faculty denied tenure would not change any scholar's lifetime research output or citations. This assumption may 
under- or over-estimate citations to post-tenure articles. For instance, the imposition of stricter tenure standards may cause scholars to increase their research output pre-tenure or post-tenure, and the scholars who replace professors denied tenure may have different career research outputs after teaching at higher-ranked schools. Second, our simulations assume that there are no spillover effects for and from other scholars at a given law school. Although denying tenure to some scholars and replacing them with professors who have higher expected citations is likely to improve the research output of their new colleagues, we do not account for any of these changes. Third, our simulations assume that scholars stay at the school at which they are granted tenure. Fourth, our simulations assume that all professors working at a school before 1970 have retired and all scholars working at a school after 1970 have not retired. This is because the quantity of interest we calculate is the citations to post-tenure articles of all the professors who were granted tenure since 1970 (or who would have been granted tenure under various replacement scenarios). A school thus gets "credit" for any scholars granted tenure, regardless of whether they later lateral to another school or retire. Fifth, our simulations count the citations to post-tenure articles of all scholars granted tenure since 1970 equally. In practice, scholars who were granted tenure earlier have had more time to accumulate citations, so they contribute more to schools' total citation counts than scholars that have received tenure more recently. We believe this is consistent with the way that law schools are ranked and evaluated, but it does place greater weight on earlier tenure decisions. Sixth, our simulations apply the increased tenure standards uniformly and do not account for differences in scholars' fields or demographic backgrounds (we revisit these assumptions in Section 6).

Finally, although our data includes faculty from the top 100 law schools, our simulations only estimate the costs and benefits of stricter tenure standards for the top 50 law schools. This is because comparing counterfactuals that draw replacements from the entry level market to replacements from the lateral market requires assessing the same set of law schools. Because we draw lateral replacements from schools ranked 20 places below a given school, we are unable to estimate the impact of lateral replacements for the lowestranked schools in our sample. Moreover, law school rankings have been relatively stable for the top law schools, so we can reliably assume that someone would lateral to a top ranked 
law school. However, for lower ranked law schools, the greater variability in the rankings makes it less appropriate to assume someone would lateral 20 spots higher in the rankings. We therefore take the conservative approach of estimating the costs and benefits for only the top 50 laws schools, but we note that the benefits of stricter tenure standards are greater and the costs are lower when we include schools ranked below 50 in our simulations. ${ }^{42}$

\subsection{Illustration of Simulations}

Figure 8 presents an illustration of the simulation. For the illustration, we first generate a distribution of citations at a representative law school. To generate the distribution, we calculate the number of citations to post-tenure articles of each decile of law professors at each law school. We then calculate each decile's average citations across law schools. The solid line reports the average citations of each decile and shows that the median professor at the representative law school has 240 citations to post-tenure articles. The dashed line then illustrates the effect of a 20 percentage point higher tenure denial rate by dropping the bottom 20 percent of the faculty at the representative law school. This shifts the curve to the left, and because this line only goes from the 0 to 80 th percentile, the median professor is at the 40th percentile on the x-axis. When the bottom 20 percent of faculty are removed, before rehiring, the new median faculty member has 330 citations (a 38 percent increase). Finally, the line labeled "Replacement" fills the vacant 20 percent of spots with professors who are in the top decile of the representative law school. Because we assess the change in median citations, this is mechanically no different than adding professors at any point above the 50th percentile. Thus, this replacement scheme may seem unrealistic, but the practical assumption that all professors added to fill the vacant spots are above the median is not unrealistic (as we will see below). With the replacements added, the median is again at the 50 th percentile of the $\mathrm{x}$-axis and the median faculty member now has 485 citations. This is a 102 percent increase from the initial median of 240 citations.

To be clear, Figure 8 is only an illustration to show the logic of the simulations. The actual simulations differ from the illustration in a number of important ways. First, the

\footnotetext{
${ }^{42}$ We use law schools ranked below 50 for two purposes. First, we use them in the estimation from which we form predictions about scholars citations to post-tenure articles. Second, we use them to fill the replacements in the counterfactuals.
} 
illustration assumes that the bottom 20 percent of the distribution of citations to post-tenure articles can be precisely identified. However, our simulations drop faculty based on their predicted citations, but then assess the improvement to a faculty's median citaitons using actual citations to post-tenure articles. Second, the illustration assumes that all replacements are above the median, but this of course will not necessarily be the case. For example, the replacement can actually turn out to have fewer citations than the faculty member who was hypothetically denied tenure (though we note that this rarely occurs when we assess the costs of stricter tenure standards in Section 5.4). Third, the illustration is based off of a representative law school and not any specific law school. The distribution of post-tenure citations will differ between law schools, and market-wide tenure denial rates will naturally lead to differences in denial rates across law schools. Consequently, the benefits of stricter tenure denial rates will vary between law schools.

\subsection{The Benefits of Stricter Tenure Standards}

Figure 9 reports the primary results of the counterfactual simulations. The x-axis depicts different counterfactual tenure denial rates from 5 percent to 30 percent, and the y-axis reports the percentage increase in the median law professor's citations to post-tenure articles. $^{43}$

As illustrated in Figure 8, there are two main ways that stricter tenure standards could improve a law school's academic impact. First, stricter tenure standards remove unproductive faculty. Second, stricter tenure standards can create vacancies, which can then be filled with faculty who are better than the faculty who failed to meet the tenure standards.

To estimate the extent to which the overall benefits are driven by the removal of unproductive faculty, we run the simulations but without replacing any of the faculty, allowing the vacant positions to remain vacant. This can be thought of as a counterfactual in which law schools have a smaller percentage of tenured faculty relative to nontenured faculty (either tenure track or otherwise). The thick solid line without markers reports the results without replacement. We find that that the median law school faculty citations

\footnotetext{
43 Section A10 reports results for the simulations using alternative statistics for the increase in law school's academic impact, including the percentage increase in each law school's 25th percentile citations, 75th percentile citations, mean citations, and cumulative citations.
} 
would be increased by 19 percent if tenure denial rates increased by 10 percentage points, 37 percent if tenure denial rates increased by 20 percentage points, and 52 percent if tenure denial rates increased by 30 percentage points. (Recall that tenure denial rates in the legal academy are approximately 5 percent, which means that even a 10 percentage point increase in the tenure denial rate would mean roughly tripling the number of faculty who are denied tenure.)

In Figure 9, the lines with markers each report the simulated results from using a different replacement procedure-these are the benefits of both removing unproductive faculty and filling the vacant positions. There are several important results in Figure 9. First, and most notably, even modest increases in tenure standards would translate into large increases in the percent of the median law professor citations. For instance, increasing tenure denial rates by 10 percentage points would translate to a 30 percent increase in median citations using the Median of Remainder replacement procedure and a 56 percent increase using the Maximize replacement procedure. Second, increases in law professor citations from higher and higher denial rates continue across the spectrum of tenure denial rates for most of the replacement procedures, but at slower rates. Much of the observed gains can be realized with a 20 percentage point increase in tenure denial rates. Third, as tenure denial rates increase, the benefits of the Lateral replacement procedure begin to decrease relative to the other replacement procedures as the pool of exceptional lateral candidates is exhausted. This suggests that as law schools increase their denial rates, they should turn to entry-level hiring more and more.

\subsection{The Costs of Stricter Tenure Standards}

Next, we estimate some of the costs of stricter tenure standards. It is nearly inevitable that stricter tenure standards will lead schools to deny tenure to some law professors who will go on to be very impactful. In technical terms, if the null hypothesis in tenure decisions is to grant tenure only in cases where there is enough evidence that the professor will be impactful, denying tenure to professors who go on to be impactful is a type II error.

To formally assess these potential costs of stricter tenure standards, we estimate the percentage of law professors denied tenure that go on to have greater academic impact 
than their hypothetical replacements. It is worth noting that there are a number of possible ways to assess the type II error. For instance, instead of comparing law professors denied tenure to their replacements, we could compare professors denied tenure to other professors who were granted tenure at the same law school. The reason we choose to assess type II error by comparing professors denied tenure to their hypothetical replacements is that we believe it most closely resembles the decisions that law schools realistically face: either to grant tenure, or to deny tenure and hire again from the entry-level or lateral pool.

Figure 10 reports the results. There are several findings worth noting. First, there are large differences in type II errors between the replacement counterfactuals even within a given tenure denial rate. With an increase in the tenure denial rate of 20 percentage points, for example, the Lateral replacement procedure leads to only 8 percent type II errors but the Median replacement procedure leads to over 18 percent type II errors. Second, the Median of Remainder and the Random Draw replacement procedures both have fairly stable type II error rates even as the increase in the tenure denial rate approaches 30 percentage points. If these are the replacement procedures that most closely resemble what law schools would actually do, it suggests that the costs of increased standards would be similar across the range of plausible stricter tenure standards. Finally, although we are agnostic about the amount of type II error that a school would find acceptable, the fact that the Maximize line is always below 10 percent, and is usually around 5 percent, suggests that the costs of stricter tenure standards may be relatively low.

\section{Differential Impacts}

We next extend our analysis to test whether applying uniform tenure denial rules would have differential impacts by law school rank, field, or demographic characteristics of the professors. It is important to emphasize the goal of this exercise. Our goal is not to assess whether any given law school should or would establish and apply different tenure standards. As such, for this exercise we are agnostic about whether and to what extent differences in tenure rates across various dimensions would be acceptable.

Instead, our goal is to assess the extent to which our results are driven overwhelm- 
ingly by denying tenure to similar professors. If the results are driven overwhelmingly by any large difference between groups, and the group with the higher rate of tenure denial is large, ${ }^{44}$ it would call into question the validity of the results because the increased tenure standards applied in our counterfactuals would presumably not be a plausible option. But if the results are not driven overwhelmingly by such differences, or if the group with the higher rate of tenure denial is small enough, the increased tenure standards applied in our counterfactuals would not be implausible.

\subsection{By Law School Rank}

It is possible that the objective assessments of law professors at the time of tenure decisions are more or less useful across law schools. If so, the benefits and costs of increasing tenure standards can vary from law school to law school. An initial question is the extent to which there is variation in the tenure denial rate across law schools. Figure 11 reports the hypothetical tenure denial rate across law schools under different market-wide tenure denial rates. ${ }^{45}$ There are at least three interesting findings. First, the figure shows some large differences in the extent to which more law professors would have been denied tenure across law schools. Under counterfactual tenure denial rates of even as high as 15 percent, some law schools would not have denied tenure to any additional law professors. At the other extreme, some law schools would have denied tenure to at least twice the marketwide rate. Second, other than these outliers, tenure denial rates would have been similar across law schools for marketwide denial rates of 5 to 20 percent. For example, most law schools would have denied tenure at the market-wide rate for a tenure denial rate of 10 percent, with roughly half of law schools denying tenure to between 5 percent and 15 percent more law professors. Third, the spread of the denial rate across law schools widens as the denial

\footnotetext{
44 The reason the size of the group is important is that high denial rates for small groups cannot be driving our results. For instance, if our simulations suggest that a high percent of admiralty law scholars should be denied tenure, it may suggest that schools should not impose a uniform tenure standard for these scholars. But if there are only a few scholars in the field, it would also suggest that our results are not primarily driven by simply denying tenure to all admiralty law scholars.

45 In addition to conducting these simulations, we first estimated the regressions from Part 4 separately by law school rank to see if the relationships is being driven more by differences between schools of different ranks rather than between the same types of schools. Section A11 provides the results and provides evidence that the general patterns above hold for different levels of law school rank.
} 
rate increases, and the spread is quite large for marketwide denial rates of over 20 percent.

Of course, it is possible that the impact of a law school's faculty could change non-linearly as tenure standards increase across different law school ranks. We assess this possibility in Figure 12, which reports the main counterfactual results after breaking out law schools by rank. The counterfactual is the Median of Remainder. ${ }^{46}$ The figure shows that the top 20 law schools would benefit less from higher tenure denial rates and make more mistakes than law schools ranked 21 to 50.

\subsection{By Field}

Our simulations apply the increased tenure standards uniformly and do not account for differences in scholars' fields. It is possible that impact differs greatly across fields, which would imply that we are denying tenure to professors only in certain fields. Because law schools need scholars to teach subjects in the law school, applying uniform standards with a disparate impact across fields would be unreasonable. In addition, citation rates are likely driven in part by the number of faculty across the country working in a given field. It would make no sense to deny tenure to all scholars working in smaller fields just because there are fewer total papers being written in those fields and thus fewer citations to be had. For example, law schools are not likely to deny tenure to all tax law professors in favor of hiring nothing but constitutional law scholars. Rather, they would likely apply field-specific tenure standards, such as comparing scholars against peers in their field. Given this reality, if there are large differences in tenure denial rates across fields, our simulations would overestimate the extent that law schools could improve the academic impact of their faculties. Here, we extend our results by testing whether stricter tenure standards would have differential impacts across law teaching fields.

While there are several ways one could assess disparate impacts across fields, we are mostly interested in the extent that a uniform tenure denial rate e.g., a 10 percentage point increase in the denial rate-leads to different percentages of tenure denials across fields. If the percentage of law professors denied tenure from each field is similar, then we should not be concerned our results are implausible for a law school that seeks to hire

\footnotetext{
${ }^{46}$ We find similar results for the other counterfactuals.
} 
across the curriculum. We cannot create law professor cohorts that include fields because of the limited number of law professors in the United States. As discussed above, we already form law professor cohorts using 5-year tenure cohorts and by 10-rank groups of companion law schools, which gives us 80 cohorts of law professors. If we also defined cohorts by an additional category (field), the curse of dimensionality would lead to cohorts that are so small that they are impractical for our purposes.

To assess whether stricter tenure standards would have differential impacts across law teaching fields, we match our sample to the "table of law teachers by subject" in the 2012 AALS, which contains the teaching areas of professors. Doing so decreases the sample to 1,263 professors for a few reasons. First, many law professors in our sample had retired as of 2012. Second, we only include law professors who are listed as teaching at least one subject, and not all law professors taught at least one subject in 2012. For this sample, we group teaching subjects into coarser fields following Bonica et al. (2017).

Figure 13 reports the percentage of professors within a field that would have been denied tenure under alternative counterfactual tenure denial rates. The fields are sorted such that the field on the left (tax) would have the highest tenure denial rate and the field on the right (constitutional law) would have the lowest tenure denial rate. Each line reports the denial rates across fields for different market-wide denial rates. We find that uniform tenure standards would result in some differences between fields, and the results are consistent with our perceptions of differences in citations across fields. Law professors in tax and constitutional law have the lowest and highest citations and thus would have the highest and lowest tenure denial rates. For example, a market-wide denial rate of 10 percent would lead to a tenure denial rate of 18 percent for tax law professors, but only 7 percent for constitutional law professors. Perhaps surprisingly, however, other than in these two fields, the tenure denial rates do not vary greatly. Forty-two percent of fields have a denial rate of between 9 and 11 percent under a market-wide denial rate of 10 percent, and 71 percent of fields have a denial rate of between 8 and 12 percent under a market-wide denial rate of 10 .

Overall, Figure 13 does not suggest that the main results are being driven primarily by only a few fields. In addition, we assessed how the main simulations would change if tenure standards were applied separately by field by regressing the prediction of citation to post- 
tenure articles on field fixed effects and obtaining residuals. We used this approach both because professors have multiple teaching areas and because of the impracticality of defining cohorts by field as well as tenure year and school rank. These residuals can be interpreted as predictions that account for differences among fields. Although this process decreased the differences in tenure denial rates between the fields with large differences in Figure 13, it created larger differences in other fields. For example, this updated prediction would lead to a tenure denial rate of greater than 15 percent for intellectual property law professors under a market-wide denial rate of 10 percent. We then repeated the above simulations regarding the costs and benefits of stricter tenure standards. We find no evidence that the original simulations significantly overstate the benefits of stricter tenure standards or understate the costs of stricter tenure standards.

\subsection{By Demographics}

Tenure standards could have differential impacts across groups of law professors, including groups that are underrepresented (Barnes and Mertz, 2012). Some evidence suggests that tenure standards would need to be flexible enough so as not to have disparate impacts on underrepresented groups and thus work against existing hiring priorities. For example, Merritt (2000) examines sex and race differences in academic impact as measured by citations of 815 professors who "began tenure-track positions at accredited U.S. law schools between 1986 and 1991," and finds white men have more citations than women and minorities. However, the author interprets the citations gap as modest, and the author also finds some evidence that the citations gap is largely explained by "differences in educational background, prestige of the institution at which a professor teaches, teaching assignments, and similar factors."

We repeat the by-field exercise in Figure 13, but for gender and racial minority status. To do so, we use the 2012 AALS list of minority law professors and the gender of the professor. This again restricts the sample to the 1,263 law professors we were able to match to the 2012 AALS list. Of this sample, female law professors comprise 26 percent of all law professors and racial minorities comprise 11 percent. Figure 14 reports the results. Figure 14 shows that a market-wide denial rate of 10 percent would lead to 9 percent of men being 
denied tenure and 12 percent of women being denied tenure. Additionally, a market-wide denial rate of 10 percent would lead to 9 percent of law professors not on the AALS minority list being denied tenure and 15 percent of law professors on the AALS minority list being denied tenure.

\section{Discussion}

Our results suggest that pre-tenure measures of research productivity and quality predict future citations, and that even modest increases in tenure standards can dramatically improve law schools' academic impact. We document that this first-order effect on academic impact would be substantial. However, there are a number of additional relevant considerations that law schools should take into account when deciding whether to raise their tenure standards. This section first discusses potential additional dynamic implications of raising tenure standards, and then addresses several limitations of our analysis.

\subsection{Implications}

As an initial matter, raising tenure standards may affect junior faculty recruitment. For instance, if an individual school were to unilaterally raise its tenure standards, some junior faculty might decide to accept offers from peer or near-peer institutions with less demanding tenure standards. There is ample anecdotal evidence that entry-level candidates consider how difficult it will be to obtain tenure when choosing between job offers. Additionally, many promising legal academic candidates have rewarding and lucrative career options outside of the academy. If a new equilibrium of stricter tenure standards were to prevail across the legal academy, these candidates might be less likely to attempt to enter the legal academy in the first place. If higher tenure standards kept promising candidates away from academia, that would represent a system-wide harm. Yet it is important to note that this effect is double-sided. While raising tenure standards might negatively impact entry-level recruiting, holding tenure standards low undoubtedly exerts a negative impact on the pool of entry-level candidates as well. Lax tenure standards enable unproductive faculty to occupy positions for decades. This decreases the number of positions available to more promising 
entry-level candidates, some of whom likely decide not to enter the academia because of the scarcity of open positions. Lax tenure standards similarly reduce the amount of lateral hiring of productive scholars from lower-ranked schools. This may similarly deter promising entry-level scholars from accepting initial positions at lower-ranked schools with the hope of moving up.

Raising tenure standards may also influence research productivity. Our simulations assume that the only way a law school's academic impact improves through raising tenure standards is through replacement. That is, our simulations estimate the impact of denying tenure to scholars whose pre-tenure research measures predict that they will fail to reach a given threshold of citations from articles written after tenure, and replacing them with scholars who are likely to be more impactful. This almost certainly understates the impact of raising tenure standards on research output. Raising tenure standards will likely incentivize many scholars to increase their research output (or at least their pre-tenure research output). Although it is possible that scholars will not do better research in the face of stricter standards (perhaps because they are already maximally focused on research), we believe that a first-order effect of raising standards will be increased research production. Additionally, our simulations assume that the scholars replacing the faculty members denied tenure will continue their pre-tenure research trajectories after lateraling to higher-ranked schools. But a scholar who produces an above-average level of research compared with her tenure cohort, despite teaching at a lower-ranked school, may become even more productive after having access to the greater resources and platform that are available at higher-ranked schools. (Alternatively, scholars may have lower research trajectories after lateraling because the possibility of lateraling may have been creating the incentives for them to be productive in the first place.) Our simulations also do not account for possible positive spillover effects from having more productive scholars together at the top law schools. Evidence suggests that peer interactions have large effects (e.g. Akcigit et al., 2018), and we expect this to be the case in the legal academy as well.

Finally, and perhaps obviously, the effect of raising tenure standards at a given law school would depend substantially on how many schools altered their standards. If only a few law schools were to raise their standards, our results suggest that over time they would 
be able to dramatically increase the academic impact of their faculties. On the other hand, if all law schools were to raise their tenure standards in relative lock-step, the impact on any given school would be much more muted. Such a shift might have little impact on the relative ordinal positions of law schools - that is, the schools with greater scholarly impact would maintain their position - assuming that schools' abilities to recruit the most influential scholars were relatively proportionate to their current level of prestige. It would, however, have a large impact on the cardinal ranking of law schools. That is, the difference between the top schools and lower ranked schools would be higher as schools engaged in more sorting among academic hires. Regardless, these points about relative rankings - which are surely important to law school faculties and to deans - are not necessarily important to society unless there are network effects; that is, unless faculty will conduct more or better research when paired with better peers. If legal research has any social value - and we are strongly invested in the idea that it does - there is value both in creating incentives for scholars to produce more high quality research and in providing opportunities for scholars who produce high quality research to migrate to the law schools that are best able to provide resources and platforms to promote that research.

\subsection{Limitations}

There are several important limitations to our study. First, we study only one criteria that is relevant to the tenure process: research. Other considerations, such as teaching, service, the diversity of the faculty, and many others are undeniably important as well. We do not mean to suggest that they should be ignored, or even that they should necessarily be prioritized behind research in tenure and hiring decisions. The goal of our project is not to argue what schools should try to maximize when making tenure decisions. Instead, it is to test whether one thing that tenure committees care about - academic impact - can be predicted based on law professors' research records at the time tenure decisions are made.

Second, our project only speaks to whether objective data on research productivity and quality predicts academic impact, as measured by citations to articles published after tenure. We do not, for instance, observe subjective assessments of research quality - such as outside letters and internal reviews - to which tenure committees have access, and thus we 
cannot compare their relative value. It is possible that these assessments are better predictors of ultimate academic impact than the objective measures we used. It is also possible that subjective assessments of academic impact are superior to citations. Citations are, at best, a proxy for overall academic impact and value. Accordingly, we could be overweighting (or underweighting) the impact of scholars whose work was cited disproportionately frequently (or infrequently) in comparison to its true quality.

Third, our sample has several shortcomings. Notably, our sample of professors is drawn entirely from professors who work at a law school ranked in the top 100 by U.S. News and World Report. It is of course possible that different patterns would emerge if we were to investigate other schools. Additionally, our sample only includes professors who were granted tenure by 2007. We made this choice to allow for a reasonable period of time after tenure (10 years) during which those professors' work could be cited. It is possible the research profiles and publishing habits of law professors have changed in the ensuring decade, perhaps due to the rise in law faculty with a PhD since 2007 (LoPucki, 2016). Also, our sample only includes articles and citations that are indexed by HeinOnline. Accordingly, we are undercounting the articles and citations of scholars who either publish outside of traditional law reviews or receive citations to their work in journals not on HeinOnline.

Fourth, our sample consists exclusively of law professors who were granted tenure between 1970 and 2007. ${ }^{47}$ Although our data include professors who were granted tenure at schools other than where they started (which could happen either because of tenure denials or voluntary lateral moves), we do not observe professors who were denied tenure and subsequently left the legal academy. We chose to focus on professors who have received tenure because our focus is on whether law professors' pre-tenure research records predict their academic impact, which requires data on post-tenure research activity and citations. Although we believe these choices are reasonable, there are certainly limitations to our decision to focus on law professors who have received tenure.

\footnotetext{
47 Yoon (2016) similarly uses a sample of professors who have received tenure in his analysis of research habits before and after tenure.
} 


\section{Conclusion}

This article studied how law schools could improve their academic impact by increasing tenure standards. We collected data on the articles and citations of 1,720 law professors who were granted tenure at top 100 law schools between 1970 and 2007. We found that law professors' pre-tenure research records can be used to make fairly accurate predictions about their post-tenure academic impact and their post-tenure outside options. We then simulated how law schools' academic impact would have changed by replacing faculty members who be denied tenure under stricter standards with other faculty under various counterfactual scenarios. We found that even modest increases in tenure standards would have meaningfully increased law schools' academic impact. We also found that the costs of stricter tenure standards - in the form of hiring a replacement who does not perform as well as the faculty member who was denied tenure - would have been modest, as low 5 percent.

These results demonstrate the potential value of using data and rigorous statistical methods to inform personnel decisions at law schools. The findings are important to the claims made about problems in the entry-level academic market in law schools, and they suggest that inefficiencies in the entry-level market can be corrected in part with stricter tenure standards. However, more research is called for. Our data has limitations, and our analysis relied on several strong assumptions about possible replacements for faculty denied tenure. Perhaps more importantly, the counterfactual scenarios we employ are static, in the sense that they do not account for any general equilibrium effects of changing tenure standards. These include possible changes in the incentive to publish and positive externalities from grouping more productive faculty together in law schools. That said, despite these limitations, we believe that our results still suggest that law schools should reconsider the way in which tenure decisions are made, as well as the standards used in those decisions. 


\section{References}

Aaberge, R. and U. Colombino (2018). Structural Labour Supply Models and Microsimulation. IZA Working Paper, No. 11562.

Abrevaya, J. and D. S. Hamermesh (2012). Charity and Favoritism in the Field: Are Female Economists Nicer (To Each Other)? Review of Economics and Statistics 94(1), 202-207.

Akcigit, U., S. Caicedo, E. Miguelez, S. Stantcheva, and V. Sterzi (2018). Dancing with the Stars: Innovation Through Interactions. Working Paper 24466, National Bureau of Economic Research.

Akerlof, G. A. (2018). Sins of Omission and the Practice of Economics. Journal of Economic Literature.

Anauati, M. V., R. H. Gálvez, and S. Galiani (2018). Differences in Citation Patterns across Journal Tiers in Economics. Working Paper 25101, National Bureau of Economic Research.

Ashenfelter, O. and D. Card (2002). Did the Elimination of Mandatory Retirement Affect Faculty Retirement? American Economic Review 92(4), 957-980.

Auerbach, A. J. and D. R. Feenberg (2000). The Significance of Federal Taxes as Automatic Stabilizers. Journal of Economic Perspectives 14(3), 37-56.

Autor, D. H. and D. Scarborough (2008). Does Job Testing Harm Minority Workers? Evidence from Retail Establishments. Quarterly Journal of Economics 123(1), 219-277.

Azoulay, P., J. S. Graff Zivin, and G. Manso (2011). Incentives and Creativity: Evidence from the Academic Life Sciences. RAND Journal of Economics 42(3), 527-554.

Baker, G. P. and T. N. Hubbard (2004). Contractibility and Asset Ownership: On-Board Computers and Governance in U.S. Trucking. Quarterly Journal of Economics 119(4), 1443-1479.

Barnes, K. and E. Mertz (2012). Is It Fair? Law Professors' Perceptions of Tenure. Journal of Legal Education 61(4), 511-539.

Basken, P. (2018). UT-Austin Professors Join Campaign Against Faculty-Productivity Company. The Chronicle of Higher Education Jan. 24, 2018.

Bersin, J. (2013). Big Data in Human Resources: Talent Analytics (People Analytics) Comes of Age. Forbes.

Bertsimas, D., E. Brynjolfsson, S. Reichman, and J. Silberholz (2015). OR Forum-Tenure Analytics: Models for Predicting Research Impact. Operations Research 63(6), 1246-1261.

Bonica, A., A. Chilton, K. Rozema, and M. Sen (2017). The Legal Academy's Ideological Uniformity. Journal of Legal Studies 41, 1-43. 
Boring, A. (2017). Gender Biases in Student Evaluations of Teaching. Journal of Public Economics 145, $27-41$.

Brogaard, J., J. Engelberg, and E. Van Wesep (2018). Do Economists Swing for the Fences after Tenure? Journal of Economic Perspectives 32(1), 179-94.

Brown, William O., J. (1997). University Governance and Academic Tenure: A Property Rights Explanation. Journal of Institutional and Theoretical Economics 153(3), 441-461.

Brynjolfsson, E., L. M. Hitt, and H. H. Kim (2011). Strength in Numbers: How Does Data-Driven Decisionmaking Affect Firm Performance? Working Paper.

Carmichael, H. L. (1988). Incentives in Academics: Why is There Tenure? Journal of Political Economy 96(3), 453-472.

Caron, P. L. and R. Gely (2004). What Law Schools Can Learn from Billy Beane and the Oakland Athletics. Texas Law Review 82, 1483-.

Chilton, A., J. Masur, and K. Rozema (2018). Political Discrimination in the Law Review Selection Process. Working Paper.

Chilton, A. and E. Posner (2015). An Empirical Study of Political Bias in Legal Scholarship. Journal of Legal Studies 44(2), 277-314.

Cole, A. J., G. Gee, and N. Turner (2011). The Distributional and Revenue Consequences of Reforming the Mortgage Interest Deduction. National Tax Journal 64, 977-1000.

Colussi, T. (2017). Social Ties in Academia: a Friend is a Treasure. Review of Economics and Statistics.

Davenport, T. H. and J. G. Harris (2007). Competing on Analytics: The New Science of Winning. Harvard Business School Press.

Dnes, A. and N. Garoupa (2005). Academic Tenure, Post-Tenure Effort, and Contractual Damages. Economic Inquiry 43(4), 831-839.

Dorsey, E. R., B. A. Raphael, L. J. Balcer, and S. L. Galetta (2006). Predictors of Future Publication Record and Academic Rank in a Cohort of Neurology Residents. Neurology 67(8), 1335-1337.

Dustin, D., J. Murphy, C. McDonald, B. Wright, J. Harper, and G. Lamke (2014). Academic Moneyball. SCHOLE: A Journal of Leisure Studies and Recreation Education 29(2), 4352 .

Ehrenberg, R. G., P. J. Pieper, and R. A. Willis (1998). Do Economics Departments with lower Tenure Probabilities pay Higher Faculty Salaries? Review of Economics and Statistics $80(4), 503-512$.

Foundation, N. S. (2014). Agency Financial Report. 2014. 
Gale, W., J. Gruber, and S. Stephens-Davidowitz (2007). Encouraging Homeownership Through the Tax Code. Tax Notes, 1171-1189.

George, T. E. and A. H. Yoon (2014). The Labor Market for New Law Professors. Journal of Empirical Legal Studies 11(1), 1-38.

Gerrity, D. M. and R. B. McKenzie (1978). The Ranking of Southern Economics Departments: New Criterion and Further Evidence. Southern Economic Journal 45(2), 608-614.

Gingras, Y. (2016). Bibliometrics and Research Evaluation: Uses and Abuses.

Hamermesh, D. S. (2018). Citations in Economics: Measurement, Uses, and Impacts. Journal of Economic Literature 56(1), 115-56.

Harper, J. W. (1997). Why Student-Run Law Reviews. Minnesota Law Review 82, 12611294.

Harvard Law Today (2018). HLS Faculty Maintain Top Position in SSRN Citation Rankings. Harvard Law Today.

Heckman, J. J. and S. Moktan (2018). Publishing and Promotion in Economics: The Tyranny of the Top Five. Working Paper 25093, National Bureau of Economic Research.

Hemel, D. and K. Rozema (2017). Inequality and the Mortgage Interest Deduction. Tax Law Review 70(4), 667-706.

Hengel (2016). Publishing while Female: Gender Differences in Peer Review Scrutiny. Working Paper.

Hoffman, M., L. B. Kahn, and D. Li (2018). Discretion in Hiring. Quarterly Journal of Economics 133(2), 765-800.

Joint Committee on Taxation (2018). Estimates of Federal Tax Expenditures for Fiscal Years 2018-2022.

Kahneman, D. (2011). Thinking Fast and Slow. New York: Farrar, Strauss, and Giroux.

Kaminski, D. and C. Geisler (2012). Survival Analysis of Faculty Retention in Science and Engineering by Gender. Science 335(6070), 864-866.

Kingi, H. and K. Rozema (2017). The Effect of Tax Expenditures on Automatic Stabilizers: Methods and Evidence. Journal of Empirical Legal Studies 14(3), 548-568.

Kleinberg, J., H. Lakkaraju, J. Leskovec, J. Ludwig, and S. Mullainathan (2018). Human Decisions and Machine Predictions. Quarterly Journal of Economics 133(1), 237-293.

Kuncel, N., D. Klieger, B. Connelly, and D. Ones (2013). Mechanical Versus Clinical Data Combination in Selection and Admissions Decisions: A Meta-Analysis. Journal of Applied Psychology 98, 1060-1072. 
LawProfBlawg and TempDean (2016). Moneyball, Law Professor Style: What Do You Care About More - The Promise of Greatness or Actual Greatness? available at https: //abovethelaw. com/2016/12/moneyball-law-professor-style/.

LeiterReports (2005). Rising Tenure Standards? Leiter Reports, September 10, 2005 available at http://leiterlawschool.typepad.com/leiter/2005/09/ rising_tenure_s. html.

Levin, S. G. and P. E. Stephan (1991). Research Productivity Over the Life Cycle: Evidence for Academic Scientists. American Economic Review 81(1), 114-132.

Lewis, M. (2004). Moneyball: The Art of Winning an Unfair Game.

Liner, G. H. and E. Sewell (2009). Research Requirements for Promotion and Tenure at PhD Granting Departments of Economics. Applied Economics Letters 16(8), 765-768.

LoPucki, L. M. (2016). Dawn of the Discipline-Based Law Faculty. Journal of Legal Education $65(3), 506-542$.

McCabe, M. J. and C. M. Snyder (2015). Does Online Availability Increase Citations? Theory and Evidence from a Panel of Economics and Business Journals. Review of Economics and Statistics 97(1), 144-165.

Mckenzie, R. B. (1996). In Defense of Academic Tenure. Journal of Institutional and Theoretical Economics 152(2), 325-341.

McPherson, M. S. and M. O. Schapiro (1999). Tenure Issues in Higher Education. Journal of Economic Perspectives 13(1), 85-98.

McPherson, M. S. and G. C. Winston (1983). The Economics of Academic Tenure: A Relational Perspective. Journal of Economic Behavior and Organization 4(2), 163-184.

Merritt, D. J. (2000). Scholarly Influence in A Diverse Legal Academy: Race, Sex, and Citation Counts. Journal of Legal Studies 29(S1), 345-368.

Mingers, J. and F. Xu (2010). The Drivers of Citations in Management Science Journals. European Journal of Operational Research 205(2), 422 - 430.

Mixon, F. G. (2018). Do Academics Swing for the Fences After Tenure? Analysis of Attributions Data from Economics Research. Scientometrics 116, 2155-2160.

Oster, S. M. and D. S. Hamermesh (1998). Aging and Productivity Among Economists. Review of Economics and Statistics 80(1), 154-156.

Posner, R. (1995). The Future of the Student-Edited Law Review. Stanford Law Review 47, $1131-1138$.

PrawfsBlawg (2014). Tenure Standards and Recruiting. October 31, 2014 available at http://prawfsblawg. blogs.com/prawfsblawg/2014/10/ tenure-standards-and-recruiting. html . 
PrawfsBlawg (2015). Contemplating Academic Analytics for Law Schools. available at http://prawfsblawg.blogs.com/prawfsblawg/2015/04/ contemplating-academic-analytics-for-law-schools. html.

Redding, R. E. (2003). Where Did You Go to Law School? Gatekeeping for the Professoriate and Its Implications for Legal Education. Journal of Legal Education 53, 594-.

Rivera, L. A. (2012). Hiring as Cultural Matching: The Case of Elite Professional Service Firms. American Sociological Review 77, 999-1022.

Rodell, F. (1936). Good Bye to Lax Reviews. Virginia Law Review 23, 38-45.

Saez, E. (2004). The Optimal Treatment of Tax Expenditures. Journal of Public Economics 88, 2657 -.

Siow, A. (1998). Tenure and Other Unusual Personnel Practices in Academia. Journal of Law, Economics, and Organization 14(1), 152-173.

Sisk, G., V. Aggerbeck, N. Farris, M. McNevin, and M. Pitner (2015). Scholarly Impact of Law School Faculties in 2015: Updating the Leiter Score Ranking for the Top Third. Report for Scholarly Impact.

Stevenson, M., D. Ledda, V. Pineda, M. Smith, and S. Kluth (2017). CAPITA - Treasury's Microsimulation Model of Personal Income Tax and Transfers. Working Paper.

Sunstein, C. R. (2016). Foreword: In Praise of Law Books and Law Reviews (and JargonFilled Academic Writing). Michigan Law Review 114, 833.

Tahamtan, I., A. Safipour Afshar, and K. Ahamdzadeh (2016, Jun). Factors Affecting Number of Citations: A Comprehensive Review of the Literature. Scientometrics 107(3), $1195-1225$.

Tomkins, A., M. Zhang, and W. D. Heavlin (2017). Reviewer Bias in Single- versus DoubleBlind Peer Review. Proceedings of the National Academy of Sciences.

Yoon, A. H. (2016). Academic Tenure. Journal of Empirical Legal Studies 13(3), 428-453. 


\section{Figures and Tables}

Figure 1: Data Example — Screenshot "AALS Law Teachers By School" Page

\section{List of Law Teachers by School at Member Schools 2006-2007}

University of Akron, C. Blake McDowell Law Center (AALS, 1974), , Akron, OH, 443252901, Telephone: (330) 972-733I, FAX: (330) 258-2343, Web Address: http:// www.uakron.edu/law/

AYNES, RICHARD L., Dean \& Prof.. (330) 972-7331 ANDERSON, LLOYD C.. Prof., (330) 972-6752. lea@uakron.edu

AYNES, RICHARD L,, Dean \& Prof., (330) 972-7331, raynes@uakron.edu

BAUMGaRTNER, SAMUEL P., Assoc. Prof., (330) 972-7331

CANNON, ROSEMARY, Ass't Dean, Fin. \& Admin., (330) 972-6366, rcannon@uakron.edu

CARRO, J. DEAN, Prof., Dir., Legal Clinic Offis. \& Staff Atty., (330) 972-775i, carrol @ uakron.edu, COHEN, RICHARD C., Assoc. Prof. \& Dir, Legal Analysis, Res. \& Writing Prog., (330) 972-7599, rcohen@uakron.edu

COLE, DANA K., Assoc. Prof., (330) 972-7960, dkc@uakron.edu

COLEMAN, MALINA, Assoc. Prof., (330) 972-6797, mcolema@uakron.edu

COOK, STEPHEN R.. Ass't Dir., Legal Clinic \& Dir., (2)

(3) 972-7331

DESSIN, CAROLYN L., Assoc. Prof., (330) 972-6358,

cld3@uakron.edu

DRATLER, JAY, JR., Prof. \& Goodyear Chaì in Intell'! Prop., (330) 972-7972, dratler@uakron.edu

ILE, LAURI S., Ass't Dean. Adms. \& Fin'l Aid \& Acting Ass't Dean, Student Affrs., (330) 972-6367.

GENETIN, BERNÁDETTE BOLLAS, Assoc. Prof., (330) 972-6939, genetin@uakron.ed GIBSON, WILLA E., Prof.,. (330) 972-6132,

willa $1 @$ ukiron.edu

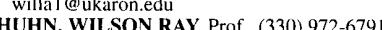
JORDAN, WILLIAM S., III, Prof., (330) 972-6751,

jordan@uakron.edu

KOOSED MARGERY MALKIN Prof (330) 972 6793, mkoosèd@ uakron.edu

KOVACH, RICHARD J., Prof., (330) 972-6794

LAVOIE, RICHARD L., Assoc. Prof., (330) 972-7331

LEE, BRANT T., Assoc. Prof., (330) 972-6616,

btlee@uakron.edu

LENART, LYNN M., Ass't Librarian, Ref. Servs., (330) 9726357

LEVINE, JAY A., Dir., Career Plng./Plmt., (330) 9725320

MESSNER, ADAM P., Adms. Counselor., (330) 972

7334

MORGA

5260 , KIMBERLY M., Dir., Dev., (330) 972-

MOR

PANE C., Assoc. Prof., (330) 972-6796, moriart@uakron.edu
MORITZ, E. STEWART, Assoc. Prof., (330) 972-2340, moritzes@uakron.edu NEWMAN, ALAN, Assoc. Prof., (330) 972-5859, newman2@uakron.edu

O'BRIEN, MOLLY TOWNES, Assoc. Prof., (330) 972-6815, mobrien@uakron.edu ODDI, A. SAMUEL, Prof. \& Giles Sutherland Rich

Chair in Intell'I Prop., (330) 972-6384,

asoddi@uakron.edu

OLSON, CAROL A., Assoc. Prof., (330) 972-6789,

colson@uakron.edu

PADFIELD, STEFAN J., 'Ass't Prof., (330) 972-7331

PASSMORE, KYLE S., Assoc. Librarian.

QUIRK, FRANK E., Dir., Miller/Becker Inst., (330)

REILLY, ELIZABETH A., Assoc. Dean \& Prof., (330) 972-6197, reilly@uakron.edu

RICH, WILLIAM DOUGLAS, Assoc. Prof., (330) 972-6792, rich@uakron.ed

RICHERT, PAUL, Librarian \& Prof., (330) 972-7330, richert@uakron.edu

RICKETT, WILLIAM G., Ass't Dean, External Progs. (330) 972-7189, wrickett@uakron.edu

SAHL, JOHN PATRICK, Prof., Fac. Fellow, Intell'

Prop. Cntr. \& Res. Fellow, Const'l Law Cntr., (330)

972-6753,jps@uakron.edu

SAMUELS, JEFFREY M.: Prof. \& Dir., Intell'1 Prop. \&

Tech. Cntr.. (330) 972-7898, samuels@uakron.edu SHAW, RONALD:R., JR., Dir., Acad. Success Prog . (330) $972-7331$

SOUARE, ANNETTE A., Public Servs. Librárian.; (330) $972-5992$

THOMAS, TRACY A., Prof., (330) 972-6617,

thomast@uakron.edu

WILliAMS, JANE L., Ass'l Librarian, Tech. Servs., (330) 972-7331

The University of Alabama School of Law (AALS, 1928), 101 Paul Bryant Drive East, Box 870382, Tuscaloosa, AL, 35487, Telephone: (205) 348-5117, FAX: (205) 348-3917, Web Address: http://www.law.ua.edu

RANDALL, KENNETH C., Dean \& Thomas E. McMillan Prof., (205) 348-5117

ALMOND, CYNTHIA LEE, Ass't Dean, Advmt., (205) 348-5752, calmond @law.ua.edu AMASON, NOEL G., Lect., Legal Writing., (205) 3489988,ndelcham@law.ua.edu

ANDERSSON, NANCY, Stuff Atty., (205) 348-6803,

nanderso@law.ua.edu

nanderso@law.ua.edu

Dir., Reciprocal Sum'r Sch. Proj. with the Austrailian

Nat'l Univ., (205) 348-7091, wandreen@law.ua.edu ANDREWS, CAROL RICE, Prof., (205) 348-0334, , candrews@law.uatedu 
Table 1: Data Example — Snapshot of AALS Data

\begin{tabular}{llll}
\hline \hline & & & \\
Law Professor & Year & Law School & Position \\
\hline & & & \\
Sunstein, Cass R. & 1981 & Chicago & Ass't. Prof. \\
Sunstein, Cass R. & 1982 & Chicago & Ass't. Prof. \\
Sunstein, Cass R. & 1983 & Chicago & Ass't. Prof. \\
Sunstein, Cass R. & 1984 & Chicago & Ass't. Prof. \\
Sunstein, Cass R. & 1985 & Chicago & Prof. \\
Sunstein, Cass R. & 1986 & Chicago & Prof. \\
Sunstein, Cass R. & 1987 & Chicago & Prof. \\
Sunstein, Cass R. & 1988 & Chicago & Prof. \\
& & & \\
\hline \hline
\end{tabular}




\section{Figure 2: Data Example — Screenshot HeinOnline Pages}

\section{A. Author Page for Cass Sunstein}

1. A Behavioral Approach to Law and Economics [article] Stanford Law Review, Vol. 50, Issue 5 (May 1998), pp. 1471-1550

Jolls, Christine (Cited 2124 times); Sunstein, Cass R. (Cited 26465 times); Thaler, Richard (Cited 1235 times) 50 Stan. L. Rev. 1471 (1997-1998)

Download PDF Download Options Email MyHein

Cited by 1192 Articles Accessed 412 Times

2. Interest Groups in American Public Law [article] Stanford Law Review, Vol. 38, Issue 1 (November 1985), pp. 29-88 Sunstein, Cass R. (Cited 26465 times) 38 Stan. L. Rev. 29 (1985-1986)

992 Articles Accessed 61 Times

3. Beyond the Republican Revival [article] Yale Law Journal, Vol. 97, Issue 8 (July 1988), pp. 1539-1590 Sunstein, Cass R. (Cited 26465 times) 97 Yale L.J. 1539 (July 1988)

\section{B. Citation Page for the Article A Behavioral Approach to Law and Economics}

1. Law and Behavioral Science: Removing the Rationality Assumption from Law and Economics [article] California Law Review, Vol. 88, Issue 4 (July 2000), pp. 1051-1144 Korobkin, Russell B. (Cited 3123 times); Ulen, Thomas S. (Cited 1495 times) 88 Calif. L. Rev. 1051 (2000)

\section{Turn to page}

A Behavioral Approach to Law and Economics, 50 STAN. L. REV. 1471 (1998); Cass Sunstein, Behavioral Law

Download PDF Download Options

Email

MyHein

† All Matching Text Pages (1)

2. The Renew Deal: The Fall of Regulation and the Rise of Governance in Contemporary Leal Thought [article] Minnesota Law Review, Vol. 89, Issue 2 (December 2004), pp. 342-470

Lobel, Orly (Cited 1163 times)

89 Minn. L. Rev. 342 (2004-2005)

\section{Turn to page}

., A Behavioral Approach to Law and Economics, 50 STAN. L. REV. 1471 (1998); see also Richard A. Posner,

Download PDF

¿ Download Options

$\triangle$ Email

\MyHein

Cited by 723 Articles Cited by 3 Cases

Accessed 230 Times

Download PDF I Download Options $\checkmark$ Email

WMyHein

Cited by 466 Articles Accessed 227 Times

$\widehat{\Delta}$ Download PDF t. Download Options $\checkmark$ Email

DMyHein

Cited by 417 Articles Cited by 2 Cases

Accessed 111 Times

., A Behavioral Approach to Law and Economics, 50 STAN. L. REV. 1471 (1998). The implicit bias social cognition

† All Matching Text Pages (1) 
Figure 3: Articles, Placement, \& Citations Before and After Tenure By Tenure-Cohort

A. Mean Number of Pre-Tenure Articles

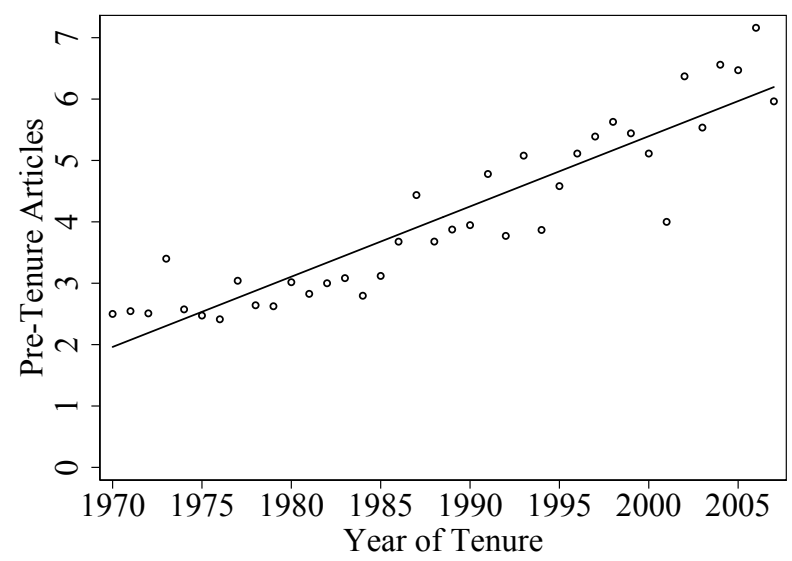

C. Mean Number of Pre-Tenure

Articles in Top 20 Law Reviews

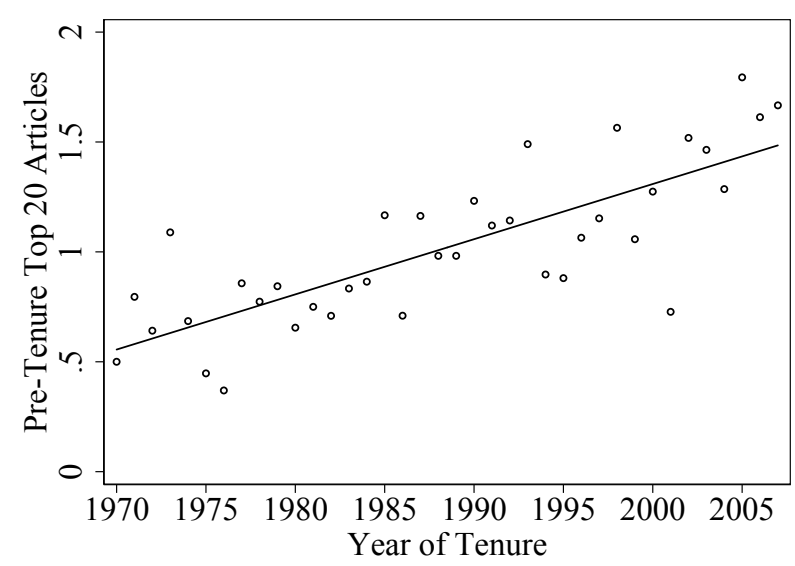

E. Mean Number of Pre-Tenure Citations

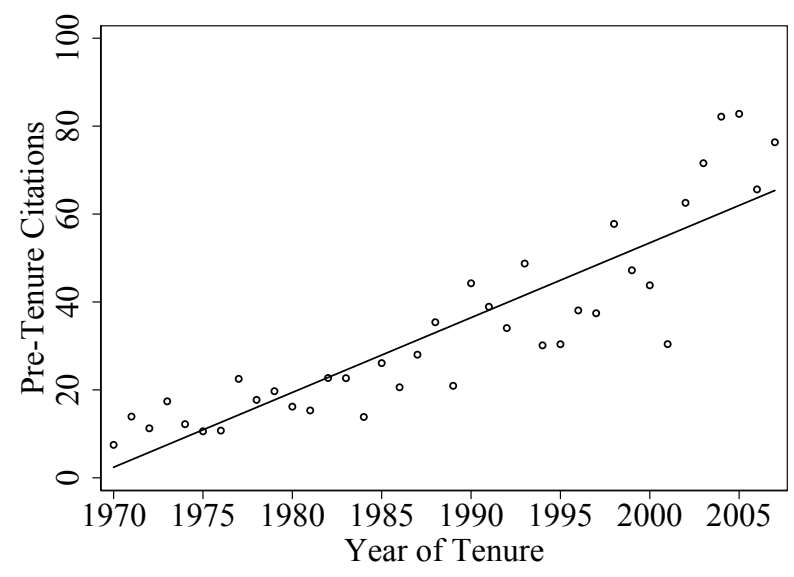

B. Mean Number of Post-Tenure Articles

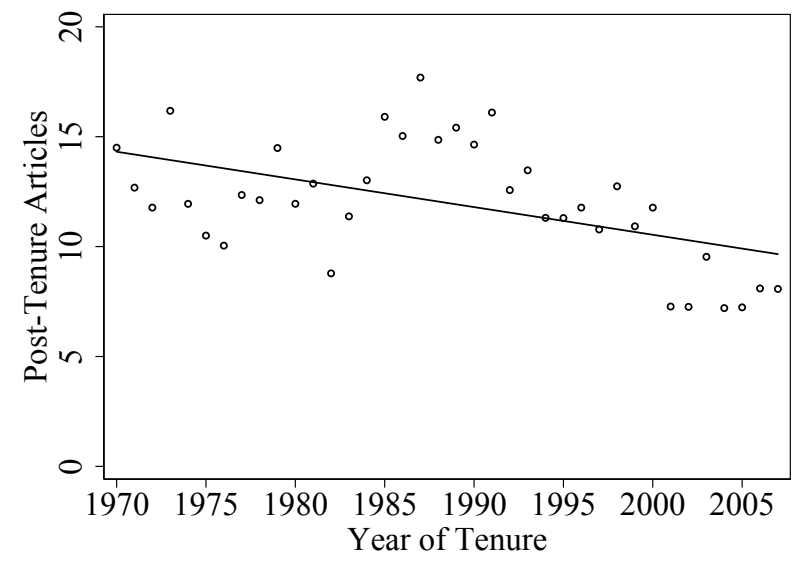

D. Mean Number of Post-Tenure Articles in Top 20 Law Reviews

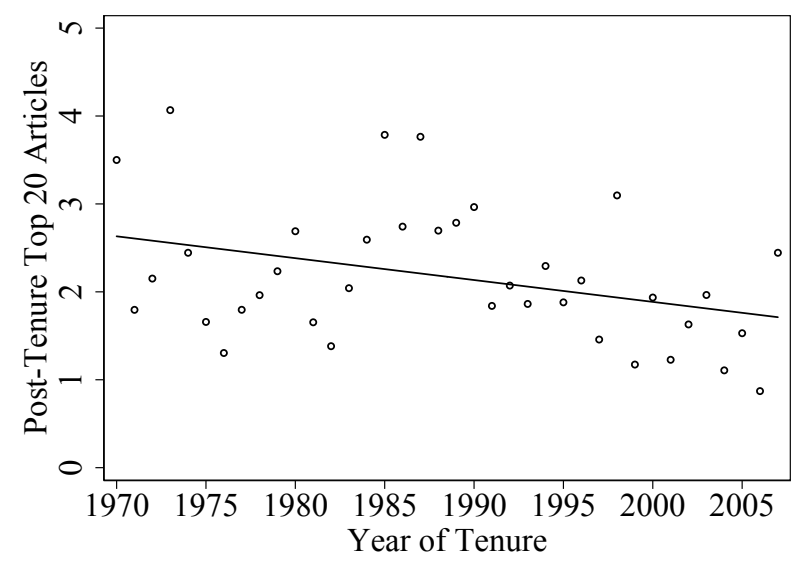

F. Mean Number of Post-Tenure Citations

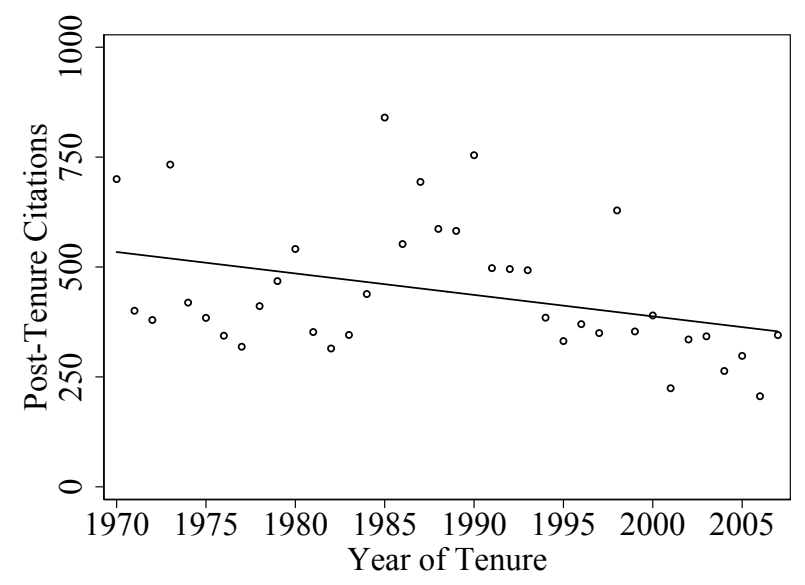


Figure 4: Distributions Faculties' of Lifetime Citations Across Law Schools by Rank

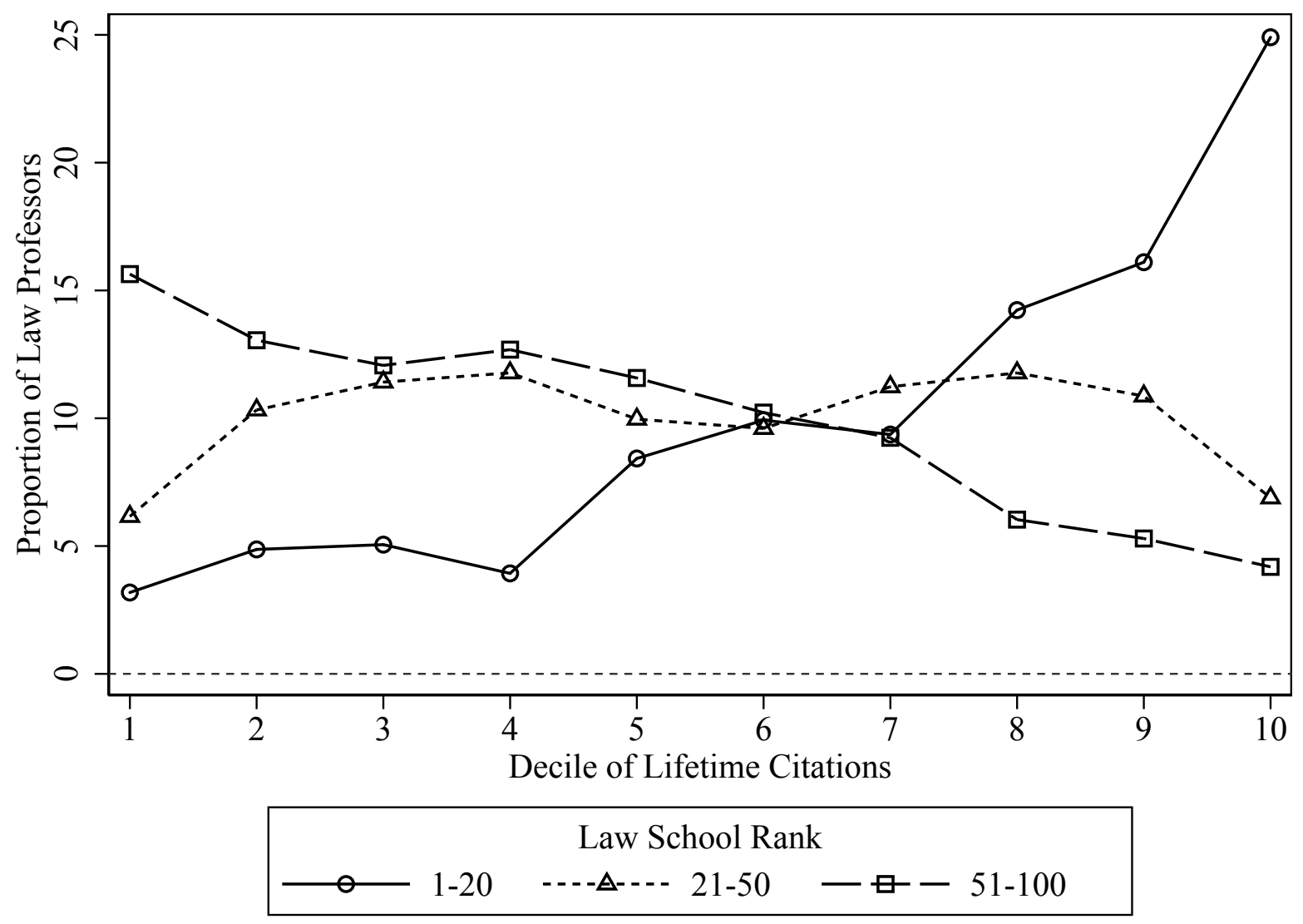


Table 2: Predicting Citations to Post-Tenure Articles with Pre-Tenure Research Records

\begin{tabular}{|c|c|c|c|c|}
\hline & \multicolumn{4}{|c|}{$\begin{array}{c}\ln (\text { Citations to } \\
\text { Post-Tenure Articles })\end{array}$} \\
\hline & (1) & $(2)$ & (3) & $(4)$ \\
\hline $\ln$ (Citations) & $\begin{array}{l}0.70^{* * *} \\
(0.04)\end{array}$ & & & $\begin{array}{l}0.18^{* * *} \\
(0.06)\end{array}$ \\
\hline $\ln$ (Articles) & & $\begin{array}{l}1.56^{* * *} \\
(0.09)\end{array}$ & & $\begin{array}{l}0.81^{* * *} \\
(0.12)\end{array}$ \\
\hline $\ln$ (Articles in Top Law Reviews) & & & $\begin{array}{l}1.53^{* * *} \\
(0.08)\end{array}$ & $\begin{array}{l}{ }^{*} 1.02^{* * *} \\
(0.10)\end{array}$ \\
\hline Tenure-Cohort FE & Yes & Yes & Yes & Yes \\
\hline Obs & 1,720 & 1,720 & 1,720 & 1,720 \\
\hline R-squared & 0.186 & 0.176 & 0.201 & 0.257 \\
\hline
\end{tabular}


Figure 5: Citations to Post-Tenure Articles with Pre-Tenure Measures of Research Records

A. Pre-Tenure Articles

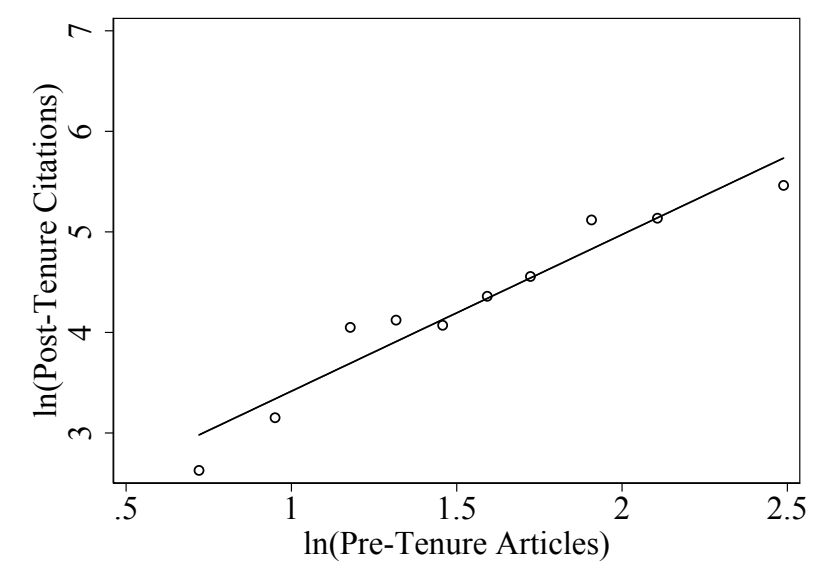

C. Pre-Tenure Articles in Top 20 Law Reviews

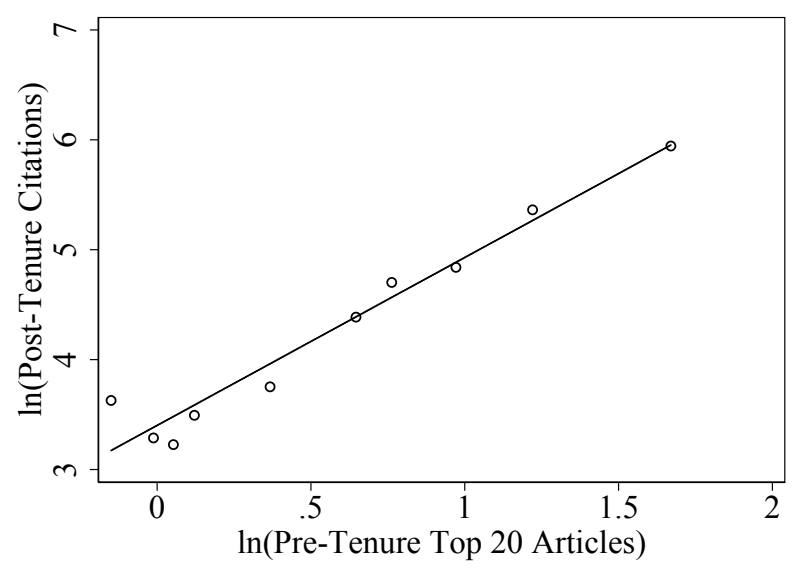

E. Pre-Tenure Citations

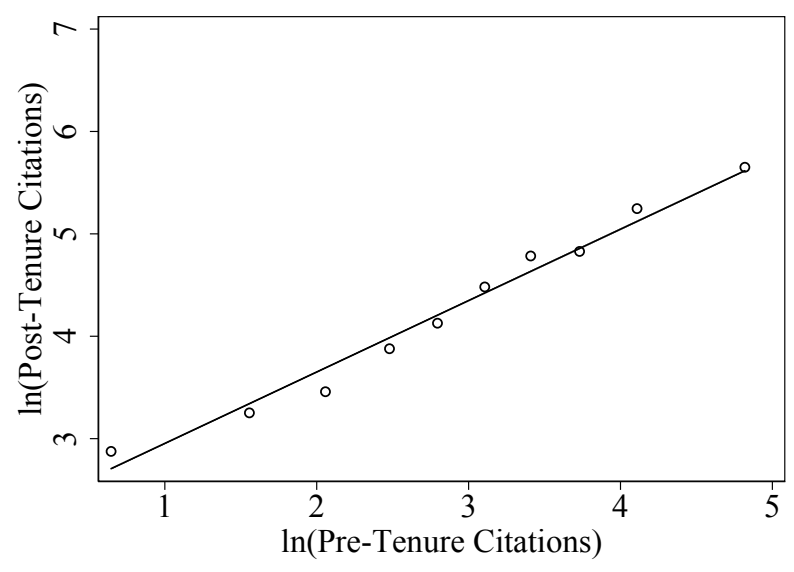


Table 3: Predicting Lifetime Citations at Tenure Decisions

\begin{tabular}{lllll}
\hline \hline & \multicolumn{4}{c}{$\begin{array}{c}\text { Percent in Lifetime } \\
\text { Citations Quartile }\end{array}$} \\
\cline { 2 - 5 } Prediction & Q1 & Q2 & Q3 & Q4 \\
\hline Q1 & 61 & 24 & 11 & 5 \\
Q2 & 29 & 34 & 25 & 12 \\
Q3 & 8 & 29 & 33 & 29 \\
Q4 & 2 & 12 & 31 & 55 \\
\hline \hline
\end{tabular}


Figure 6: Sankey Diagram of Predicted Citations to Post-Tenure Articles at Tenure Decisions

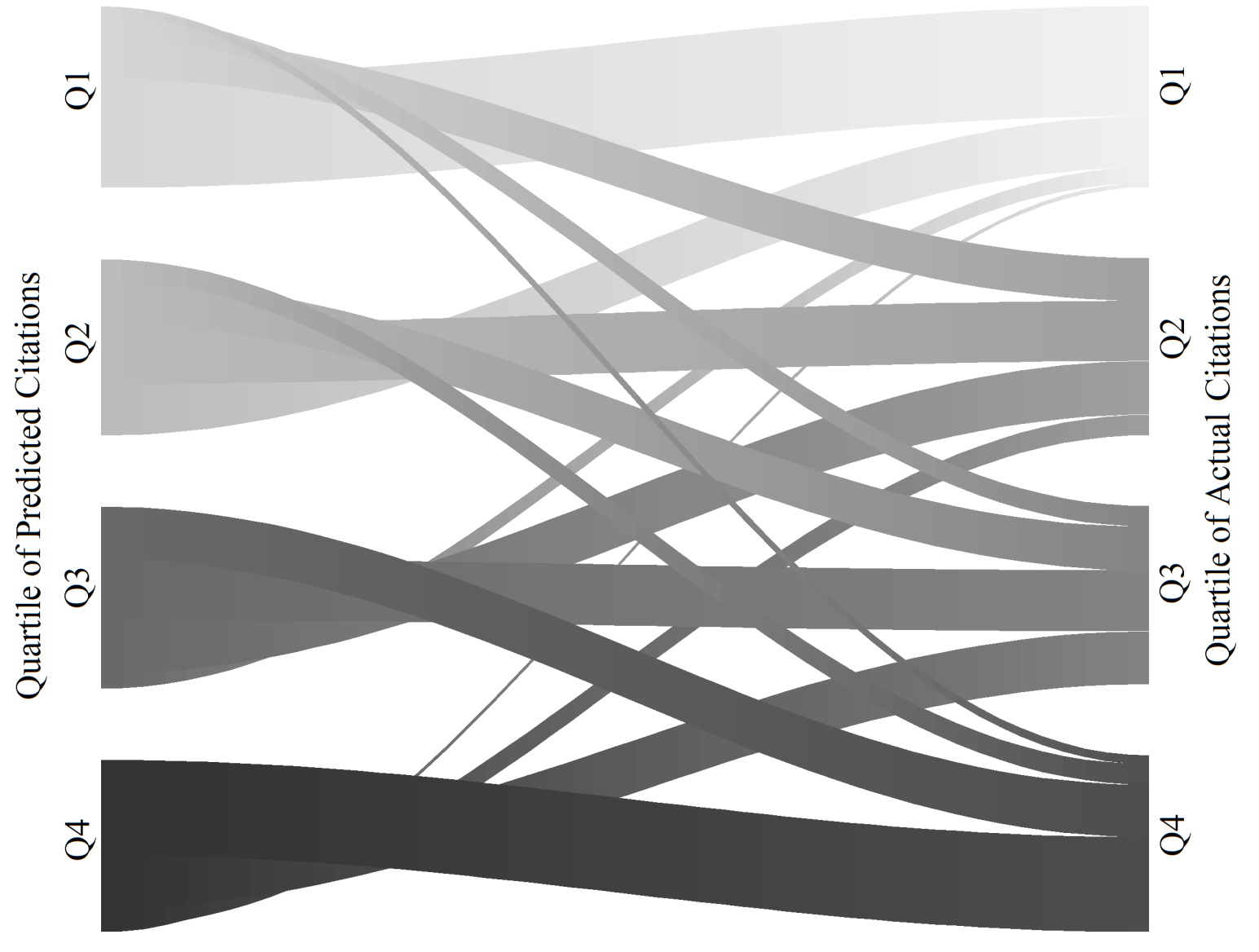


Figure 7: Law Professors Moving Law Schools After Tenure by Predicted Citations to PostTenure Articles

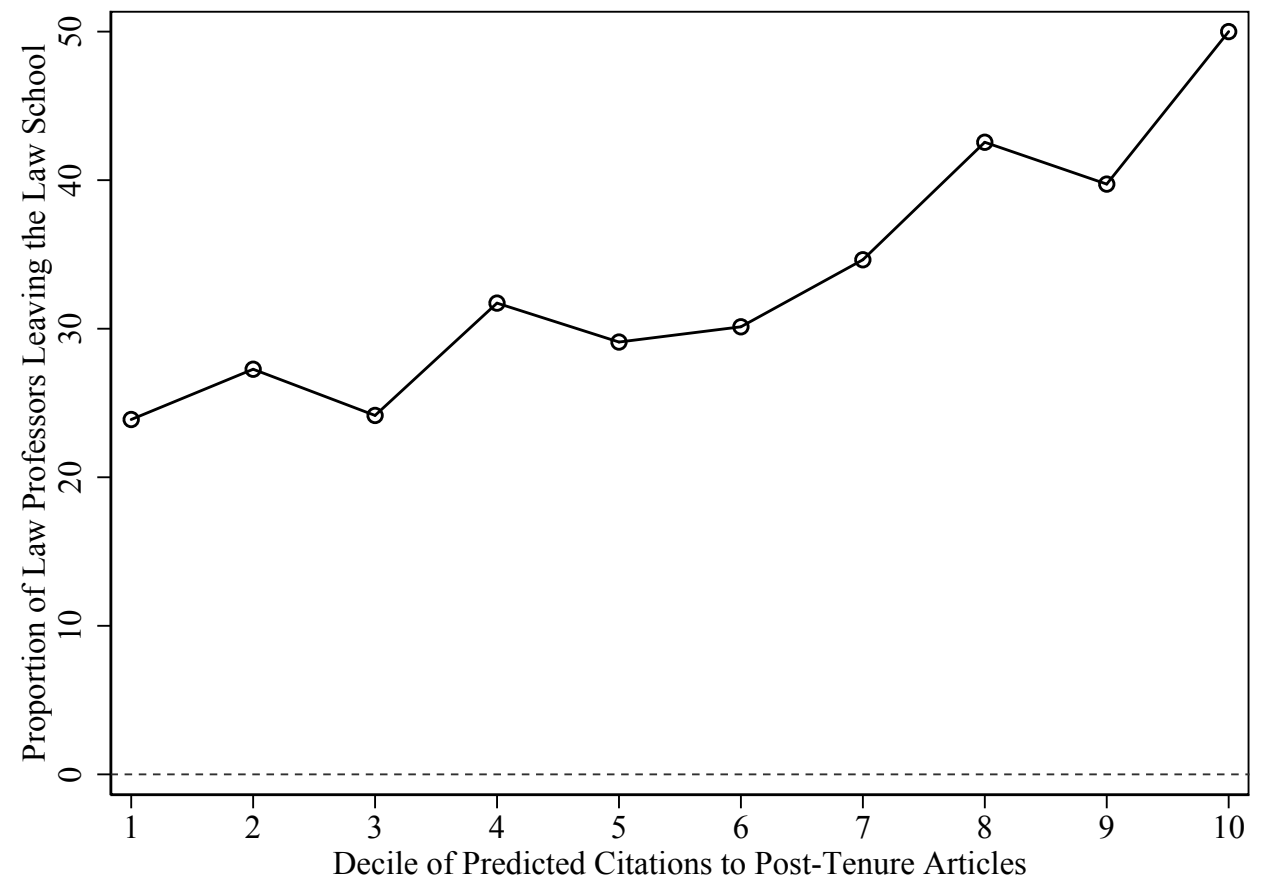


Figure 8: Illustration of Simulation

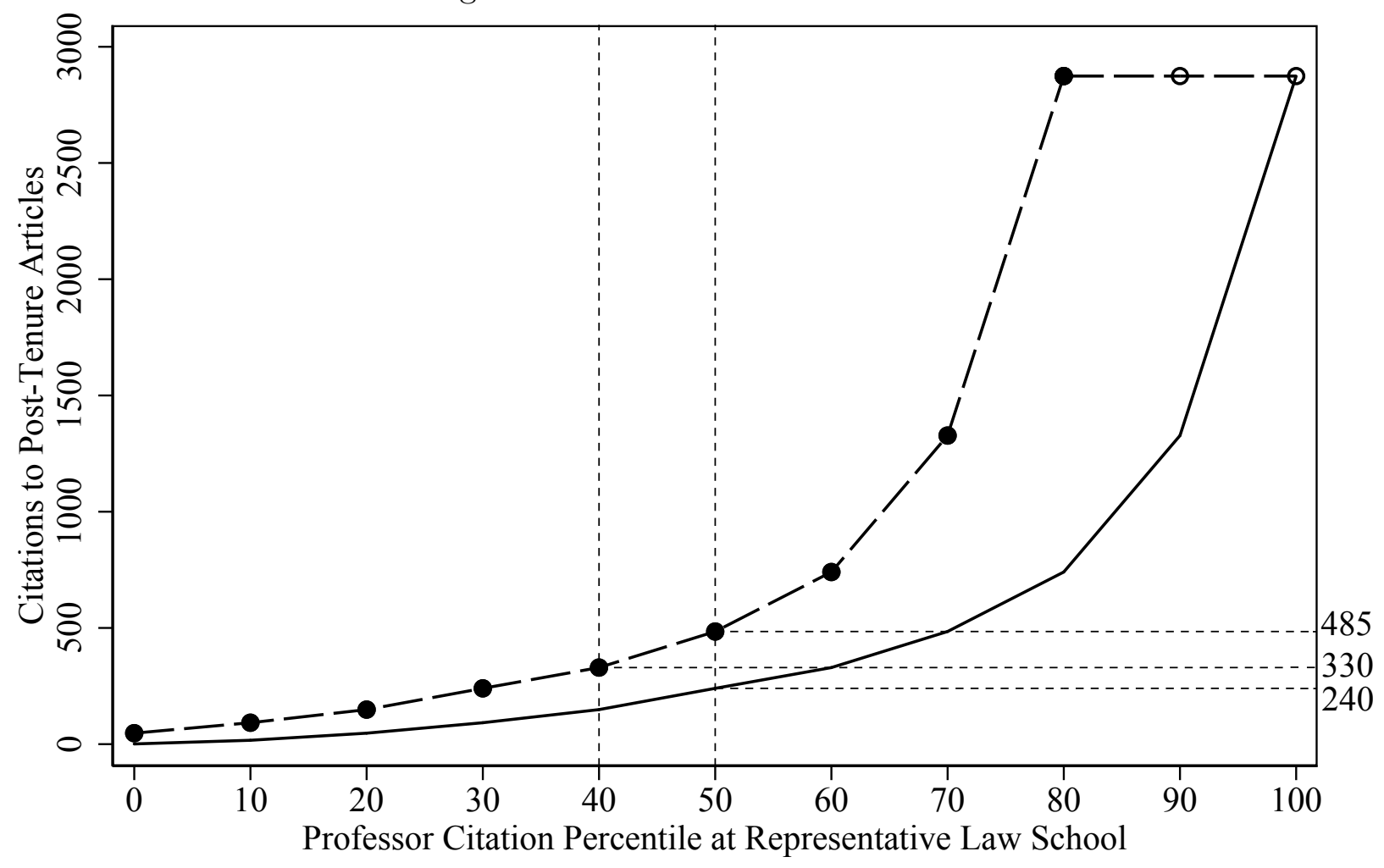

$$
\text { Actual -๑ー No Replacement } \quad-\bullet-\text { Replacement }
$$


Figure 9: Simulated Benefits of Stricter Tenure Standards

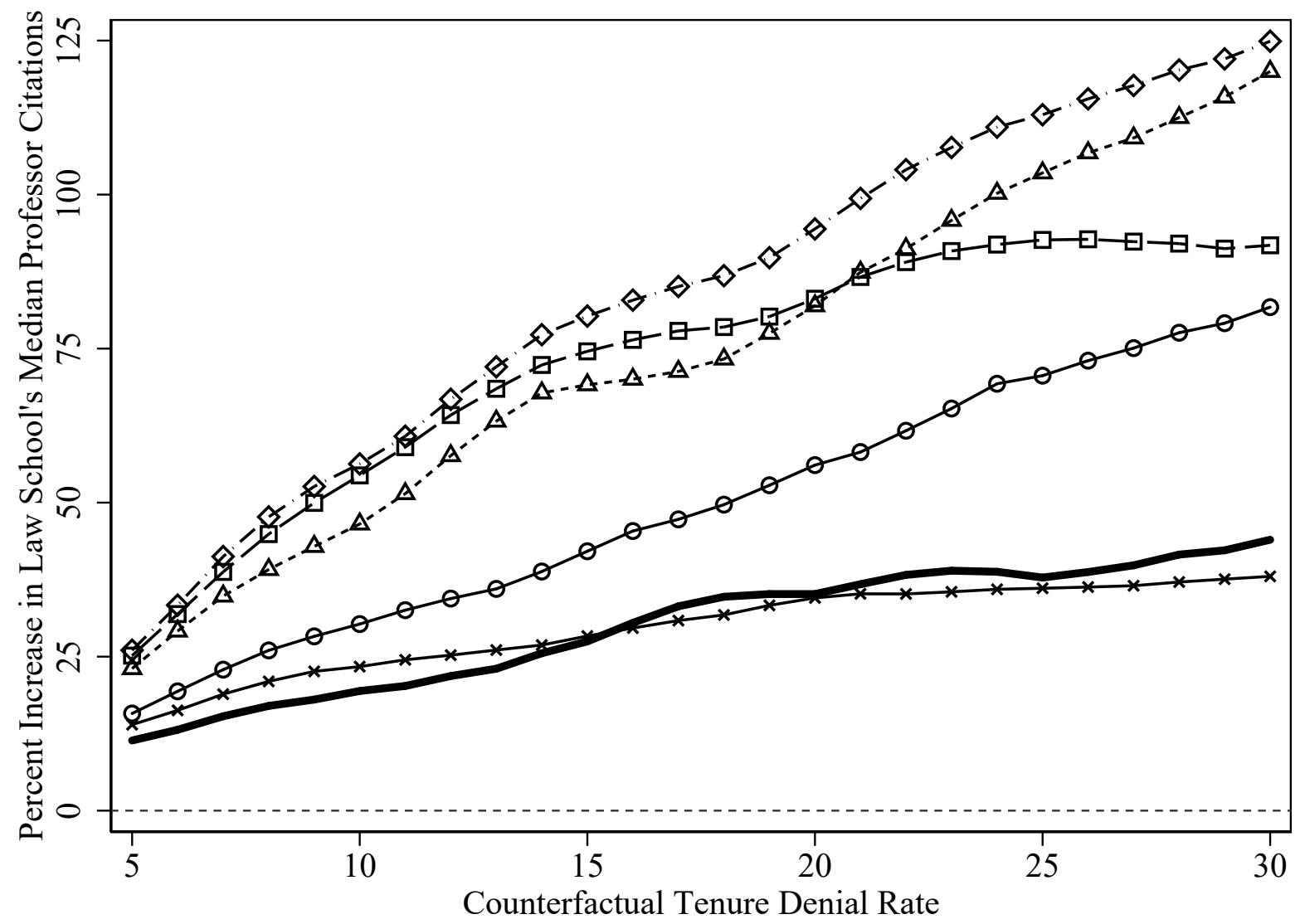

Resampling Procedure

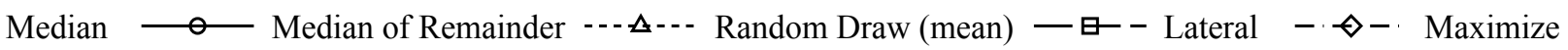


Figure 10: Simulated Costs of Stricter Tenure Standards

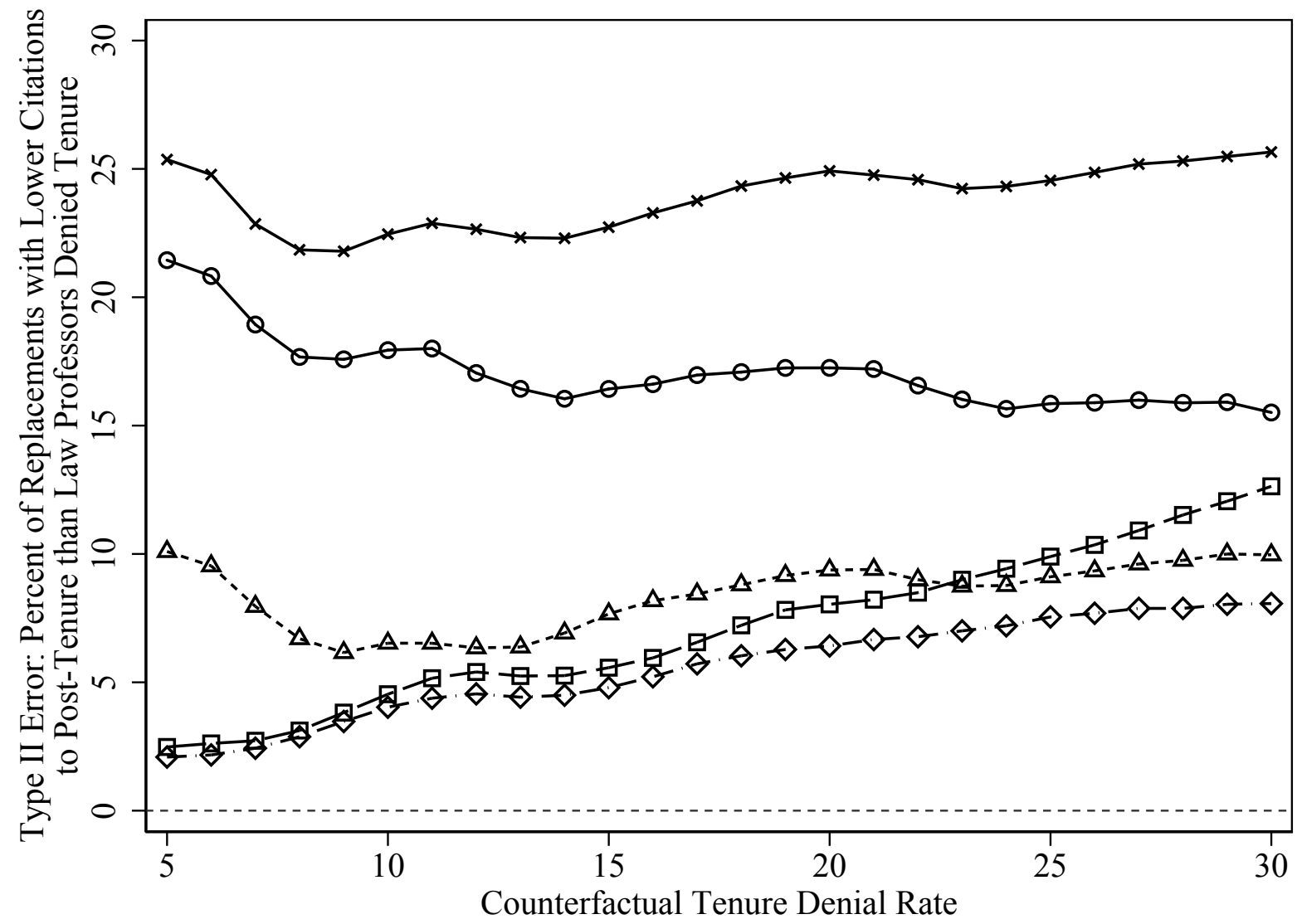

Resampling Procedure

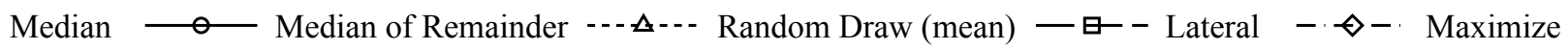


Figure 11: Distribution of Tenure Denial Rates by Law School

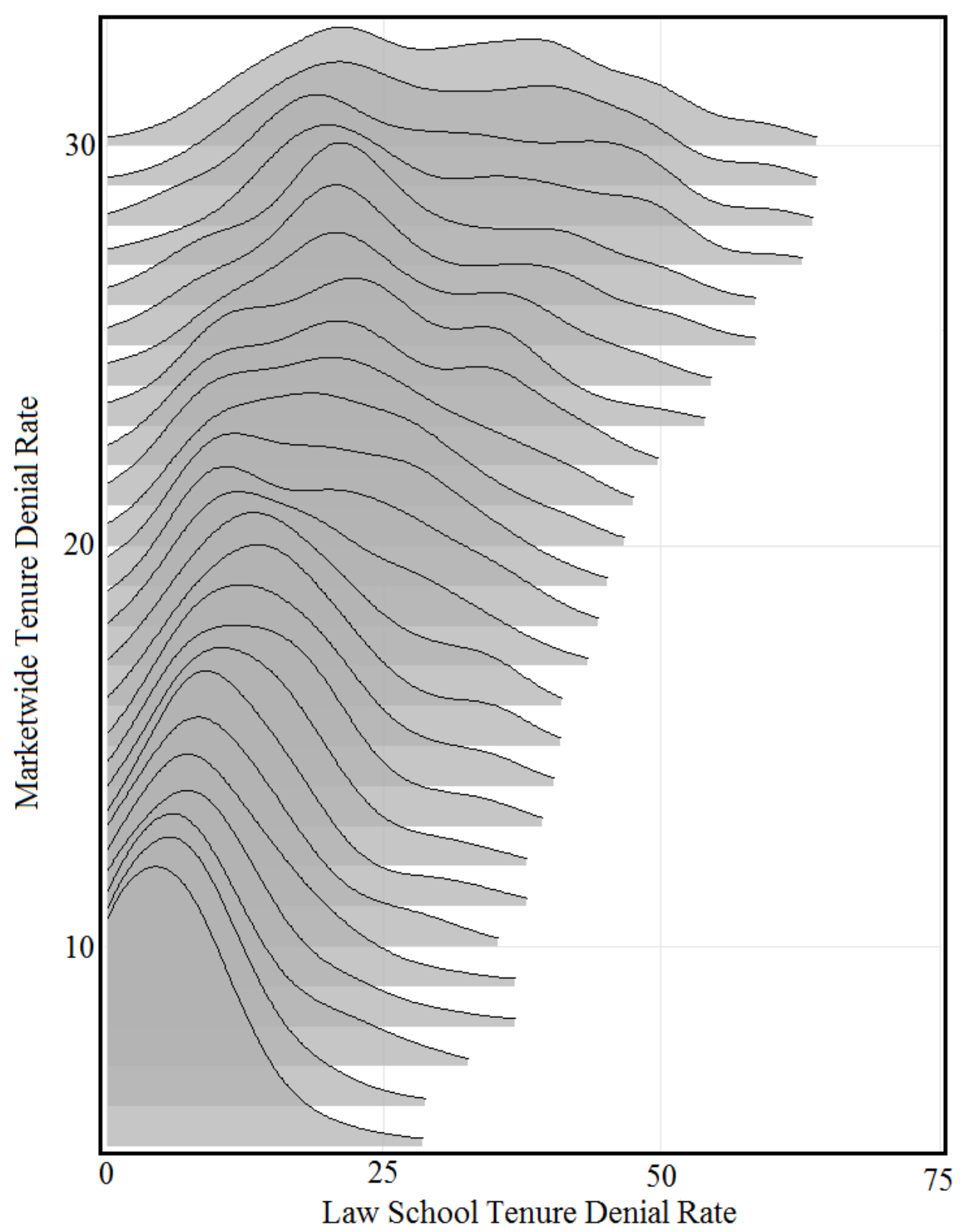


Figure 12: Simulated Benefits and Costs of Stricter Tenure Standard by Law School Rank A. Benefits

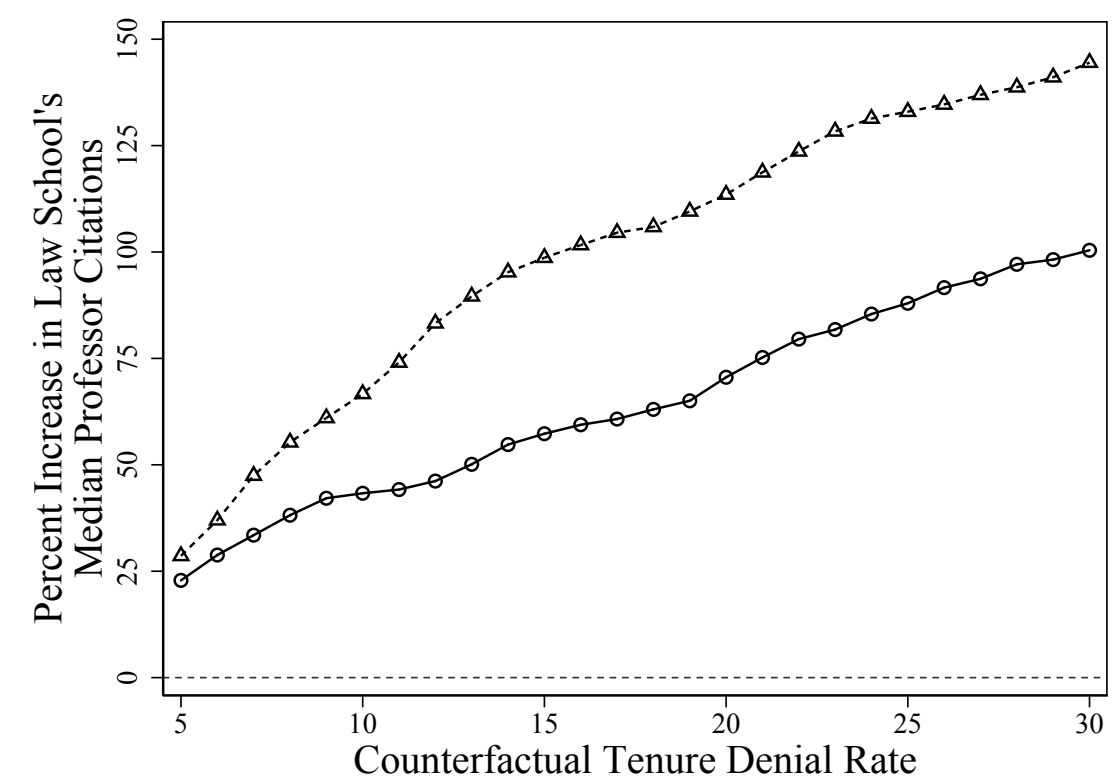

B. Costs

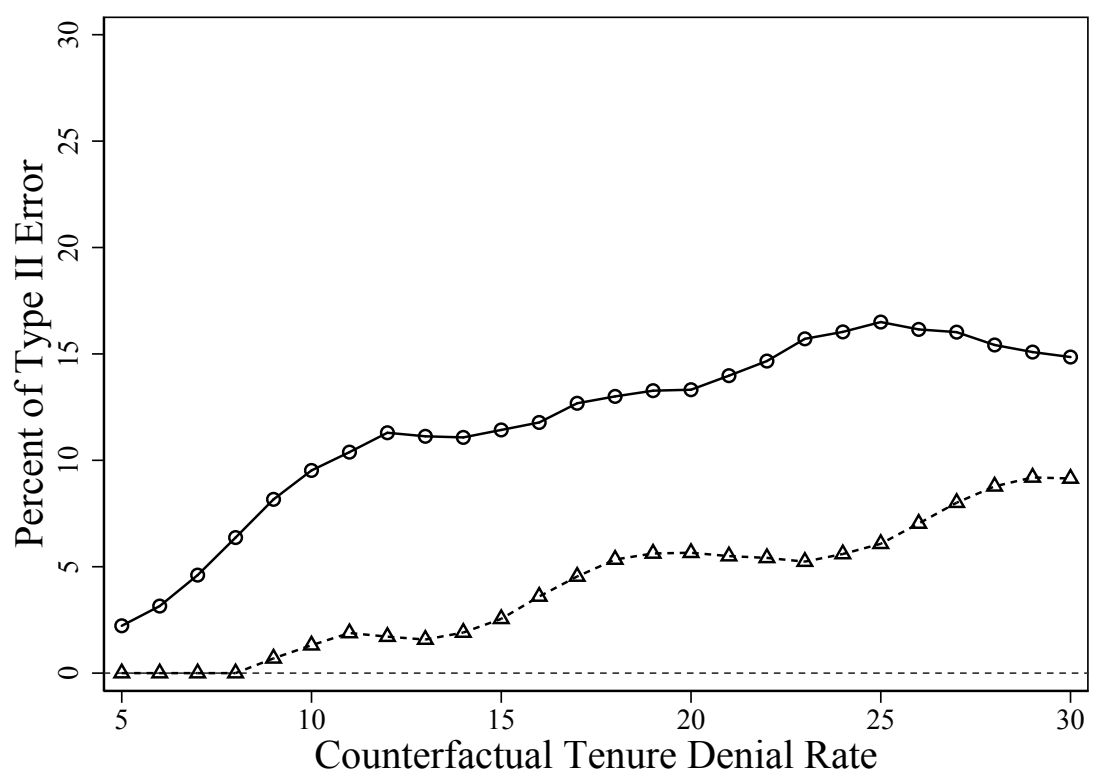

\begin{tabular}{|l} 
Law School Rank \\
\hline$\quad$ 1-20 $\quad$ - - - - - - - 2 21-50 \\
\hline
\end{tabular}


Figure 13: Simulated Tenure Denial Rates by Field

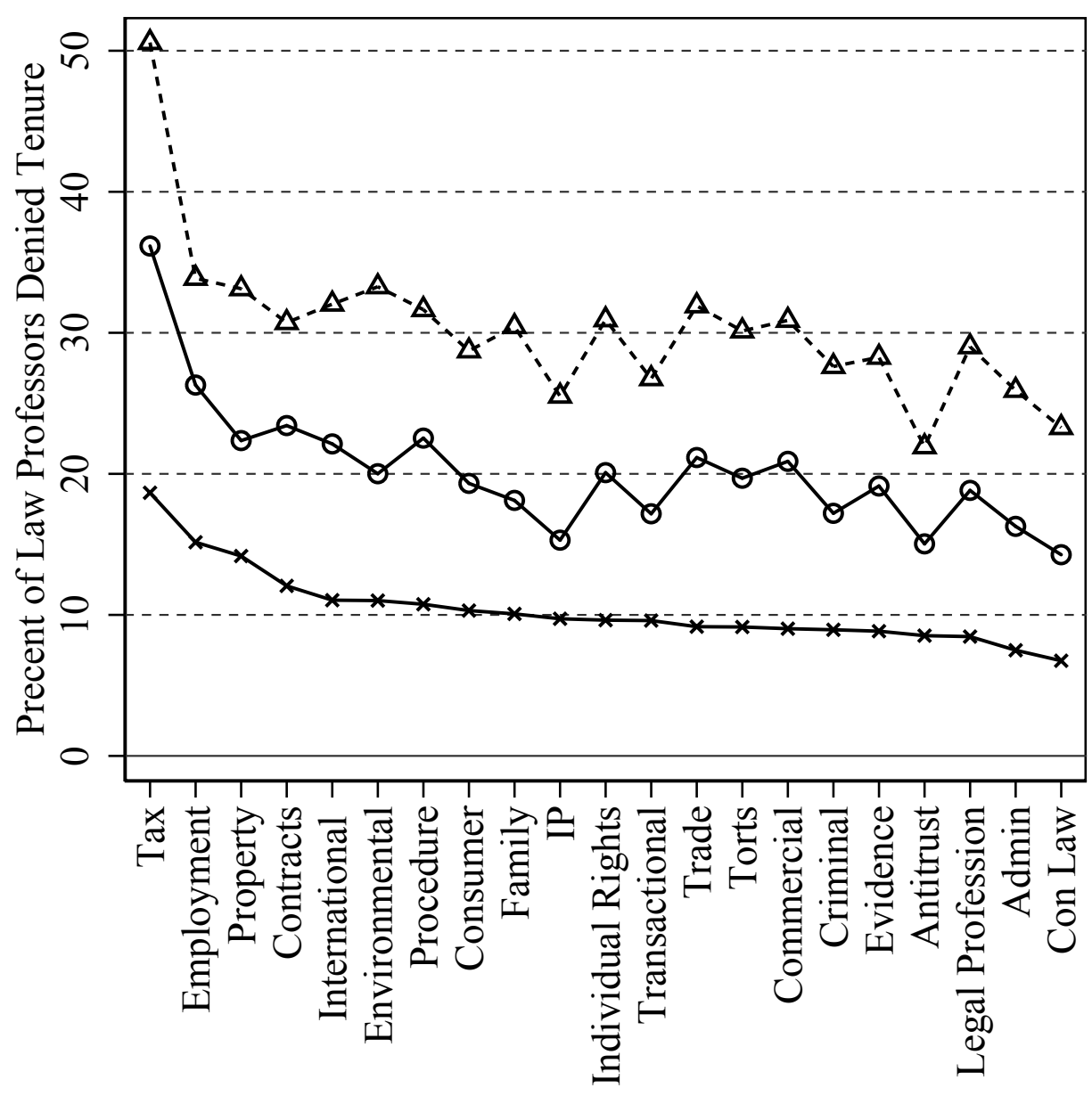

Counterfactual Tenure Denial Rate

$\longrightarrow \quad 10 \longrightarrow 20 \quad$ - 2 - 20 - 30 
Figure 14: Simulated Tenure Denial Rates by Professor Demographics

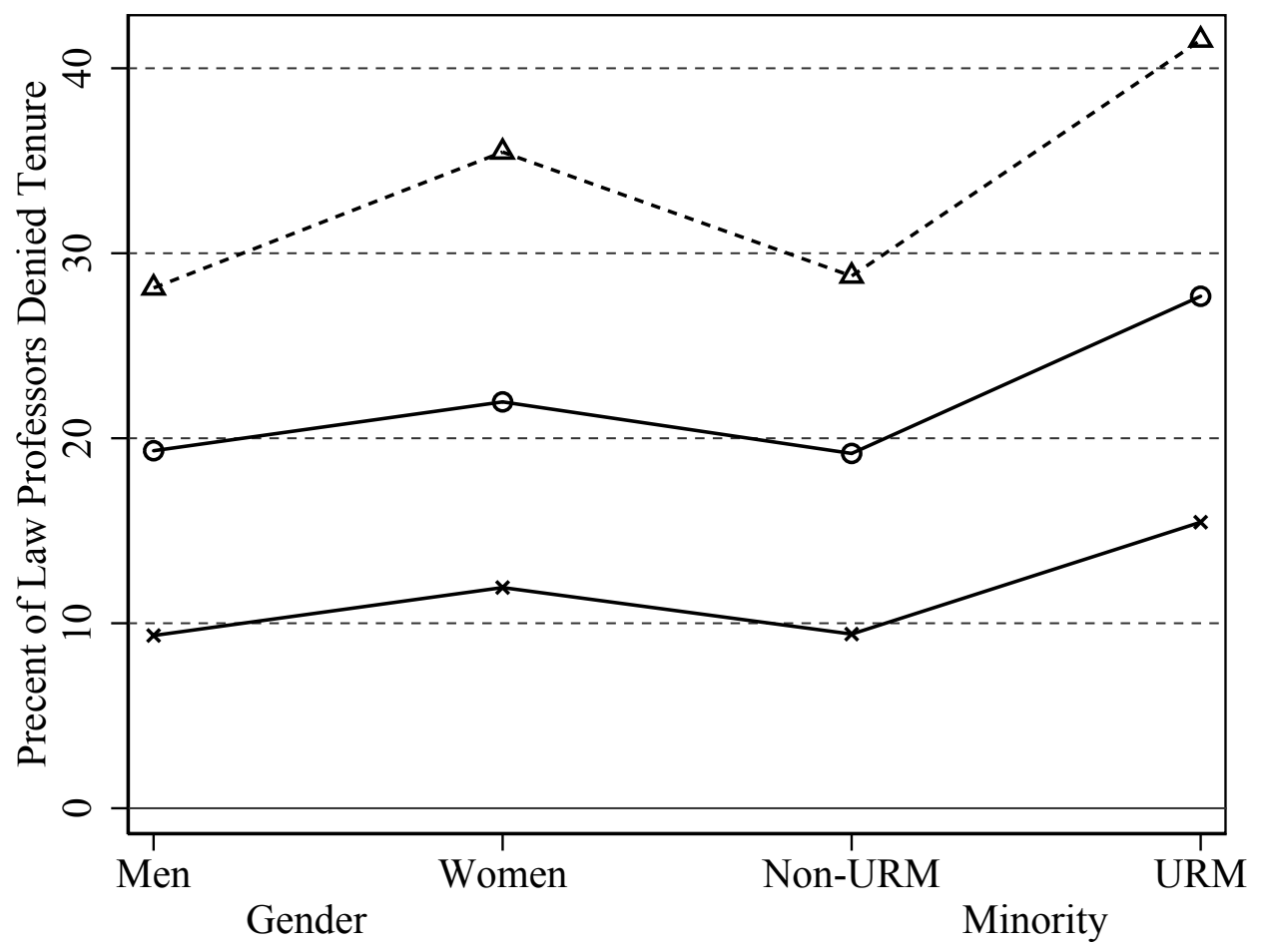

Counterfactual Tenure Denial Rate
$\times \quad 10 \quad 10-\cdots-\cdots$




\section{Appendix}

\section{A1 Inability to Form Predictions using Future Tenure Cases}

Our simulations assume that law schools would be able to form the same predictions we do. Although this may be realistic because we use data from law professors tenured from 1970 to 2007, a law school making a decision in any one of those years would only have information on people tenured in earlier years. To check whether this influences the estimated costs and benefits of increasing tenure standards, we estimate the regression on a sample of law professors getting tenure from 1970 to 1996 and using the estimated coefficients to form predictions for professors getting tenure after 1996. We use 1996 as the cutoff to have ten years of professors getting tenure. Figure A1 shows that breaking the sample does not meaningfully change the simulated benefits (Panel A) and costs (Panel B) of stricter tenure standards. Note that the results are not directly comparable because the sample for which to assess the percent increase in the median law professor citation is different. In other words, even if law schools did not have the full data, this suggests that past data should have still allowed committees to make reasonable predictions based on pre-tenure research records. 
Figure A1: Predictions from Pre-1997 and Tenure in Post-1997 A. Benefits of Stricter Tenure Standards

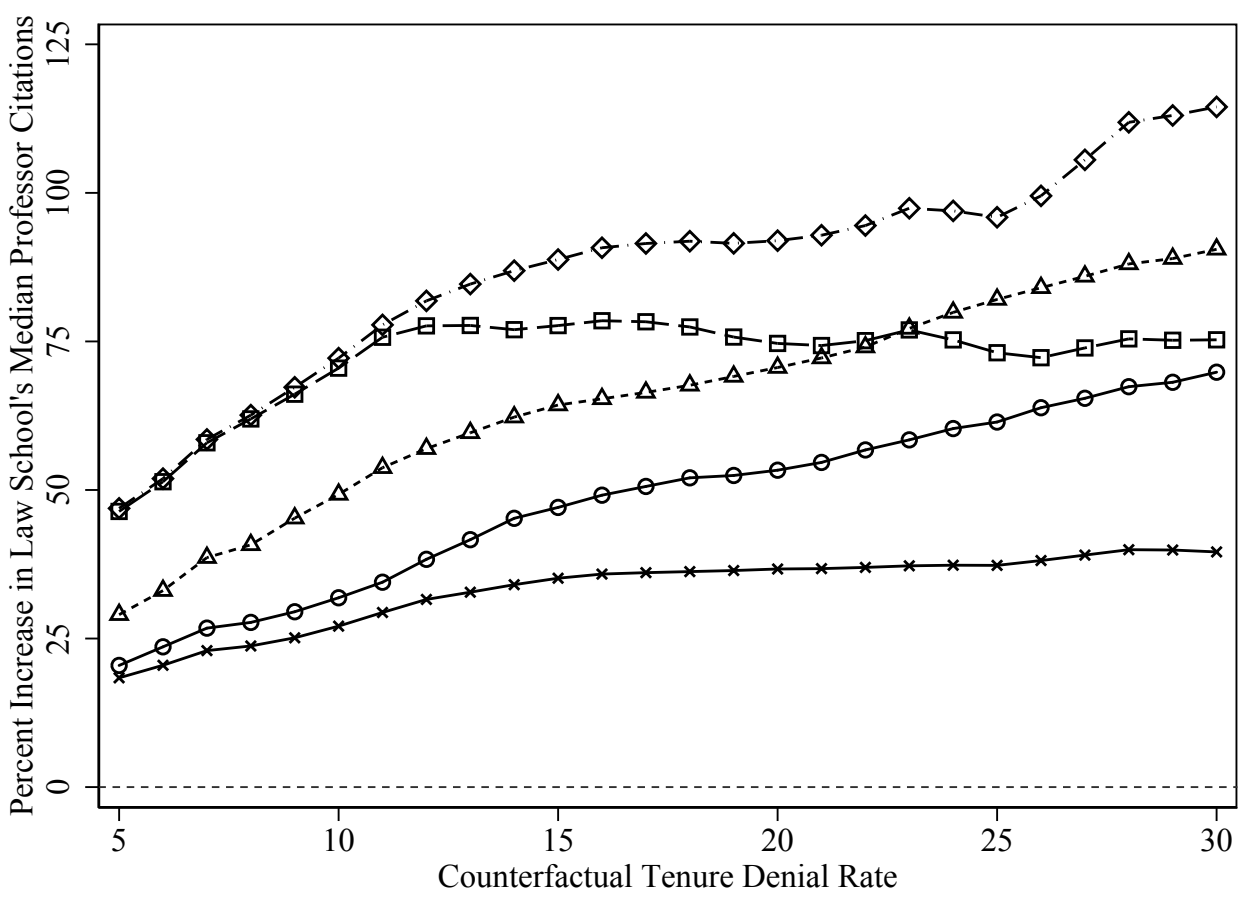

B. Costs of Stricter Tenure Standards

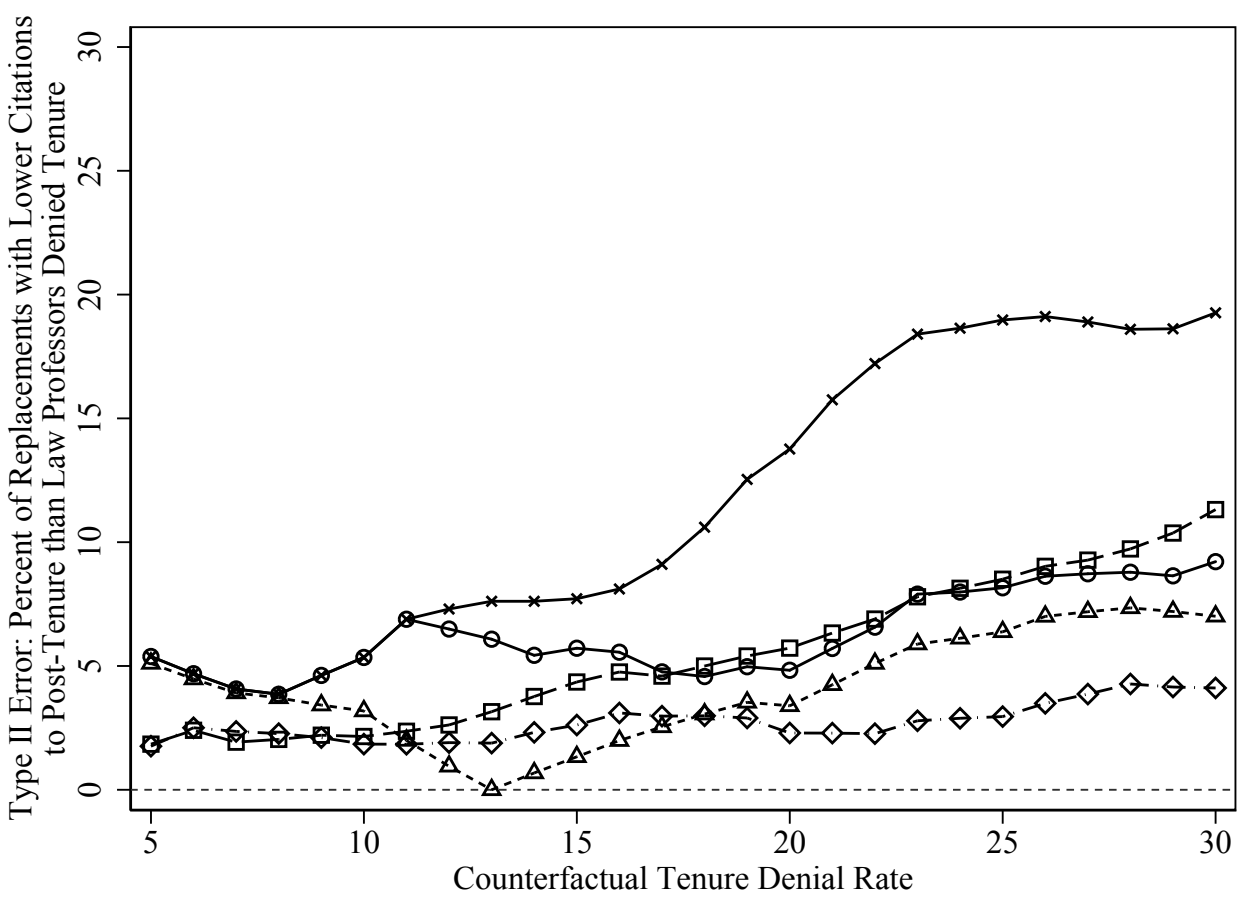

Resampling Procedure

Median $\_-$Median of Remainder -- $\_--$Random Draw (mean) — -- Lateral $\_\diamond-$ Maximize 


\section{A2 Additional Descriptive Statistics}

Figure A2 reports the author-level distributions of citations, articles, and articles published in top 20 law reviews for before tenure and after tenure. The left hand panel reports distributions that first detrend each of the measures to account for changes in publication records over time. To compare pre- and post-tenure distributions, the right hand panel reports distributions that divide by the standard deviations and report the normalized distributions. 
Figure A2: Distribution of Citations, Articles, \& Article Placement
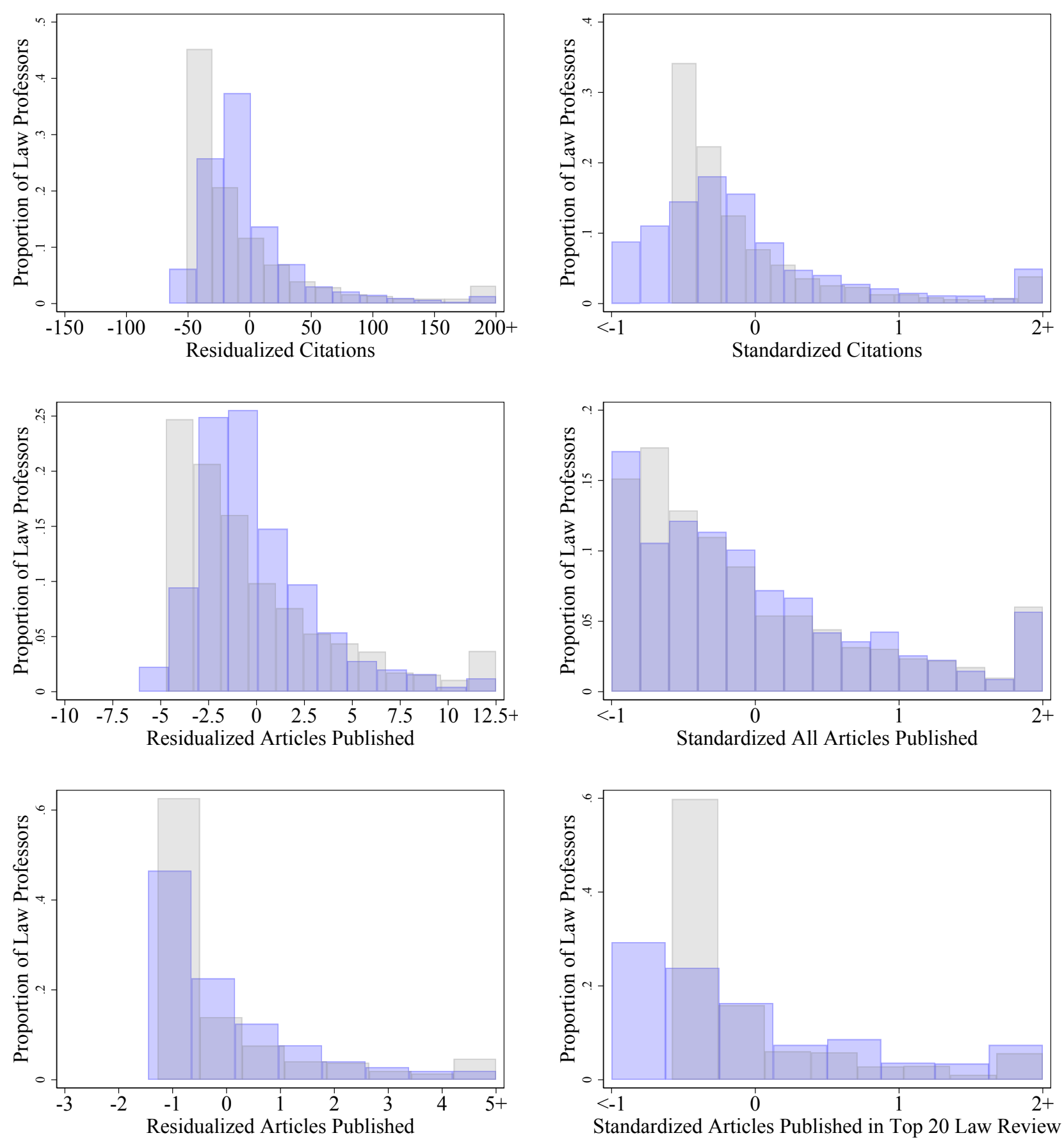

Pre-Tenure $\square$ Post-Tenure 


\section{A3 Alternative Measures of Academic Impact}

Section 2.4 explained how the scholarly impact that academic departments might be attempting to maximize in tenure decisions could be measured in three ways: (1) posttenure citations to post-tenure articles; (2) post-tenure citations to all research (both past and future); and (3) lifetime citations. As we discussed, each of the citation measures for tenure decisions comes with advantages and disadvantages, and the extent that each of these measures should be used depends on context. If pre-tenure citations make up a large share of lifetime citations, then one might expect the results to be sensitive to the measure of academic impact.

We assess potential differences between the measures in two ways. First, Figure A3 reports the distribution of post-tenure citations as a proportion of lifetime citations. Note that the sample includes law professors who are still relatively early in their career, with just 10 years post-tenure to accumulate citations. Even so, the figure shows that most law professors get most of their citations post-tenure, with 36 percent of law professors receiving over 95 percent of their citations after tenure, 55 percent receiving over 90 percent of their citations after tenure, 83 percent receiving over 75 percent of their citations after tenure, and 96 percent receiving over 50 percent of their citations after tenure. Second, Figure A4 reports scatterplots of the three measures. The correlation between the measures is high. The correlation between lifetime citations and post-tenure citations is 0.98 , the correlation between lifetime citations and post-tenure citations to post-tenure articles is 0.95 , and the correlation between lifetime citations and post-tenure citations is 0.98 .

We recreate our primary regression of law professors' academic impact on their pre-tenure research record using the two alternative measures of academic impact. Table A1 reports the results. Panel A uses post-tenure citations to all work as the outcome and Panel B uses lifetime citations as the outcome. There are three things worth noting about these 
results. First, both pre-tenure measures of a law professors research record continue to have coefficients that are substantively large and statistically significant. Second, the coefficient on citations is larger for the prediction based on all post-tenure citations compared to the prediction based on post-tenure citations to post-tenure articles, and it is larger still for the prediction based on lifetime citations. This is perhaps unsurprising because both these measures incorporate some research output that occurred pre-tenure (that is, either on the articles written in the case of Panel A or in the articles written and the citations already received in the case of Panel B), so pre-tenure measures of research output should be more predictive. Finally, the specifications here explain meaningfully more of the variation than post-tenure citations to post-tenure articles: the R-squared in Column 4 of Table 2 is 0.257, in Panel A of Table A1 is 0.421, and in Panel B of Table A1 is 0.477.

Finally, we recreate the counterfactual simulations with these two alternative outcomes. Figure A5 reports the results. Panel A reports the simulations using the prediction based on post-tenure citations to both pre- and post-tenure articles. Panel B reports the simulations using the prediction based on lifetime citations. Because there is a mechanical relationship between pre-tenure citations and lifetime citations, one would expect the type II error to be the smallest using this prediction. And because post-tenure citations to pre-tenure articles can be partly explained by the number and placement of pre-tenure articles, one also expects the prediction using post-tenure citations to improve upon the prediction using the post-tenure citations to post-tenure articles. Figure A5 provides evidence consistent with these predictions. 
Figure A3: Post-Tenure Citations as a Proportion of Lifetime Citations

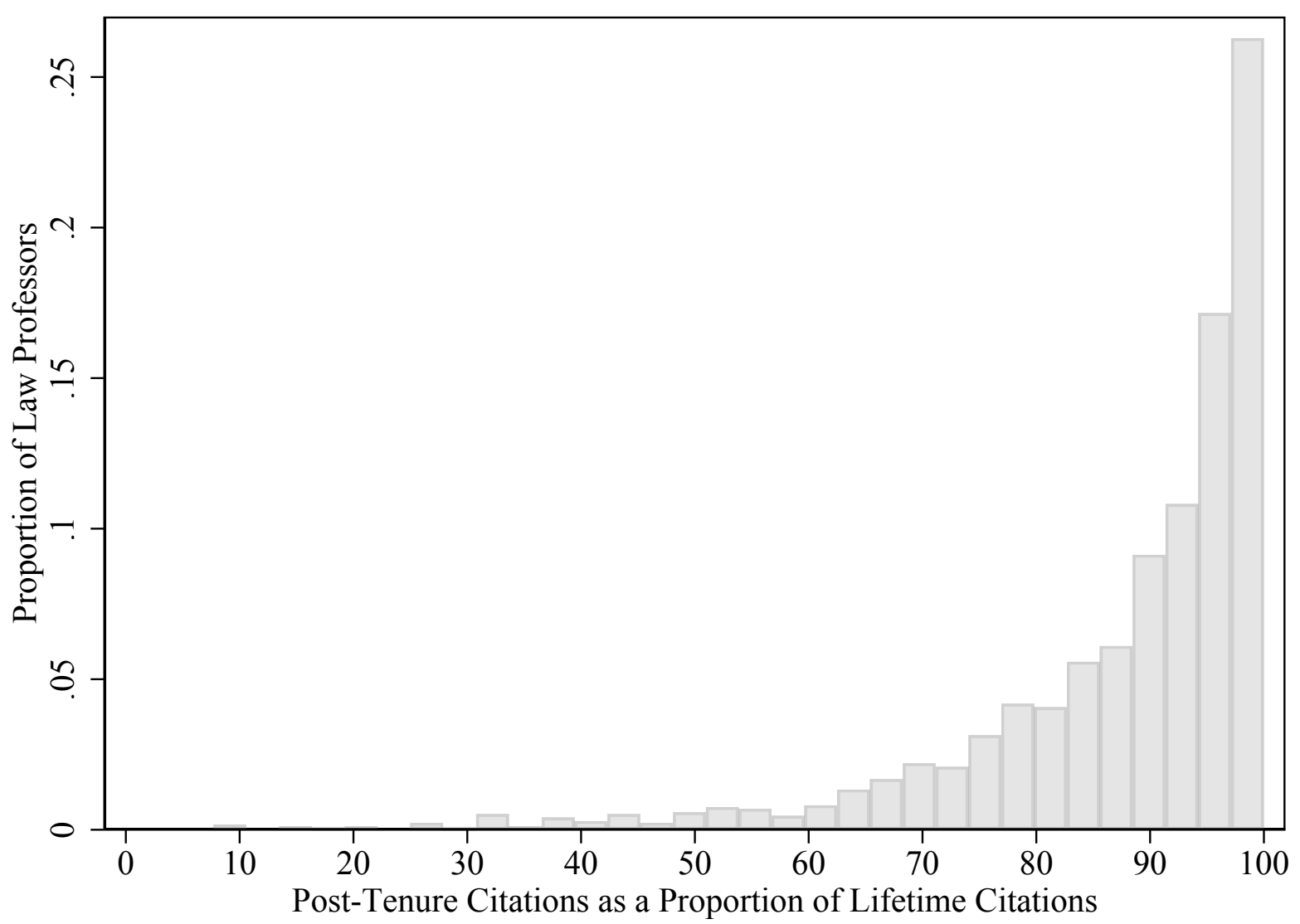


Figure A4: Scatters of Different Outcomes

A. Lifetime Citations and Post-Tenure Citations

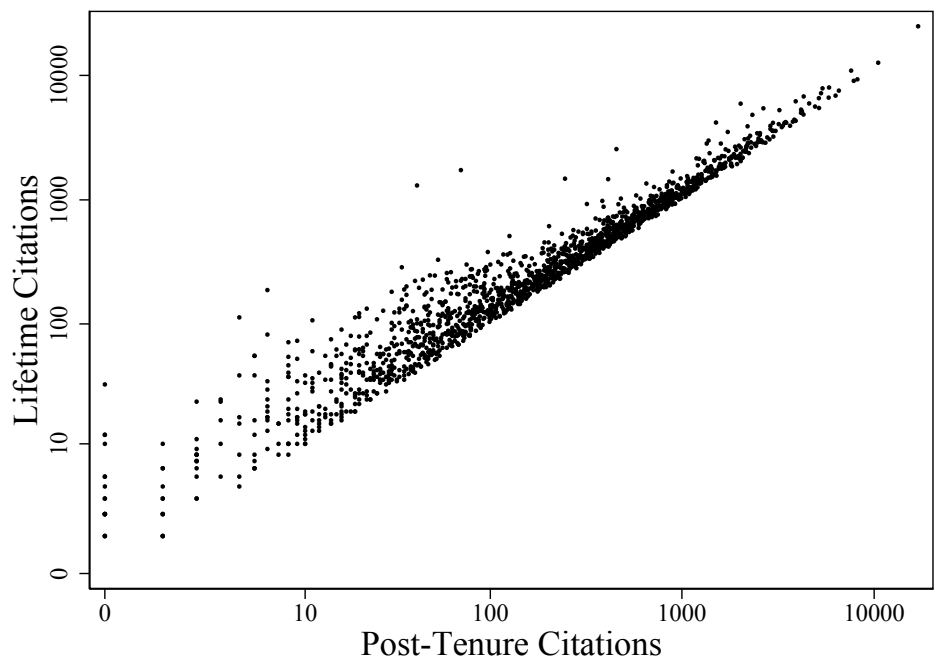

B. Lifetime Citations and Citations to Post-Tenure Articles

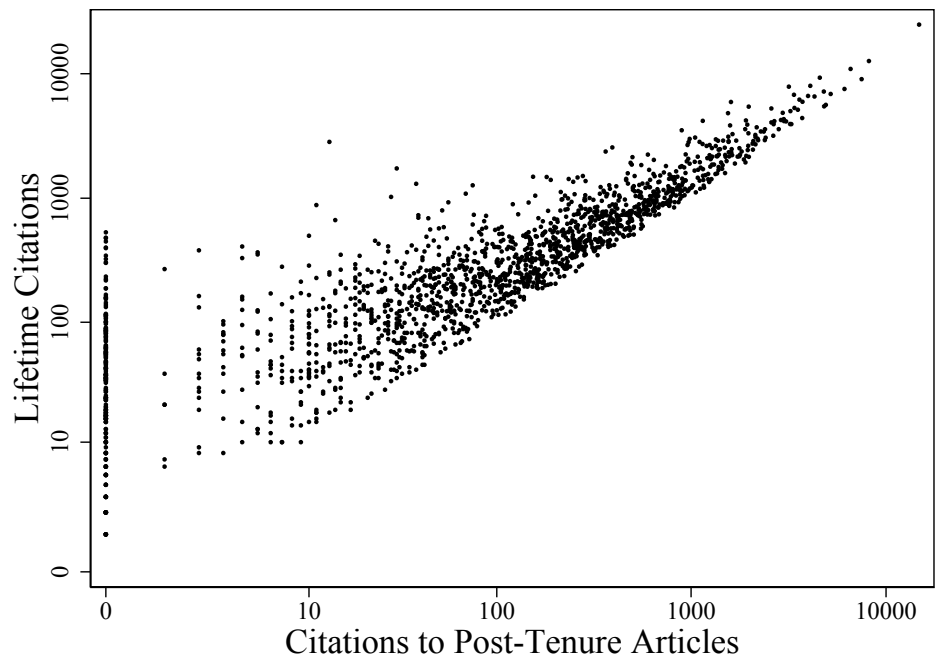

C. Post-Tenure Citations and Citations to Post-Tenure Articles

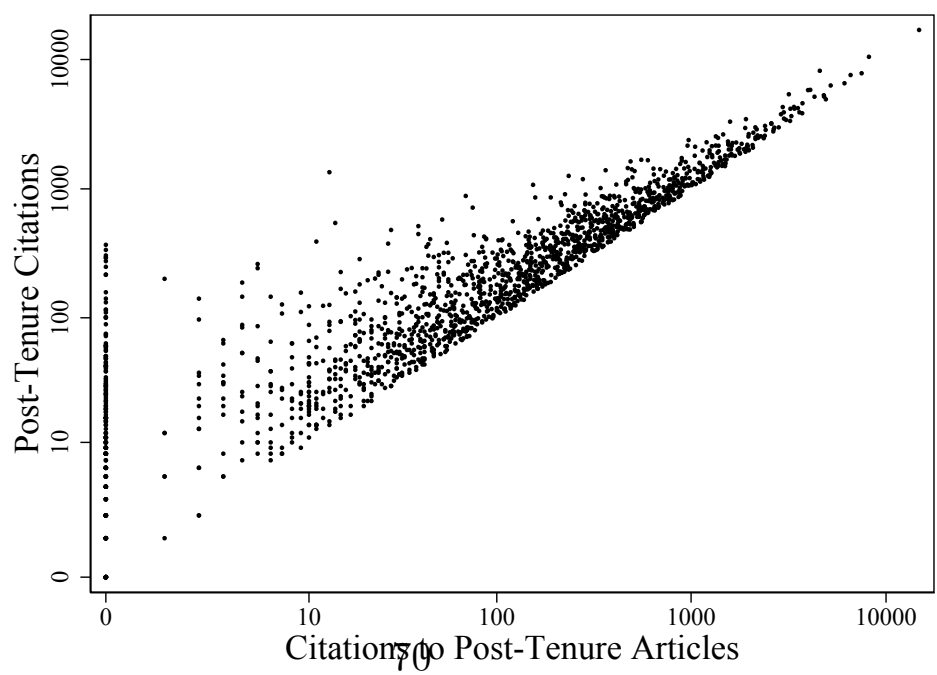


Table A1: Alternative Outcomes of Academic Impact for Tenure Decisions

\begin{tabular}{|c|c|c|c|c|}
\hline & (1) & $(2)$ & (3) & (4) \\
\hline \multicolumn{5}{|c|}{ A. Outcome: $\ln ($ All Post-Tenure Citations) } \\
\hline $\ln ($ Citations $)$ & $\begin{array}{l}0.76^{* * *} \\
(0.03)\end{array}$ & & & $\begin{array}{c}0.36^{* * *} \\
(0.04)\end{array}$ \\
\hline $\ln$ (Articles) & & $\begin{array}{l}1.48^{* * *} \\
(0.07)\end{array}$ & & $\begin{array}{l}0.47^{* * *} \\
(0.08)\end{array}$ \\
\hline $\ln$ (Articles in Top Law Reviews) & & & $\begin{array}{l}1.55^{* * *} \\
(0.06)\end{array}$ & $\begin{array}{l}0.94^{* * *} \\
(0.07)\end{array}$ \\
\hline Tenure-Cohort FE & Yes & Yes & Yes & Yes \\
\hline $\begin{array}{l}\text { Obs } \\
\text { R-squared }\end{array}$ & $\begin{array}{l}1,720 \\
0.337\end{array}$ & $\begin{array}{l}1,720 \\
0.250\end{array}$ & $\begin{array}{l}1,720 \\
0.322\end{array}$ & $\begin{array}{l}1,720 \\
0.421\end{array}$ \\
\hline \multicolumn{5}{|l|}{ B. Outcome: $\ln$ (Lifetime Citations) } \\
\hline $\ln$ (Citations) & $\begin{array}{l}0.75^{* * *} \\
(0.02)\end{array}$ & & & $\begin{array}{c}0.42^{* * *} \\
(0.03)\end{array}$ \\
\hline $\ln$ (Articles) & & $\begin{array}{l}1.40^{* * *} \\
(0.06)\end{array}$ & & $\begin{array}{l}0.35^{* * *} \\
(0.07)\end{array}$ \\
\hline $\ln$ (Articles in Top Law Reviews) & & & $\begin{array}{l}1.43^{* * *} \\
(0.05)\end{array}$ & $\begin{array}{l}0.80^{* * *} \\
(0.06)\end{array}$ \\
\hline Tenure-Cohort FE & Yes & Yes & Yes & Yes \\
\hline Obs & 1,720 & 1,720 & 1,720 & 1,720 \\
\hline $\mathrm{R}$-squared & 0.403 & 0.278 & 0.347 & 0.477 \\
\hline
\end{tabular}


Figure A5: Simulated Benefits of Stricter Tenure Standards Using Different Measures of Predictions

A. Measure for Prediction: Post-Tenure Citations
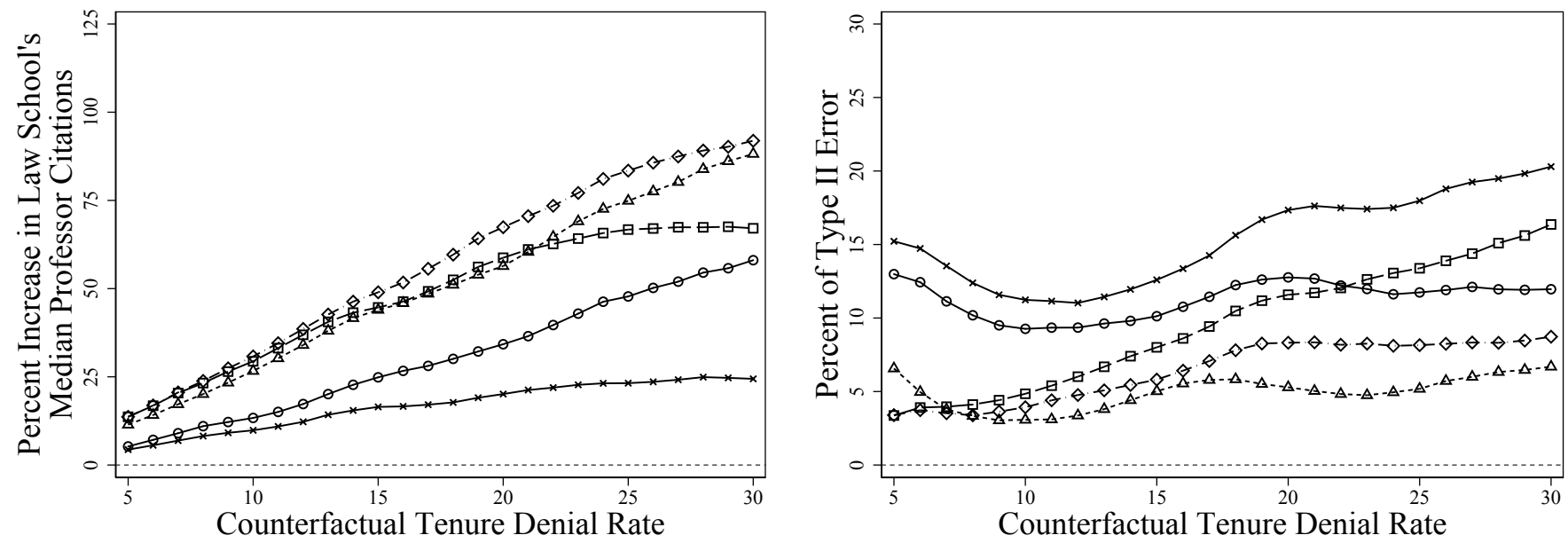

B. Measure for Prediction: Lifetime Citations
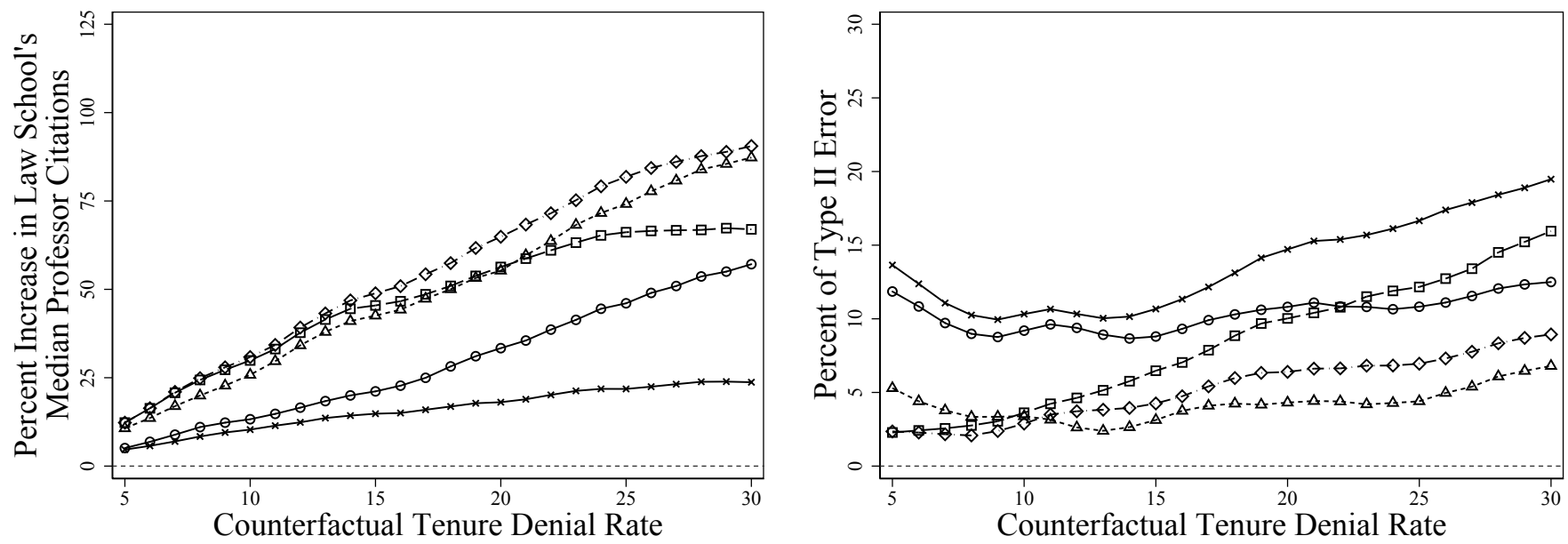

Resampling Procedure

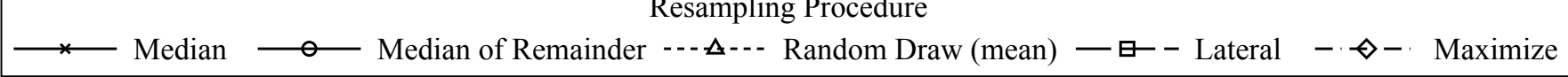




\section{A4 Alternative Definitions of Top Law Reviews}

Our definition of a "good" placement is whether an article is placed in the top 20 ranking law reviews. Here we investigate the sensitivity of the results to the particular definition of top law reviews by assessing how different thresholds of defining good law reviews change the relationship. In particular, we use a cutoff of 10, 20, 50, and 100 top law reviews. Table A2 provides the results. The size of the point estimate on articles changes for different definitions of a good journal, but size of the point estimate for citations remains fairly constant.

We also assess the effects within the top 100 together by estimating a model that includes all of the different counts together. Table A3 reports the results. The point estimate on citations decreases but the point estimate on articles is not overly sensitive to the other counts. In Column 4 where we estimate the joint model, the estimate on each of the number of articles is positive and somewhat precisely estimated. Combined, the results provide evidence that there is signal value contained in a scholar's productivity before tenure and their placements, including placements within the top 20 and 10 law reviews. 
Table A2: Predicting Citations to Post-Tenure Articles with Different Definitions of Top Law Reviews

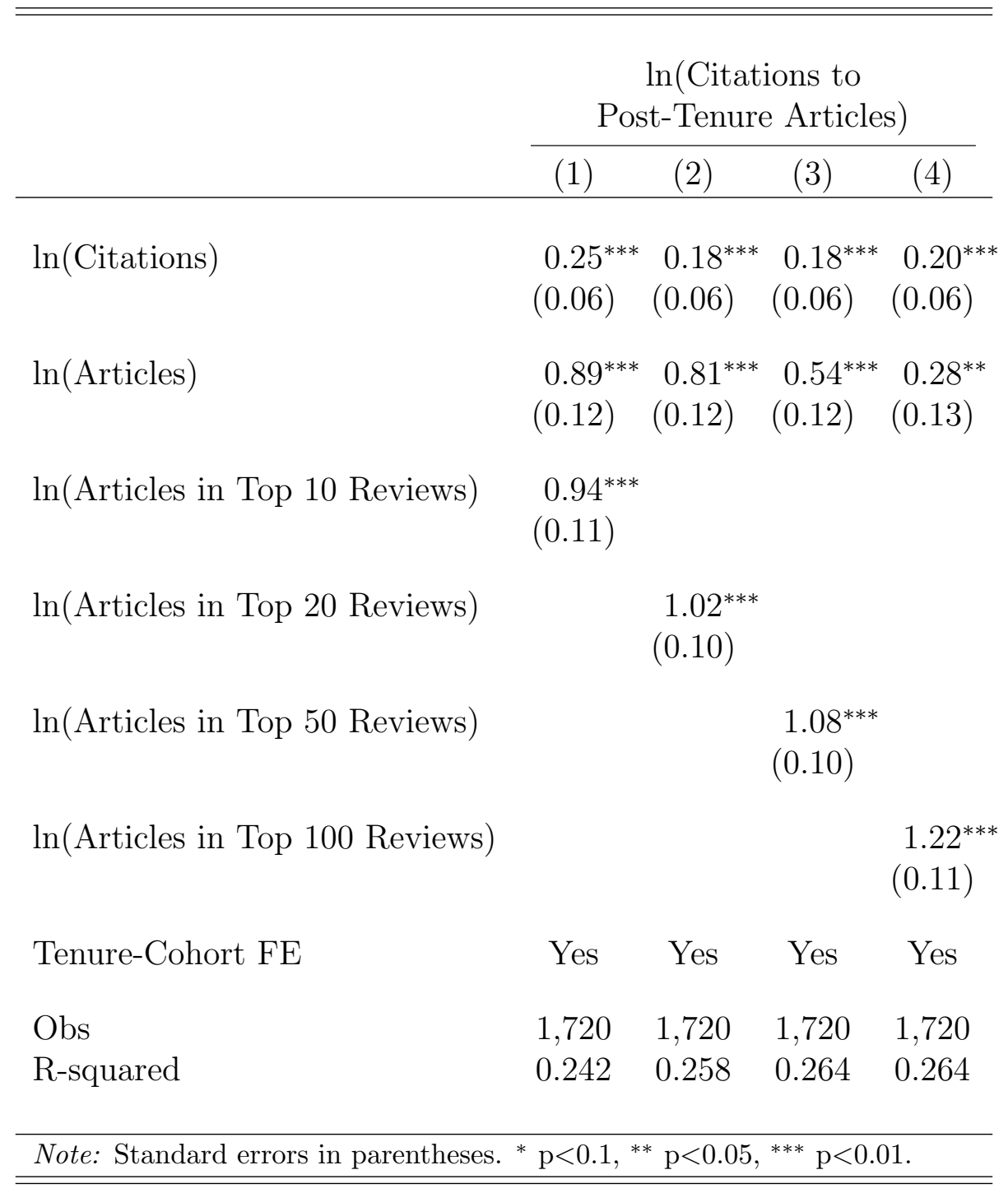


Table A3: Predicting Citations to Post-Tenure Articles with Productivity Measured by Top 100 Law Review Articles

\begin{tabular}{|c|c|c|c|c|}
\hline & \multicolumn{4}{|c|}{$\begin{array}{c}\ln (\text { Citations to } \\
\text { Post-Tenure Articles })\end{array}$} \\
\hline & $(1)$ & $(2)$ & $(3)$ & $(4)$ \\
\hline $\ln ($ Citations $)$ & $\begin{array}{l}0.16^{* * *} \\
(0.06)\end{array}$ & $\begin{array}{l}0.12^{* *} \\
(0.06)\end{array}$ & $\begin{array}{c}0.13^{* *} \\
(0.06)\end{array}$ & $\begin{array}{r}0.10^{*} \\
(0.06)\end{array}$ \\
\hline $\ln$ (Articles) & $\begin{array}{l}0.35^{* * *} \\
(0.13)\end{array}$ & $\begin{array}{l}0.43^{* * *} \\
(0.13)\end{array}$ & $\begin{array}{l}0.40^{* * *} \\
(0.13)\end{array}$ & $\begin{array}{l}0.45^{\text {*** }} \\
(0.13)\end{array}$ \\
\hline $\ln$ (Articles in Top 100 Reviews) & $\begin{array}{l}0.70^{* * *} \\
(0.17)\end{array}$ & $\begin{array}{l}0.84^{* * *} \\
(0.13)\end{array}$ & $\begin{array}{l}1.01^{* * *} \\
(0.11)\end{array}$ & $\begin{array}{l}0.71^{* * *} \\
(0.17)\end{array}$ \\
\hline $\ln$ (Articles in Top 50 Reviews) & $\begin{array}{l}0.59^{* * *} \\
(0.15)\end{array}$ & & & $\begin{array}{c}0.23 \\
(0.18)\end{array}$ \\
\hline $\ln$ (Articles in Top 20 Reviews) & & $\begin{array}{l}0.61^{* * *} \\
(0.11)\end{array}$ & & $\begin{array}{r}0.32^{*} \\
(0.17)\end{array}$ \\
\hline $\ln$ (Articles in Top 10 Reviews) & & & $\begin{array}{l}0.57^{* * *} \\
(0.11)\end{array}$ & $\begin{array}{r}0.30^{*} \\
(0.15)\end{array}$ \\
\hline Tenure-Cohort FE & Yes & Yes & Yes & Yes \\
\hline Obs & 1,720 & 1,720 & 1,720 & 1,720 \\
\hline R-squared & 0.271 & 0.277 & 0.275 & 0.279 \\
\hline
\end{tabular}




\section{A5 Functional Form}

In the main regression table above, Table 2 assumes a functional form for the relationship between the three measure of law professors' research records and future impact. In particular, we use a natural log to be able to interpret each of the coefficients as a percent change. Table A4 in the Appendix assesses the sensitivity of these results with respect to the functional form assumptions. Panel A reports the results where citations to post-tenure articles is in logs but the predictors are in levels, and Panel B reports the results where both citations to post-tenure articles and the predictors are in levels. Overall, the relationships between law professors' pre-tenure research record and future impact are present under different functional forms. 
Table A4: Predicting Citations to Post-Tenure Articles with Different Functional Forms

$\begin{array}{llll}(1) & (2) & (3) & (4)\end{array}$

A. Outcome: $\ln$ (Citations to Post-Tenure Articles)

$\begin{array}{lcl}\text { Citations } 0.01^{* * *} & 0.00\end{array}$

$(0.00)$

$(0.00)$

Articles

$0.22^{* * *}$

$0.12^{* * *}$

$(0.02)$

(0.02)

Articles in Top Law Reviews

$0.58^{* * *} \quad 0.45^{* * *}$

(0.03) (0.04)

R-squared

$0.117 \quad 0.139$

0.185

0.215

B. Outcome: Citations to Post-Tenure Articles

\begin{tabular}{ccc}
\hline Citations & $3.9^{* * *}$ & $0.9^{* *}$ \\
& $(0.4)$ & $(0.5)$
\end{tabular}

Articles

$47.7^{* * *}$

5.1

$(5.5)$

Articles in Top Law Reviews

$196.3^{* * *} 173.3^{* * *}$

(11.5) (14.0)

R-squared

$\begin{array}{lll}0.112 & 0.087 & 0.186\end{array}$

0.190

\begin{tabular}{|c|c|c|c|c|}
\hline Tenure-Cohort FE & Yes & Yes & Yes & Yes \\
\hline Obs & 1,720 & 1,720 & 1,720 & 1,720 \\
\hline \multicolumn{5}{|c|}{$\begin{array}{l}\text { Note: Standard errors in parentheses. }{ }^{*} \mathrm{p}<0.1,{ }^{* *} \mathrm{p}<0.05,{ }^{* * *} \mathrm{p}<0.01 \text {. The } \\
\text { dependent variable mean in Panels A and B is } 337.5 \text { citations to post-tenure } \\
\text { articles. }\end{array}$} \\
\hline
\end{tabular}




\section{A6 Alternative Non-Citation Based Outcomes}

Although citations are probably a better measure of academic impact than other outcomes, like the number of articles published or the placement of those articles, they are admittedly an imperfect measure. Table A5 assesses the extent to which aspects of law professors' research records predict these other outcomes. The outcome in Panel A is the (natural $\log$ ) of the number of post-tenure articles. We find that the number of pre-tenure articles predicts the number of post-tenure articles, which could be interpreted as evidence that productivity is stable after tenure and is consistent with evidence in Yoon (2016). Curiously, we find no evidence that pre-tenure citations predict post-tenure articles. The outcome in Panel B is the (natural log) of the number of post-tenure articles in top 20 law reviews. We find no evidence that the number of pre-tenure articles predicts the number of post-tenure articles in top 20 law reviews, but that pre-tenure articles in top 20 law reviews and citations predict post-tenure articles in top 20 law reviews. Comparing the R-squared

in Table A5 to that in Table 2, law professors' pre-tenure research records explains more of the variation in post-tenure placement than post-tenure articles and citations.

Next, Table A6 presents a table analogous to Table 3. Panel A is for the outcome of post-tenure articles and Panel B is for the outcome of post-tenure articles in top 20 law reviews. Consistent with Table A5, the predicted post-tenure articles and articles in top 20 law reviews is well predicted by law professors' pre-tenure research records. 
Table A5: Non-Citation Based Post-Tenure Outcomes

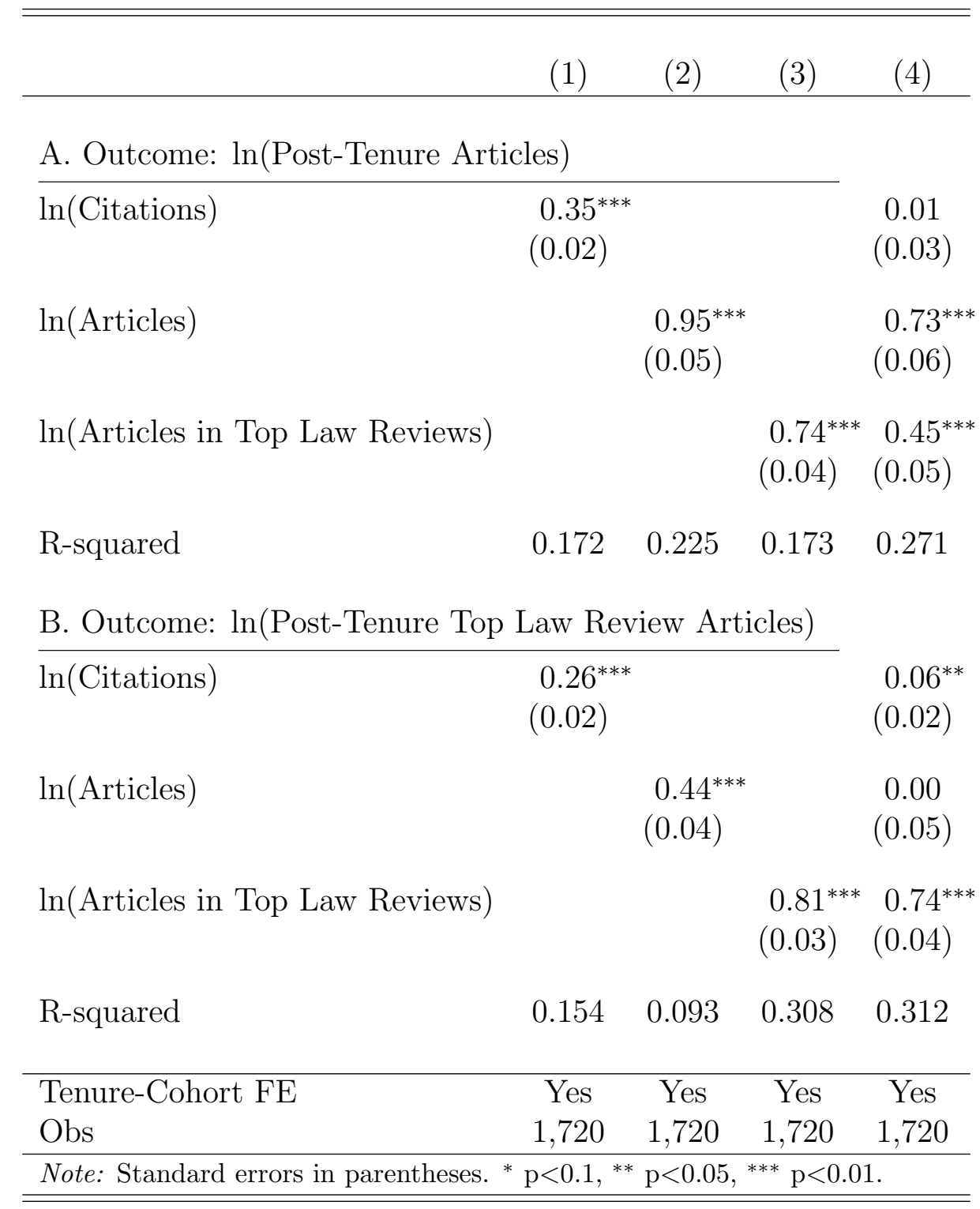


Table A6: Predicting Post-Tenure Articles at Tenure Decisions

\begin{tabular}{|c|c|c|c|c|}
\hline Prediction & Q1 & Q2 & Q3 & Q4 \\
\hline \multicolumn{5}{|c|}{ A: Percent in Post-Tenure Articles Quartile } \\
\hline Q1 & 55 & 23 & 15 & 7 \\
\hline Q2 & 31 & 30 & 25 & 14 \\
\hline Q3 & 19 & 28 & 28 & 25 \\
\hline Q4 & 8 & 15 & 27 & 50 \\
\hline \multicolumn{5}{|c|}{$\begin{array}{l}\text { B. Percent in Post-Tenure Articles } \\
\text { in Top } 20 \text { Law Review Quartile }\end{array}$} \\
\hline Q1 & 76 & 4 & 14 & 7 \\
\hline Q2 & 65 & 3 & 23 & 9 \\
\hline Q3 & 41 & 3 & 30 & 25 \\
\hline Q4 & 25 & 2 & 26 & 48 \\
\hline
\end{tabular}




\section{A7 Results by Decile}

Figure A6 reports results comparable to Column 4 of Table 2, but it we first create decile bins for each of the law professors pre-tenure research records by tenure cohort and estimate the specification in Equation 1 by replacing the continuous variables with indicators for the bins. The point estimates indicate the difference between the professors in the deciles relative to professors in the bottom 10 percent of each of the distributions. Over 30 percent of law professors do not publish an article in a top 20 law review before tenure; these professors are grouped together in the bottom bin and serve as the control group. The relationships are roughly linear across the deciles. 
Figure A6: Graphing Citations to Post-Tenure Articles with Pre-Tenure Measures of Research Records

A. Pre-Tenure Articles

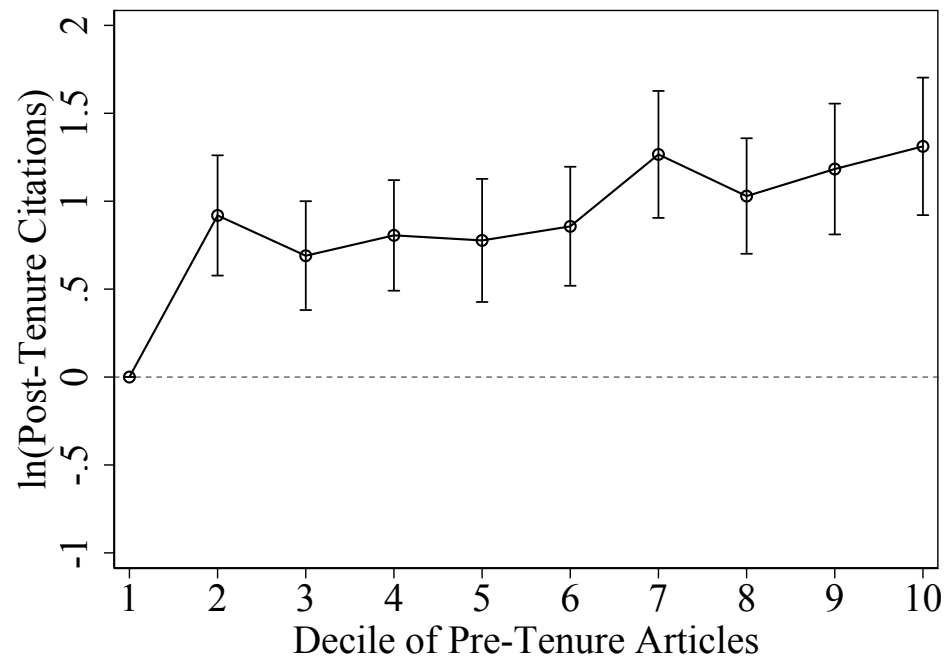

B. Pre-Tenure Articles in Top 20 Law Reviews

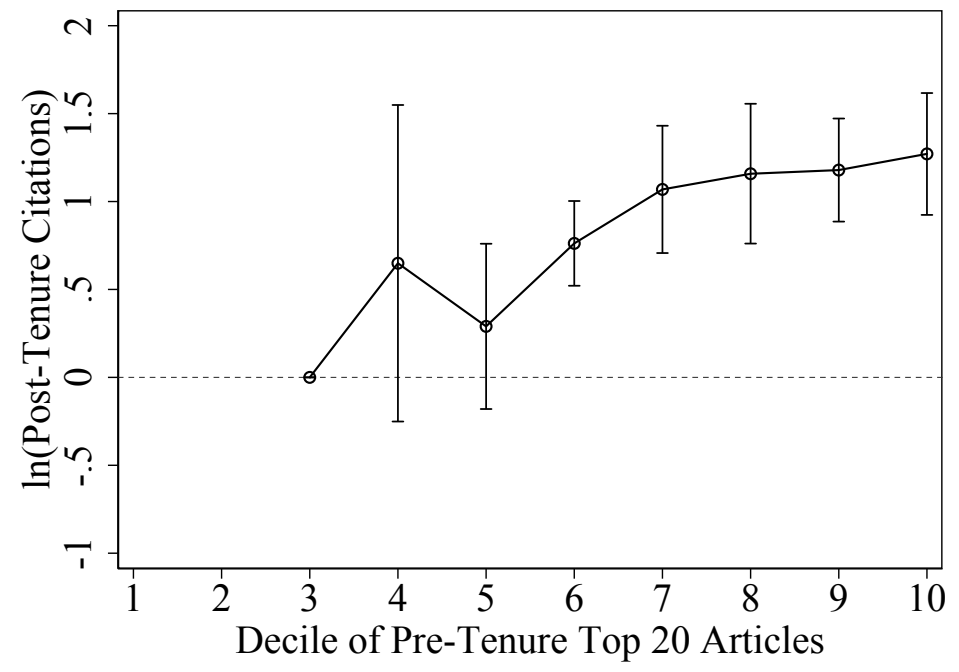

C. Pre-Tenure Citations

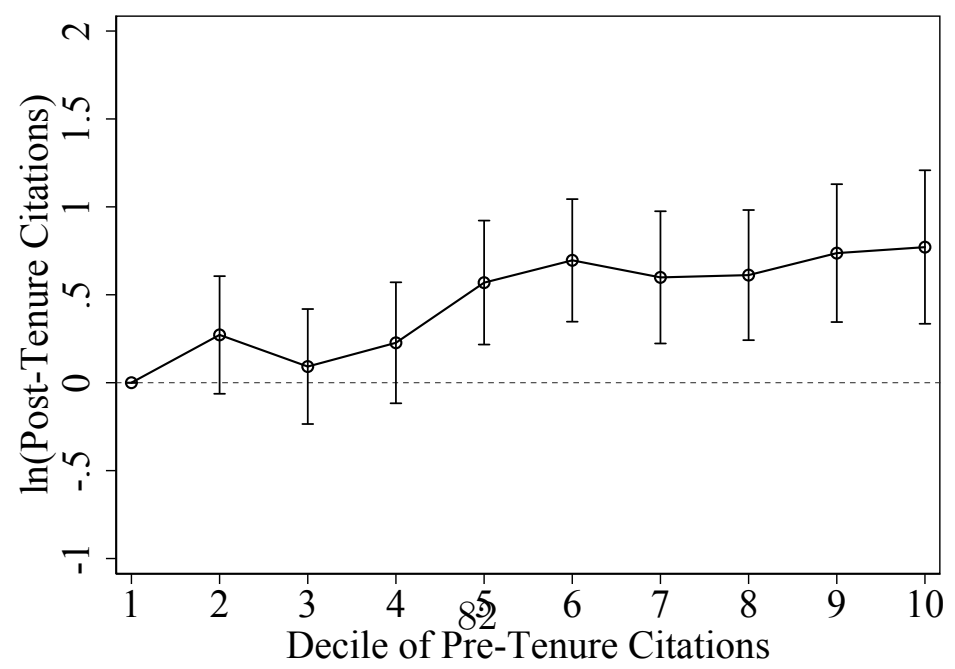




\section{A8 Outside Options by Law School Rank}

Figure 7 shows that law professors' research records are predictive of their outside options after tenure, as measured by whether they lateraled to another law school after tenure. Here, we assess the extent that outside options differ for law professors at different parts of the predicted impact distribution by law school rank. Figure A7 reports the results. There are several interesting findings. First, comparing the mobility of the bottom 30 percent of law professors in terms of their predicted impact at different ranked schools, we find evidence that the bottom are less mobile down the ranking. For example, for the law professors in the bottom 30 percent, 34 percent of law professors at top 20 law schools have since left the law school that granted them tenure, 23 percent of law professors at law schools ranked 21 to 50 have since left the law school that granted them tenure, and 20 percent of law professors at law schools ranked 51 to 100 have since left the law school that granted

them tenure. Second, the outside options of the bottom 30 percent is lower for the top schools compared to everyone else at the law school. For example, whereas those in the top 70 percent are 72 percent more likely to leave than those in the bottom 30 percent at law schools ranked 21 to 50 , those in the top 70 percent are 23 percent more likely to leave than those in the bottom 30 percent at the top 20 law schools. 
Figure A7: Law Professors Moving Law Schools After Tenure by Predicted Citations to Post-Tenure Articles by Law School Rank

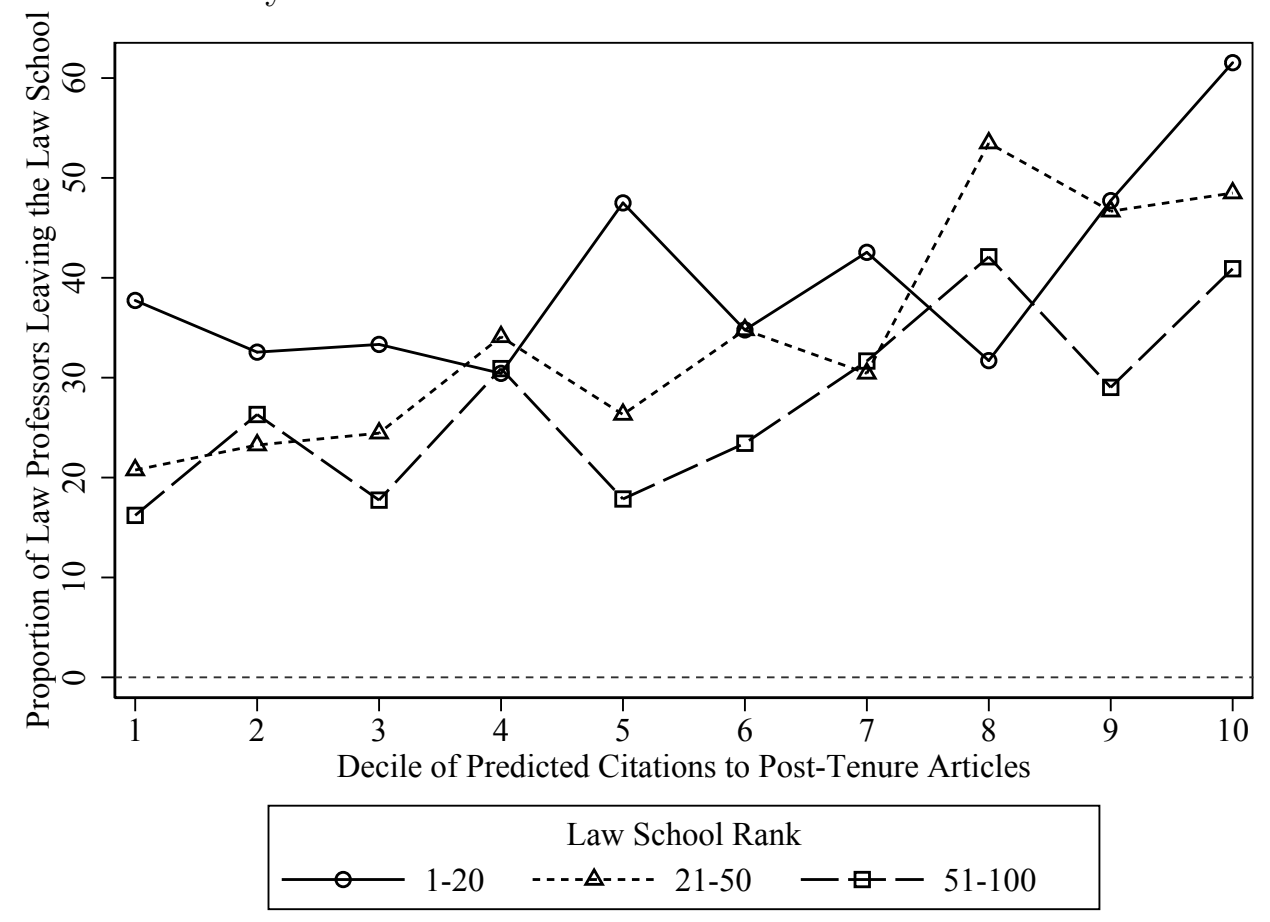




\section{A9 Brightline Tenure Standards}

In the main analysis, we use three measures of a professors pre-tenure research record to form a prediction of their citations to post-tenure articles. One criticism of this approach is that it requires modeling, and tenure committees may have been unable to form the predictions we create or unwilling to rely on them. However, it was possible throughout this period to have a sense of distribution of citations, publications, and journal placement, and schools could have used a brightline rule for tenure decisions using any of these measures in isolation. We assess the ability of applying brightline rules based on only one of the three measures to improve a law schools academic impact. We generate cohorts of law professor by law school and tenure year as above, and then calculate the percentile of the law professor within each of the citations, articles, and articles in top 20 distribution.

Table A7 reports the percent of law professors in the citations to post-tenure articles quartiles for the different pre-tenure measures. Panel A reports the results for pretenure citations, Panel B reports the results for pre-tenure articles, and Panel C reports the results for pre-tenure articles in top 20 law reviews. There are several findings worth highlighting. First, and similar to the prediction based on all three pre-tenure measures in Table 3, each of the measures in isolation are highly predictive of the citations to post-tenure articles. The measures are predictive of both the bottom and top ends of the distributions, the former of which is most relevant for our exercise. Second, and focusing on the bottom end of the distributions, the relative predictive power of pre-tenure citations is greater than that of pre-tenure articles, followed by pre-tenure articles in top 20 law reviews. In particular, 51 percent of law professors in the lowest quartile of pre-tenure citations are also in the lowest quartile post-tenure, and an additional 29 percent are in the second to lowest quartile; 46 percent of law professors in the lowest quartile of pre-tenure articles are in the lowest quartile post-tenure citations, and an additional 28 percent are in the second to lowest quartile; 41 
percent of law professors in the lowest quartile of pre-tenure articles in top 20 law reviews are in the lowest quartile post-tenure citations, and an additional 30 percent are in the second to lowest quartile.

Finally, we repeat the counterfactual separately using each of the three measures. Figure A8 provides the results for the counterfactual. It shows that using brightline rules for any of the measures would have increased the influence of law professors at law schools, but to a meaningfully lower extent than the prediction based on all three measures together. 
Table A7: Movements in the Pre- and Post-Tenure Distributions

\begin{tabular}{|c|c|c|c|c|}
\hline \multirow[b]{2}{*}{ Pre-Tenure } & \multicolumn{4}{|c|}{$\begin{array}{c}\text { Percent in Citations to } \\
\text { Post-Tenure Articles Quartile }\end{array}$} \\
\hline & Q1 & $\mathrm{Q} 2$ & Q3 & Q4 \\
\hline \multicolumn{5}{|l|}{ A. Citations } \\
\hline Q1 & 51 & 29 & 15 & 5 \\
\hline Q2 & 32 & 32 & 22 & 14 \\
\hline Q3 & 11 & 26 & 35 & 28 \\
\hline Q4 & 3 & 13 & 29 & 55 \\
\hline \multicolumn{5}{|l|}{ B. Articles } \\
\hline Q1 & 46 & 28 & 17 & 9 \\
\hline Q2 & 22 & 29 & 27 & 22 \\
\hline Q3 & 10 & 26 & 31 & 33 \\
\hline Q4 & 7 & 16 & 29 & 48 \\
\hline \multicolumn{5}{|c|}{ C. Articles in Top 20 Law Reviews } \\
\hline Q1 & 41 & 30 & 19 & 10 \\
\hline Q2 & 18 & 29 & 32 & 21 \\
\hline Q3 & 8 & 26 & 33 & 33 \\
\hline Q4 & 2 & 8 & 27 & 63 \\
\hline
\end{tabular}


Figure A8: Separate Predictions from the Three Measures of Pre-Tenure Research Record

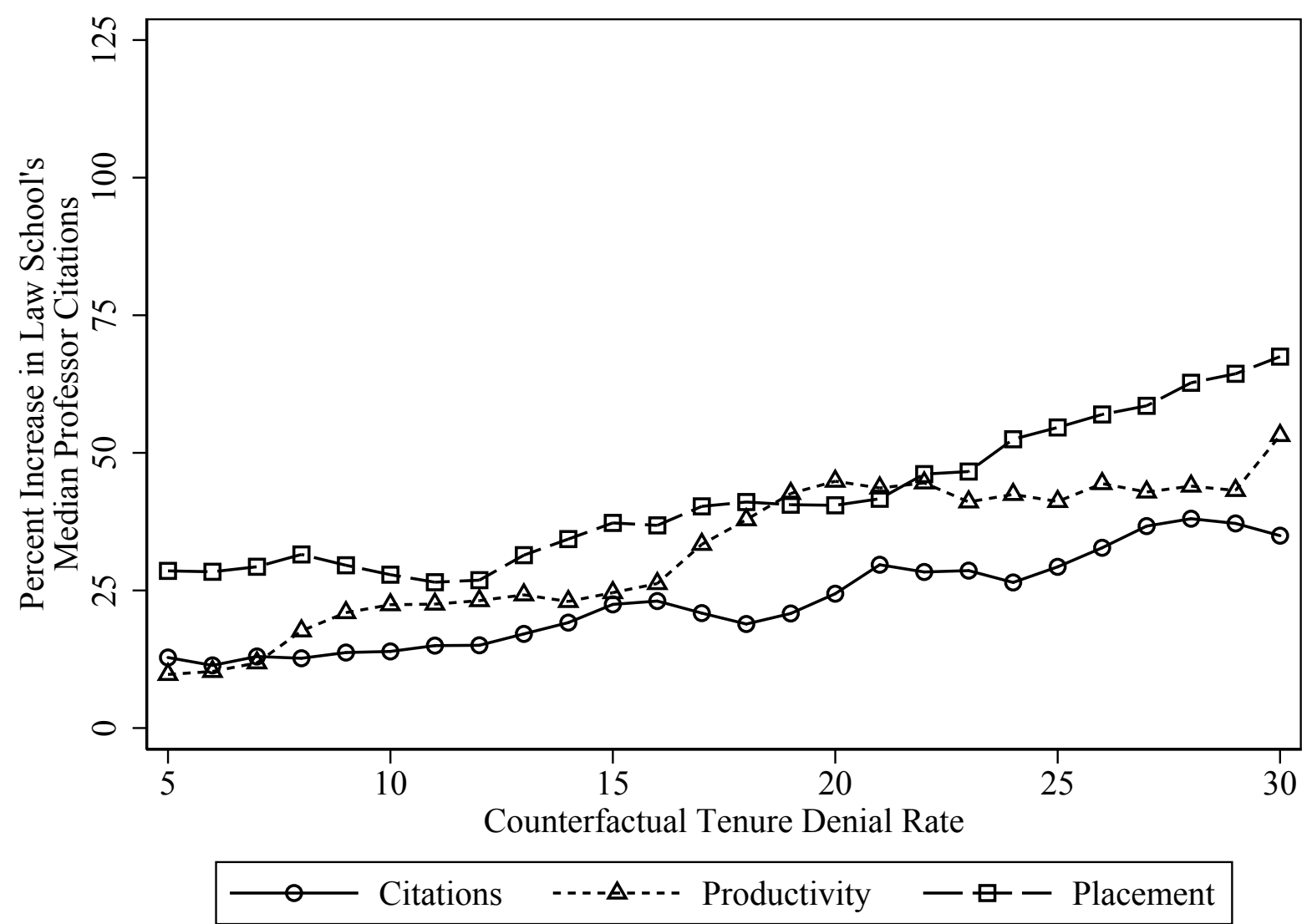




\section{A10 Alternative Statistics}

In Section 5.3, we estimated the benefits of stricter tenure standards by assessing the percent increase in the median law professor's citations to post-tenure articles. Figure A9 reports results using alternative statistics. Panel A reports the percent increase in law school's 25th percentile citations. The percent increase in the 25 th percentile is greater than increases for the 50th percentile (Figure 9 reports these results). This is expected because many of the faculty denied tenure in the simulations are in the bottom of the distribution.

Panel B of Figure A9 reports the percent increase in law school's 75th percentile citations. There are several notable findings. First, the percent increase in the 75 th percentile is less than increases for the 50th percentile (again, Figure 9 reports these results). Second, the percent increase in the 75 th percentile is greater in the simulation without replacement than two of the counterfactuals with replacement. For law schools where less than half of the faculty are denied tenure, this is mechanical because the replacements in the Median and Median of Remainder counterfactuals will never be above the 75 th percentile of the distribution.

Panel C of Figure A9 reports the percent increase in law school's mean and cumulative citations. The solid line without markers is the percent increase in the mean without replacement, and the dashed line without markers is the percent increase in the cumulative citations without replacement. Before discussing these results, there are three points about this exercise worth noting. First, for the counterfactuals with replacements, the percent percent change in a law school's mean citations is mechanically the same as the percent change in the law school's cumulative citations. To see why, let $c_{i}$ be the citations of a faculty position $i$ at a law school with $I$ faculty members, and let $\hat{c}_{i}$ be the citations of a faculty position $i$ at the same law school after some of the faculty have been denied tenure and the vacant spot filled by a counterfactual replacement. Defining $T$ and $\hat{T}$ as the law school's 
cumulative citations before and after the countefactual replacements, the percent change in the cumulative citations is $\Delta T$ :

$$
\begin{aligned}
T & =\sum_{i=1}^{I} c_{i} \\
\hat{T} & =\sum_{i=1}^{I} \hat{c}_{i} \\
\Delta T & =\frac{\hat{T}-T}{T}=\frac{\sum_{i=1}^{I} \hat{c}_{i}-\sum_{i=1}^{I} c_{i}}{\sum_{i=1}^{I} c_{i}}
\end{aligned}
$$

Next, defining $\mu$ and $\hat{\mu}$ as the law school's mean citations before and after the counterfactual replacements, the percent change in the mean citations is $\Delta \mu$ :

$$
\begin{aligned}
\mu & =\frac{1}{I} \sum_{i=1}^{I} c_{i} \\
\hat{\mu} & =\frac{1}{I} \sum_{i=1}^{I} \hat{c}_{i} \\
\Delta \mu & =\frac{\hat{\mu}-\mu}{\mu}=\frac{\frac{1}{I} \sum_{i=1}^{I} \hat{c}_{i}-\frac{1}{I} \sum_{i=1}^{I} c_{i}}{\frac{1}{I} \sum_{i=1}^{I} c_{i}}=\frac{\sum_{i=1}^{I} \hat{c}_{i}-\sum_{i=1}^{I} c_{i}}{\sum_{i=1}^{I} c_{i}}=\Delta T
\end{aligned}
$$

where $I$ is the same before and after the countefactual replacements because all the vacant spots are filled (that is, the number of faculty do not change, just the distribution).

Second, if there are no replacements, the percent change in a law school's mean citations is different from the percent change in the law school's cumulative citations. This is because simulating increased tenure denials without replacement results in schools having lower cumulative citations, but the smaller faculty size may result in higher mean citations.

Third, assessing these statistics differs in an important way from assessing any given percentile as above (e.g., the median, the 25 th percentile, and the 75 th percentile). By their nature, the percentiles are not influenced by outliers. But the mean and cumulative citations are influenced by outliers, and a small group of influential faculty account for a large 
portion of a law school's citations. At the average law school in our data, for example, 10 percent of the faculty account for over 30 percent of the law school's citations, and 5 percent of the faculty account for over 20 percent of the law schools citations. This is precisely why we decided to focus the main analysis on the median-because the mean is overly influenced by the outliers.

There are two notable findings in Panel C of Figure A9. First, the decrease in the cumulative citations without replacements is fairly low. For example, if law schools denied tenure to 10 percentage points more faculty and did not replace them, their cumulative citations would only decrease by 4 percent. Second, and as expected, the percent increase in the law school's mean and cumulative citations is much lower than the percent increase in the law school's median citations. In the Maximize counterfactual, Figure A9 shows that the mean/cumulative law school faculty could be improved by 26 percent if 10 percentage points more faculty were denied tenure, 36 percent if 20 percentage points more faculty were denied tenure, and 43 percent if 30 percentage points more faculty were denied tenure. 
Figure A9: Simulated Benefits of Stricter Tenure Standards Using Different Statistics A. Change in 25th Percentile Citations

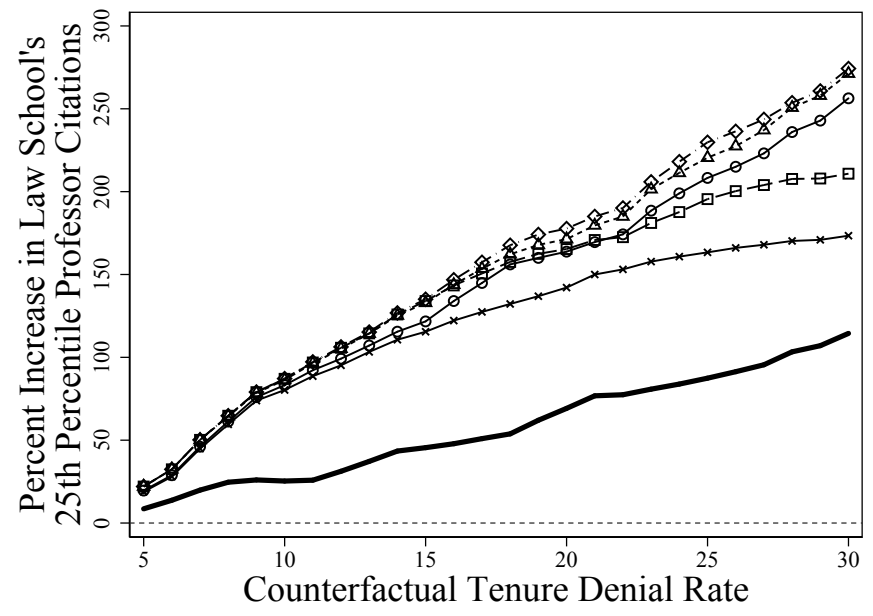

B. Change in 75th Percentile Citations

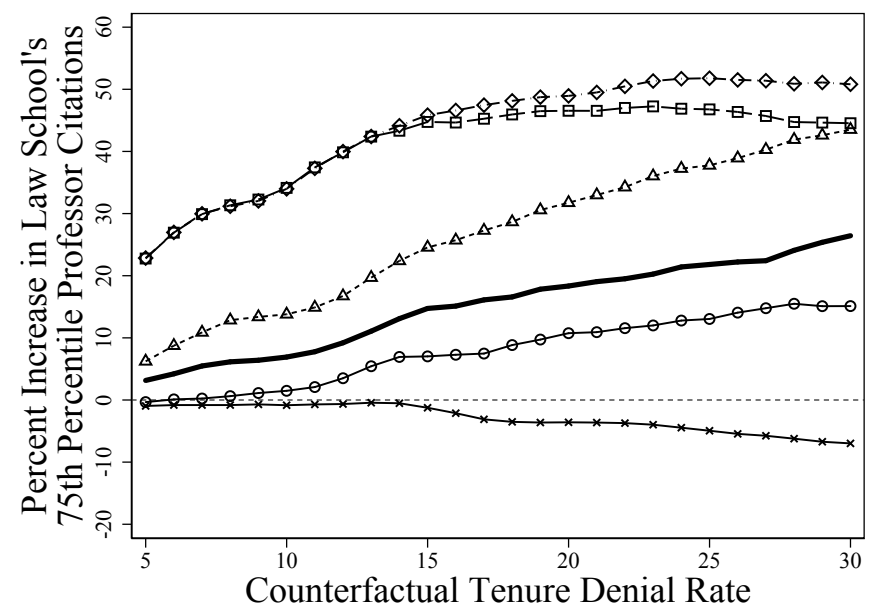

C. Change in Mean and Cumulative Citations

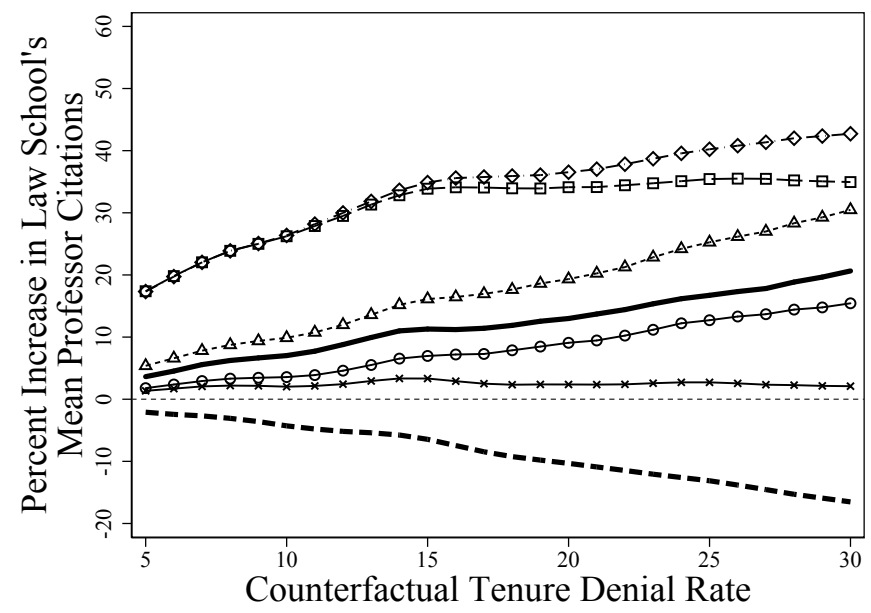

Resampling Procedure

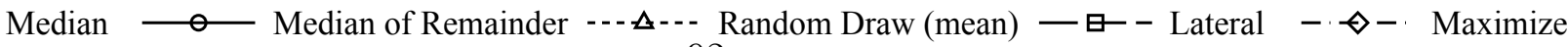




\section{A11 Results by Law School Rank}

Here we estimate the regressions from Part 4 separately by law school ranks to assess if the relationships are being driven more by differences between schools of different ranks rather than between the same types of schools. Table A8 reports these results. The results provide evidence that the general patterns above hold for different levels of law school rank. Additionally, Figure 12 reports the main counterfactual results after breaking out law schools by rank when the counterfactual is the Median of Remainder. Figure A10 reports these results for all counterfactuals. 
Table A8: Predicting Citations to Post-Tenure Articles by Law School Rank

\begin{tabular}{|c|c|c|c|c|}
\hline & $(1)$ & $(2)$ & $(3)$ & $(4)$ \\
\hline A. Top 20 Law Schools & & & & \\
\hline $\ln ($ Citations $)$ & $\begin{array}{l}0.60^{* * *} \\
(0.08)\end{array}$ & & & $\begin{array}{c}0.12 \\
(0.10)\end{array}$ \\
\hline $\ln$ (Articles) & & $\begin{array}{l}1.61^{* * *} \\
(0.17)\end{array}$ & & $\begin{array}{l}0.97^{\text {*** }} \\
(0.24)\end{array}$ \\
\hline $\ln$ (Articles in Top Law Reviews) & & & $\begin{array}{l}1.33^{\text {*** }} \\
(0.15)\end{array}$ & $\begin{array}{l}0.73^{* * *} \\
(0.19)\end{array}$ \\
\hline $\begin{array}{l}\text { Obs } \\
\text { R-squared }\end{array}$ & $\begin{array}{c}484 \\
0.237\end{array}$ & $\begin{array}{c}484 \\
0.270\end{array}$ & $\begin{array}{c}484 \\
0.254\end{array}$ & $\begin{array}{c}484 \\
0.304\end{array}$ \\
\hline B. Law Schools 20 to 50 & & & & \\
\hline $\ln$ (Citations) & $\begin{array}{l}0.55^{* * *} \\
(0.07)\end{array}$ & & & $\begin{array}{c}0.01 \\
(0.11)\end{array}$ \\
\hline $\ln$ (Articles) & & $\begin{array}{l}1.26^{* * *} \\
(0.16)\end{array}$ & & $\begin{array}{l}0.82^{\text {*** }} \\
(0.22)\end{array}$ \\
\hline $\ln$ (Articles in Top Law Reviews) & & & $\begin{array}{l}1.35^{\text {*** }} \\
(0.15)\end{array}$ & $\begin{array}{l}1.03^{* * *} \\
(0.17)\end{array}$ \\
\hline $\begin{array}{l}\text { Obs } \\
\text { R-squared }\end{array}$ & $\begin{array}{c}513 \\
0.191\end{array}$ & $\begin{array}{c}513 \\
0.201\end{array}$ & $\begin{array}{c}513 \\
0.228\end{array}$ & $\begin{array}{c}513 \\
0.268\end{array}$ \\
\hline C. Law Schools 50 to 100 & & & & \\
\hline $\ln ($ Citations $)$ & $\begin{array}{l}0.63^{* * *} \\
(0.06)\end{array}$ & & & $\begin{array}{r}0.18^{*} \\
(0.09)\end{array}$ \\
\hline $\ln$ (Articles) & & $\begin{array}{l}1.58^{* * *} \\
(0.14)\end{array}$ & & $\begin{array}{l}1.09^{* * *} \\
(0.19)\end{array}$ \\
\hline $\ln$ (Articles in Top Law Reviews) & & & $\begin{array}{l}1.30^{* * *} \\
(0.16)\end{array}$ & $\begin{array}{l}0.59^{* * *} \\
(0.18)\end{array}$ \\
\hline Obs & 723 & 723 & 723 & 723 \\
\hline R-squared & 0.186 & 0.209 & 0.141 & 0.235 \\
\hline Tenure-Cohort FE & Yes & Yes & Yes & Yes \\
\hline Note: Standard errors in parentheses. & $\mathrm{p}<0.1,{ }^{* *}$ & $\mathrm{p}<0.05$ & *** $\mathrm{p}<0.01$ & \\
\hline
\end{tabular}


Figure A10: Simulation for Tenure Denial Rates under Alternative Counterfactual Replacement by Law School Rank

A. Top 20 Law Schools
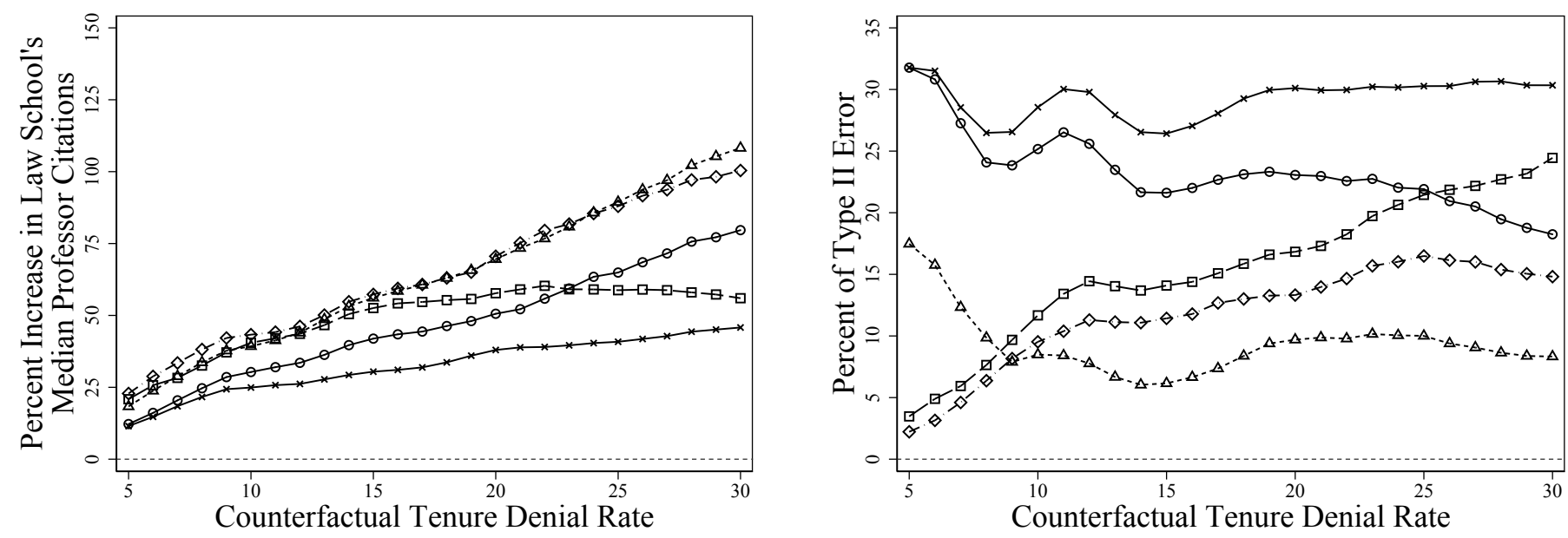

B. Law Schools Ranked 21 to 50
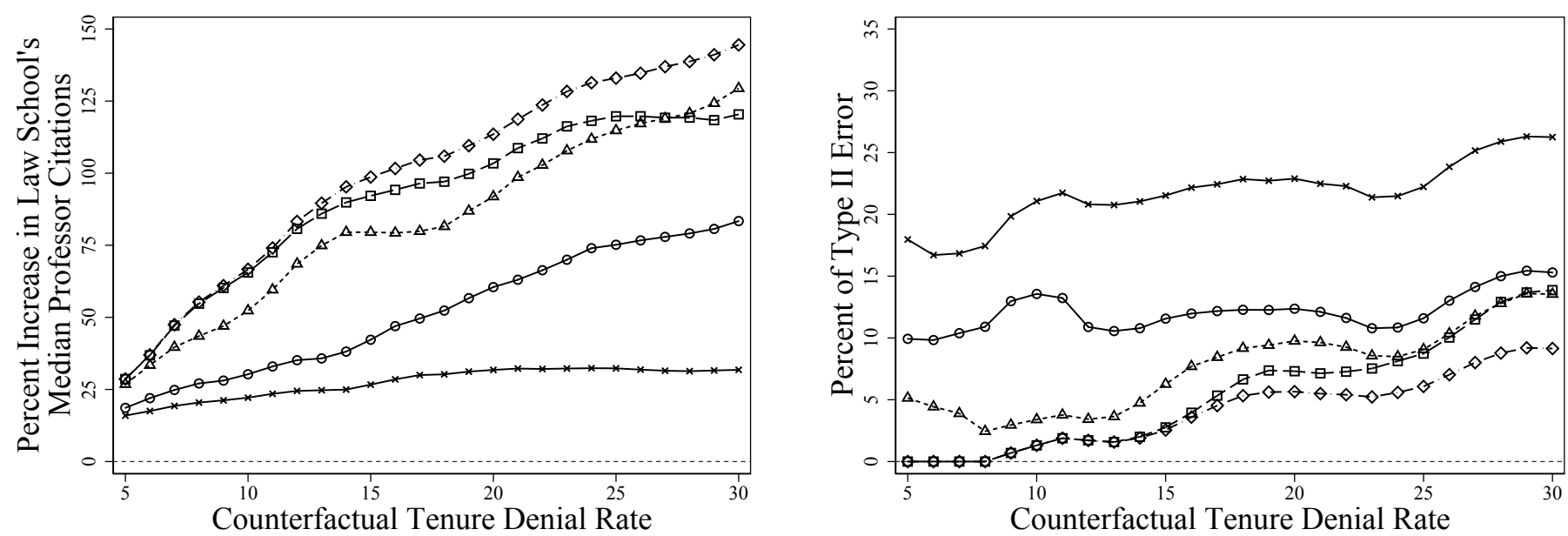

Resampling Procedure

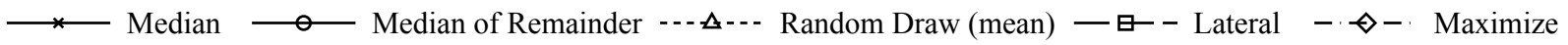

